\title{
THE DESIRE TO GAMBLE
}

\author{
A thesis submitted to \\ the Faculty of Graduate Studies and Research \\ in Partial Fulfillment of the requirements for the degree \\ Doctor of Philosophy
}

by

Matthew Maclaren Young

Department of Psychology

Carleton University

May, 2008

@2008 Matthew M. Young 


$\begin{array}{ll}\begin{array}{l}\text { Library and } \\ \text { Archives Canada }\end{array} & \begin{array}{l}\text { Bibliothèque et } \\ \text { Archives Canada }\end{array} \\ \begin{array}{l}\text { Published Heritage } \\ \text { Branch }\end{array} & \begin{array}{l}\text { Direction du } \\ \text { Patrimoine de l'édition }\end{array} \\ \begin{array}{l}\text { 395 Wellington Street } \\ \text { Ottawa ON K1A 0N4 } \\ \text { Canada }\end{array} & \begin{array}{l}\text { 395, rue Wellington } \\ \text { Ottawa ON K1A 0N4 } \\ \text { Canada }\end{array}\end{array}$

Your file Votre référence ISBN: 978-0-494-40547-5 Our file Notre référence ISBN: 978-0-494-40547-5

NOTICE:

The author has granted a nonexclusive license allowing Library and Archives Canada to reproduce, publish, archive, preserve, conserve, communicate to the public by telecommunication or on the Internet, loan, distribute and sell theses worldwide, for commercial or noncommercial purposes, in microform, paper, electronic and/or any other formats.

The author retains copyright ownership and moral rights in this thesis. Neither the thesis nor substantial extracts from it may be printed or otherwise reproduced without the author's permission.
AVIS:

L'auteur a accordé une licence non exclusive permettant à la Bibliothèque et Archives Canada de reproduire, publier, archiver, sauvegarder, conserver, transmettre au public par télécommunication ou par l'Internet, prêter, distribuer et vendre des thèses partout dans le monde, à des fins commerciales ou autres, sur support microforme, papier, électronique et/ou autres formats.

L'auteur conserve la propriété du droit d'auteur et des droits moraux qui protège cette thèse. $\mathrm{Ni}$ la thèse ni des extraits substantiels de celle-ci ne doivent être imprimés ou autrement reproduits sans son autorisation.
In compliance with the Canadian Privacy Act some supporting forms may have been removed from this thesis.

While these forms may be included in the document page count, their removal does not represent any loss of content from the thesis.
Conformément à la loi canadienne sur la protection de la vie privée, quelques formulaires secondaires ont été enlevés de cette thèse.

Bien que ces formulaires aient inclus dans la pagination, il n'y aura aucun contenu manquant.

\section{Canada}




\begin{abstract}
Most problem gamblers experience an overwhelming desire to gamble despite understanding the negative consequences of continued gambling. The present investigations sought to elucidate some of the processes underlying the desire to gamble by: (1) examining influence of wins and losses on desire to continue gambling following a short gambling episode, and (2) pilot testing a novel, multidimensional measure of gambling craving. In the first two studies, the influence of gambling outcomes on the efficacy of a short gambling episode to prime motivation to continue gambling was determined. Desire to gamble was evaluated while participants played a slot machine located in a virtual reality (VR) casino. In Study 1, 38 high-risk (>2 PGSI) and 36 nonproblem gamblers (0 PGSI) either won or lost money. Among high-risk gamblers, winning resulted in a greater increase in the desire to continue gambling than losing. In
\end{abstract} Study 2, 39 high-risk, 33 low-risk $(0<\mathrm{PGSI}<3)$, and 31 non-problem gamblers experienced either a single large win or a series of small wins (equivalent monetary gain). Participants could then continue playing as long as they wanted (all subsequent spins being losses). High-risk gamblers experiencing a large win reported greater desire to gamble upon cessation than those experiencing a series of small wins. In Studies 3 and 4, a new multidimensional measure of gambling craving was tested. In Study 3 an initial pool of 18 items assessing 4 dimensions of craving to gamble were pilot tested on a sample of 220 (73 non-problem, 60 low-risk, and 87 high-risk) gamblers. Principal components analysis (PCA) revealed the emergence of three components: desire, anticipation, and relief. The GACS predicted problem gambling severity, negative gambling outcome expectancies, depression, and positive and negative affect. In Study 4, 
the GACS predicted behaviour. Forty-six gamblers (14 non-problem, 15 low-risk, and 16 high-risk gamblers) played slots in the VR casino for 10 minutes during which time participants won money. Participants' persistence was then determined by permitting them to continue playing as long as they wanted (all subsequent spins being losses). Desire and relief (and GACS total scores) reliably predicted gambling persistence in the face of continued loss. 


\section{Acknowledgements}

First and foremost I would like to thank my advisor Michael Wohl for the guidance and support he has provided me over the course of my doctoral studies. He gave me enough supervision that I always had solid direction and guidance, yet enough independence to make me feel like a colleague. Thank you Michael for all your help.

I would also like to extend a great deal of thanks to Hymie Anisman and Kim Matheson for their wisdom, advice, and support. As well, my thanks to past and present members of the gambling lab at Carleton University for all the discussions, help conducting research, and other support provided to me during my graduate studies In addition, I would like to thank Karen Finlay and Florence Kellner for agreeing to sit on my committee.

Finally, I would like to thank my mother and father; my father for any creativity and curiosity about the world that I can claim, and my mother for any tolerance and peacefulness I have been able to nurture. Last, but certainly not least, I would like to thank my partner Georgina for the unconditional love and support she has always provided me. Thank you all.

This research was funded by the Ontario Problem Gambling Research Centre. 
Table of Contents

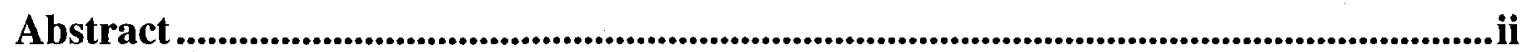

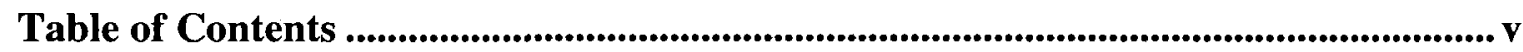

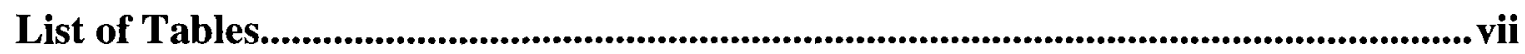

List of Figures ............................................................................................................iii

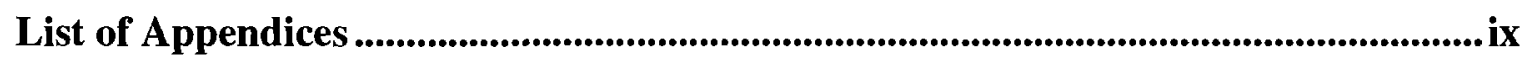

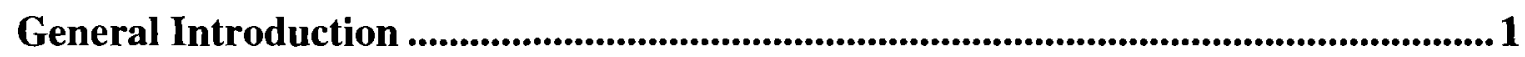

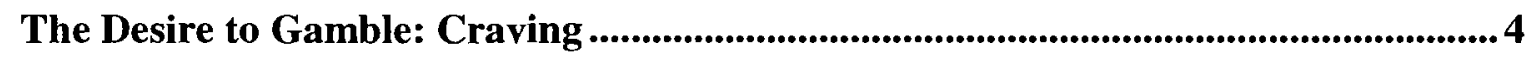

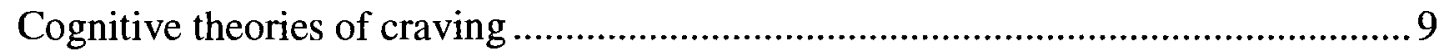

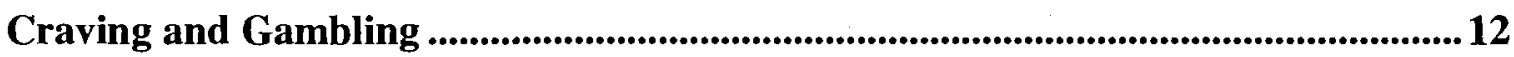

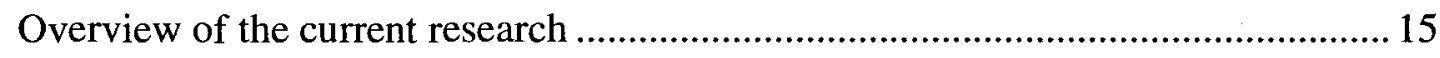

Study 1: The influence of wins and losses on desire to continue gambling................17

The influence of gambling outcomes on desire to gamble...................................... 18

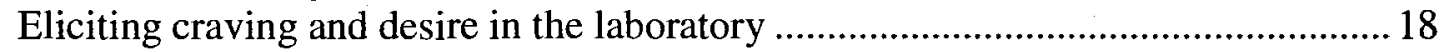

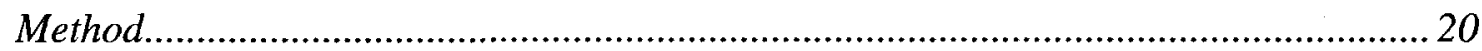

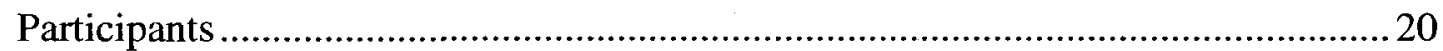

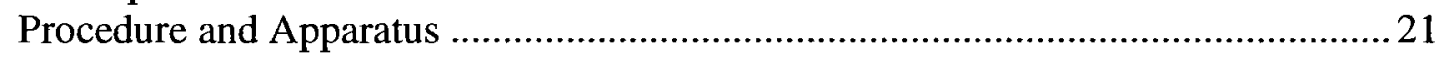

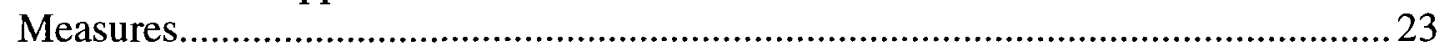

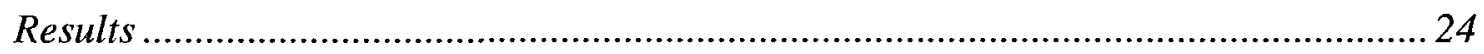

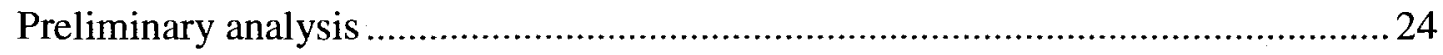

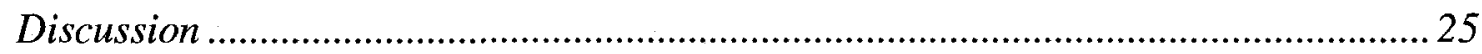

Study 2: The influence of win type on desire to continue gambling.........................227

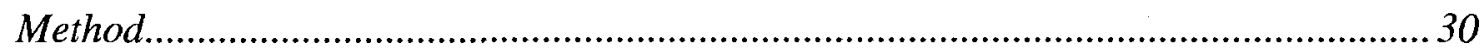

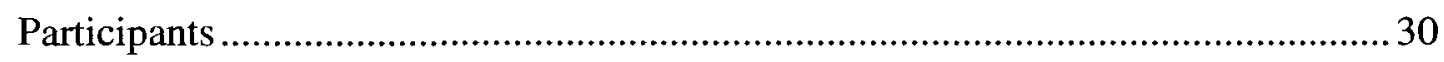

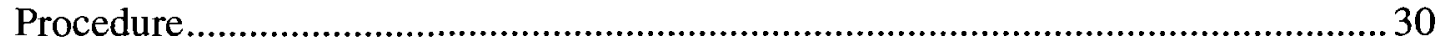

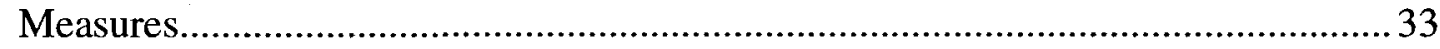

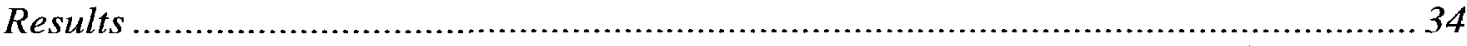

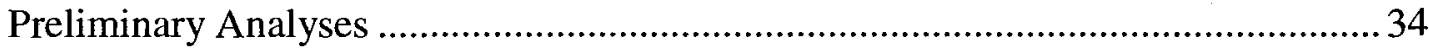

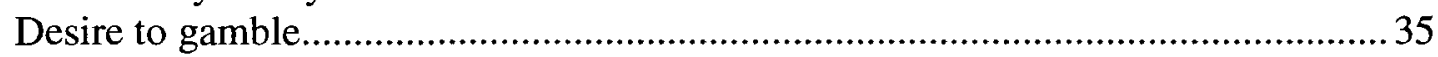

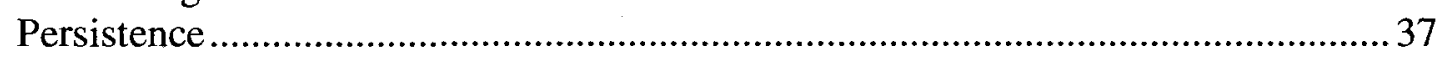

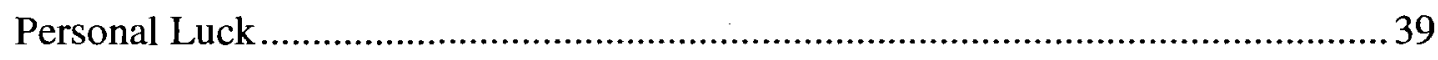

Mediation analysis for craving by personal luck .......................................... 40 


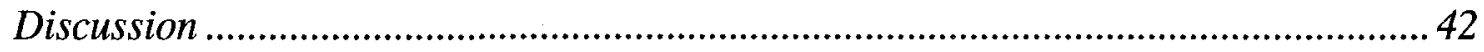

Study 3: The Gambling Craving Scale ......................................................................................45

Methods ................................................................................................................ 48

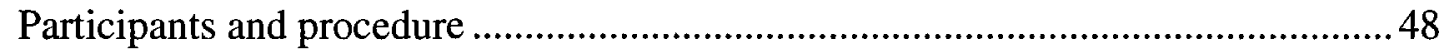

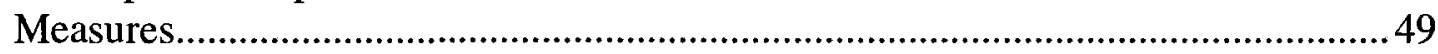

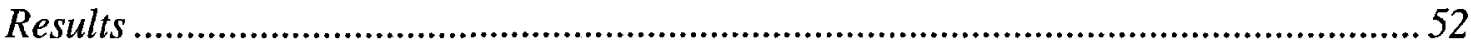

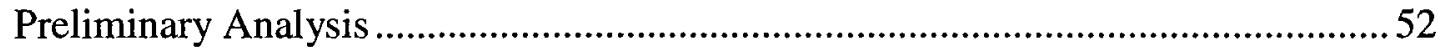

Analysis of Scale Structure ……………........................................................56

Labelling the components ...................................................................................58

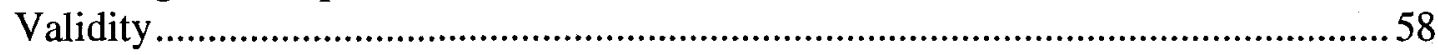

Relationship of GACS and GACS subscales with other measures .............................6 60

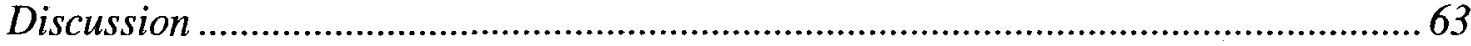

Study 4: The GACS and gambling behaviour .....................................................................65

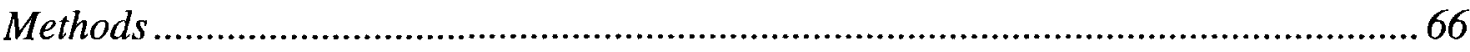

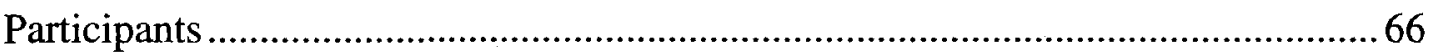

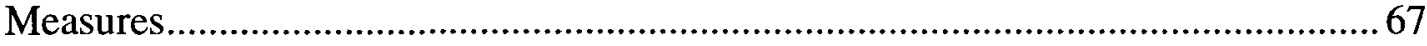

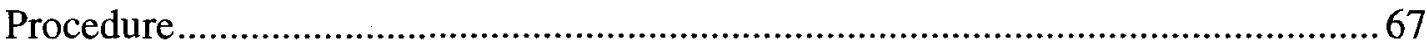

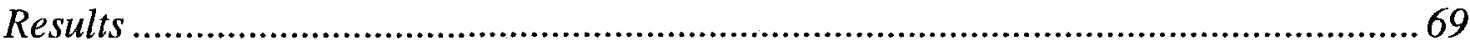

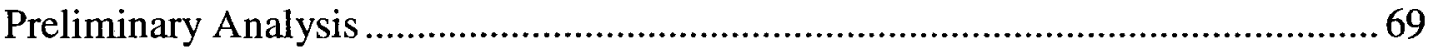

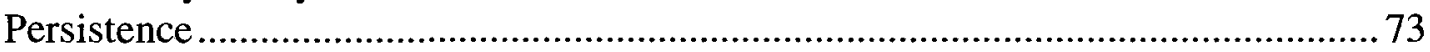

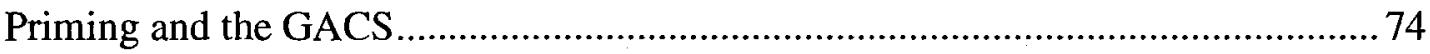

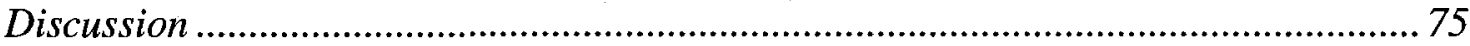

General Discussion ................................................................................................................76

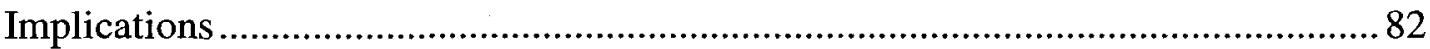

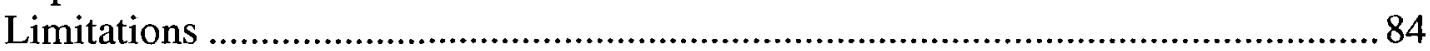

References ..............................................................................................................................................88 


\section{List of Tables}

Table 1. Means $( \pm S E)$ of desire ratings at the 4 assessment times by condition 36

Table 2. Means (+/-SD) of all measured variables in Study 3 by problem gambling severity. 54

Table 3. Correlations between measured variables in Study 3 (Cronbach's $\alpha$ 's located on the diagonal).. 55

Table 4. Rotated factor loadings on the three components extracted by principle components analysis of the Gambling Craving Scale (GACS). 57

Table 5. Coefficients of multiple determination ( $R 2$ 's) and standardized regression coefficients generated from multiple regression analyses conducted by regressing all three GACS subscales simultaneously on each of the variables measured in Study 3

Table 6. Means (+/-SD) of all measured variables in Study 4 by problem gambling severity.

Table 7. Correlations between measured variables in Study 4 (Cronbach's $\alpha$ 's located on the diagonal). 


\section{List of Figures}

Figure 1. Desire ratings $(M+/-S E M)$ among high-risk gamblers before gambling, following the $25^{\text {th }}$ and $50^{\text {th }}$ spins, as well as upon voluntary cessation as a function of win type. 38

Figure 2. Perceptions of personal luck mediation model. Coefficients with an asterisk indicate significant standardized beta weights $\left(^{*} p<.05, * * p<.01\right)$. Coefficients in parentheses indicate the effect of each variable on desire to continue gamble while controlling for the other.

Figure 3. Mean Gambling Craving subscale scores $(M+/-S E M)$ of non-problem, lowrisk, moderate risk, and problem gamblers. 59 


\section{List of Appendices}

Appendix A. Study 1 Screening Questionnaire............................... 103

Appendix B. Study 1 Informed Consent................................. 105

Appendix C. Study 1 Debriefing............................................. 106

Appendix D: Study 2 Informed Consent................................ 109

Appendix E. Study 2 Questionnaire..................................... 110

Appendix F. Study 2 Debriefing ............................................ 113

Appendix G. Study 3 Informed Consent................................... 115

Appendix H. Study 3 Questionnaire....................................... 116

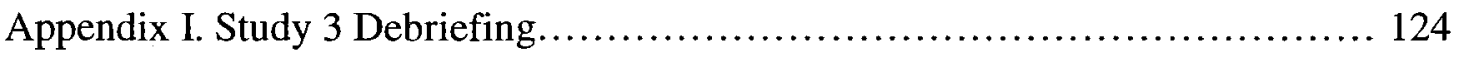

Appendix J: Study 4 Informed Consent ................................... 126

Appendix K. Study 4 Questionnaire....................................... 127

Appendix L. Study 4 Debriefing......................................... 129 


\section{General Introduction}

According to the American Psychiatric Association's (APA) Diagnostic and Statistical Manual of Mental Disorders (DSM IV; APA, 1994), there are 10 criteria used to diagnose the presence of pathological gambling. Among these criteria are two seemingly conflicting characteristics: one, repeated efforts to cut down or stop gambling, and two, a preoccupation with gambling or obtaining money in order to gamble. These conflicting characteristics highlight that, despite understanding the negative consequences of continued gambling, the typical problem gambler still experiences an overwhelming, often irresistible, desire to gamble.

Though the self-reported motivational state of desire for reward has not received much attention among gambling researchers, it has received greater attention by those studying substance use/abuse. These researchers refer to this state variously as temptation (Myers, Stice, \& Wagner, 1999), urge (Marlatt, 1985), drive (Verheul, Van den Brink, \& Geerlings, 1999), or desire (Chutuape, Mitchell, \& DeWit, 1994). However, the term used most frequently among substance abuse researchers is craving (see Drummond, Litten, Lowman, \& Hunt, 2000).

Even though craving is the most common term used to refer to the self-reported motivational state of desire, it is, according to Tiffany and colleagues (2000), the most debated and controversial construct within the field of addictive behaviours. Researchers differ greatly concerning the time-frame of the craving experience, scope of the craving definition, or whether craving is a necessary condition for relapse to occur (for a review of these issues see Sayette, Shiffman, Tiffany, Niaura, Martin, \& Schadel, 2000). It is 
also unclear whether the motivational state experienced in response to reward related cues prior to engaging in consummatory behaviour is distinct from that experienced during consumption. Though researchers investigating the priming effects of alcohol and other drugs (in which a small dose a desired substance increases desire to continue consumption) tend to use the terms craving and desire interchangeably (e.g., DeWit, 1996; Hutchison, Swift, Rohsenow, Monti, Davidson, \& Almeida, 2001), it is possible that the motivational state experienced while in the midst of consumption (as is the case with priming studies) may be confounded with response to reward. Because the present series of investigations examined gamblers desire to gamble before, during and after gambling, the term craving is used to refer to the motivational state reported by the gambler when they are not in the midst of gambling (i.e., they have not yet begun, or believe they are finished), and desire to continue is used to refer to the motivational state experienced by the gambler while in the midst of gambling.

Although craving and the desire to continue are both thought to be central to substance addiction (for review see Drummond, 2001), these motivational states have received limited attention in the gambling literature (for exceptions see Raylu \& Oei, 2004b; Tavares, Zilberman, Hodgins, \& el-Guebaly, 2005). Yet, craving has been postulated to maintain addictive behavior, may be fundamental in promoting relapse (Drummond et al., 2000), and is an important feature in both substance abuse disorders and pathological gambling (APA, 1994). Considering the popularity of gambling as well as the high rates of problematic play in the general population (e.g. Marshall \& Wynne, 
2003; Wiebe, Mun, \& Kauffman, 2006; Wiebe, Single, \& Falkowski-Ham, 2001), understanding craving and desire to continue among problematic gamblers is imperative.

The first two studies in this investigation examined desire to continue gambling among problem and recreational gamblers as they played a slot machine located in a virtual reality (VR) casino. It is well established that exposure to a small amount of a desired substance, such as alcohol, can stimulate increased desire for that substance (see DeWit, 1996 for review). This 'priming effect' has also been shown among gamblers (Ladouceur, Mayrand, \& Tourigny, 1987; Loba, Stewart, Klein, \& Blackburn, 2001). However it is unknown whether wins or losses might influence the effectiveness of a gambling episode to prime desire to continue gambling. Therefore, the first two experiments (Studies 1 and 2) examined the influence of gambling outcomes (i.e., wins and losses) on the desire to continue gambling.

In Studies 1 and 2 desire to gamble was measured using a single item measure. Although, the majority of craving-related investigations in the substance abuse literature use single item self-report measures when assessing craving and desire, the use of such a measure has been criticized as having limited reliability and limited by the assumption that the desire to gamble is a unidimensional construct. Among the limited number of studies that have examined craving to gamble (e.g., Kushner, Abrams, Donahue, Thuras, Frost, \& Kim, 2007; Raylu \& Oei, 2004b), none have examined the dimensional structure of craving to gamble (i.e., whether craving is composed of dimensions such as anticipation of positive affect or relief from negative affect). This is because currently no multidimensional measures exist to assess craving to gamble. In light of this absence, 
Studies 3 and 4 examined the factor structure, reliability, psychometric properties, and predictive validity of a new multi-item craving scale designed to measure the multidimensional nature of craving to gamble.

The Desire to Gamble: Craving

Notwithstanding the various debates surrounding craving, craving is understood by most researchers to be a conscious, subjective state of desire to consume a substance or engage in a behaviour (see Berridge \& Robinson, 1995 for an exception). Sayette and colleagues (2000) note that most researchers conceptualize craving as a drug-acquisitive state that motivates drug use, but that the precise definition of craving employed by the researcher reflects the particular conceptual model he or she adheres to. Therefore, an appropriate conceptual model of craving that is most suitable to an investigation of gambling must be chosen in order to determine a working definition of craving appropriate to the study of gambling.

Many models have been developed to explain craving (for reviews see Drummond, 2001; Lowman, Hunt, Litten, \& Drummond, 2000), however all have been derived from research on substance abuse and none have specifically addressed craving among problematic gamblers. Though there are many similarities between substance abuse and problematic gambling (see APA, 1994), there are also important differences. For example, because gambling does not directly affect the neurotransmission system (as do drugs), symptoms such as tolerance and withdrawal experienced by substance abusers may not function in the same manner among problem gamblers. Because such symptoms 
often play a central role in craving theories, these theories must be reviewed and judged insofar as they are useful in explaining craving to gamble.

Most theories of craving employ principles of classical conditioning (Pavlov, 1927) to explain how environmental cues are capable of eliciting craving among substance abusers (Tiffany, 1990). Classical conditioning occurs when a stimulus, such as a bell, is paired repeatedly with another stimulus, such as food. In this example, food is capable of directly eliciting salivation. Thus, food is referred to as the unconditioned stimulus (US) and salivation as the unconditioned response (UR). Conditioning is said to occur when, after repeated pairings of the bell with food, the bell begins to elicit salivation in the absence of food. The bell is then referred to as the conditioned stimulus (CS) and salivation as the conditioned response (CR).

Most craving theories fit into two general classes: (1) theories emphasizing drug withdrawal (see Wikler, 1948), and (2) theories emphasizing a drug's positive-incentive properties (see Wise, 2004). Theories emphasizing withdrawal posit that craving arises from a desire to rid one's self of negative symptoms associated with the reduction or cessation of (often chronic) drug use (Ludwig, Wikler, \& Stark, 1974; Wikler, 1948). These withdrawal symptoms can be experienced directly from actual withdrawal following use of a drug, or from conditioned withdrawal. For example, in the case of a habitual cigarette smoker, actual withdrawal occurs when falling nicotine levels (US) directly trigger withdrawal symptoms such as headache and decreased heart rate (UR). In the case of conditioned withdrawal, cues in the environment, such as a bell or buzzer signalling a work break (CS), that are repeatedly associated with low or falling blood 
nicotine levels (US) are eventually capable of eliciting withdrawal-like symptoms directly (CR). According to these conditioning theories, withdrawal and conditioned withdrawal promote a drive to rid the self of these symptoms. This drive is experienced subjectively as craving.

Theories emphasizing withdrawal (e.g., Wikler, 1948), however, originated to explain craving associated with opiate dependency and have been less successful explaining craving for drugs such as stimulants for which withdrawal symptoms are less severe (Stewart, DeWit, \& Eikelboom, 1984). Similarly, withdrawal-based theories are also of limited use in an examination of gambling craving. In contrast to drugs, such as alcohol or heroin, there is no chemical substance in gambling that acts directly on the body. Therefore, there are no direct, physiological withdrawal symptoms. For example, all people experience hangovers from drinking too much, regardless of whether or not they are alcohol dependant. A hangover is an example of direct withdrawal or an unconditioned physiological response to alcohol consumption. It is this unconditioned response that is posited to become associated with the environmental cues that ultimately come to elicit craving. As there are no direct withdrawal symptoms that result following a gambling session, there is no unconditioned response, and consequently, nothing for environmental cues to become conditioned to. Therefore, this model of craving is unlikely to account for the desire to engage in waging behaviour among problematic gamblers.

Theories emphasizing a drug's positive, incentive, motivational properties, however, hold greater promise for explaining craving among gamblers than those 
emphasizing withdrawal. These theories posit that after prolonged drug use, depending on the internal state of the organism (i.e., whether the organism is drug-deprived or sated), unconditioned and conditioned stimuli elicit an incentive motivational state experienced in humans as craving (Bindra, 1974; Wise, 2004). However according to these theories, it is the reinforcing effects of the drug that become associated with environmental stimuli. According to the incentive motivation approach, positive affective states directly resulting from drug use become conditioned to environmental stimuli (Stewart et al., 1984; Wise, 1988). After repeated pairings, these conditioned stimuli begin to elicit a central motivational state in which the organism is driven to approach environmental cues previously paired with the drug effects. The subjective correlate of this high-drive state is craving. Incentive motivational approaches explain priming effects in much the same way. In the case of priming effects, however, it is the unconditioned direct effects of the drug that are the energizing stimuli that trigger craving (DeWit, 1996). For example, if the pleasant, positive, arousing effects of alcohol are repeatedly paired with the sounds, sights, and smells of a bar or nightclub, when these stimuli are presented in absence of alcohol, they begin to activate an incentive motivational state in which people report craving for alcohol. Upon consuming a small amount of alcohol, the unconditioned effects of alcohol also serve as stimuli which increase the desire to continue consuming alcohol (DeWit, 1996). Of course the amount of craving that the unconditioned effects of alcohol will elicit is dependent on the internal state of the organism. Though the first few sips of beer may cause an initial increase in desire, this desire will begin to wane as more and more alcohol is consumed. 
Indeed, several studies have demonstrated that gamblers experience physiological arousal while gambling (e.g., Anderson \& Brown, 1984; Ladouceur, Sevigny, Blaszczynski, O'Connor, \& Lavoie, 2003) and problem gamblers frequently describe the ‘buzz’ of gambling to be particularly appealing (Wood \& Griffiths, 2007). In addition, pathological gamblers report significantly greater craving than controls, and increased neuronal activity in well defined brain regions when presented with gambling-related cues (Crockford, Goodyear, Edwards, Quickfall, \& el-Guebaly, 2005; Potenza, Steinberg, Skudlarski, Fulbright, Lacadie, Wilber, Rounsaville, Gore, \& Wexler, 2003). Further, the dopamine stimulant $\mathrm{d}$-amphetamine has been found to be an effective priming stimulus among problem gamblers, whereas alcohol was not (Zack \& Poulos, 2004). This finding suggests that by stimulating reward pathways thought to be activated when gambling, damphetamine may be mimicking the unconditioned effects of gambling and is thus capable of increasing motivation to continue gambling.

However, it is perhaps not only the positively reinforcing consequences of gambling that might become paired with environmental cues, but negatively reinforcing consequences might also undergo similar associations and thus also play a role in craving to gamble. Although evidence suggests that gamblers are motivated to gamble out of a desire for the positive consequences of gambling described above, there is also evidence suggesting that problematic gamblers wager to relieve themselves from negative affective states. For example, research has found that some problem gamblers enter into a pleasurable dissociative-like state of consciousness that permits them to escape the problems of everyday life, including problems caused by past gambling (e.g., Diskin \& 
Hodgins, 2001; Grant \& Kim, 2003; Jacobs, 1988; Kofoed, Morgan, Buchkowski, \& Carr, 1997). In interviews with pathological gamblers, Wood and Griffiths (2007) found that a desire for escape from day to day problems was one of the primary motivations for gambling. Therefore, in the context of gambling, environmental cues may not only be conditioned with positive affective states, but also with relief from negative affective states. Thus, craving to gamble may not only be composed of the desire for positive affect, but also a desire for relief from negative affect. Accordingly, gambling related cues are likely to activate a motivational state that may be characterised as both a desire for positive affect and relief from negative affect (i.e., gambling is likely both positively and negatively reinforcing). The simultaneous desire for positive affect and relief from negative affect has been observed in craving research with smokers (Tiffany \& Drobes, 1991), cocaine addicts (Tiffany, Singleton, Haertzen, \& Henningfield, 1993), and alcoholics (Love, James, \& Willner, 1998). However, the factorial structure of gambling craving has yet to be investigated.

Cognitive theories of craving

According to Tiffany (1999), most conditioning theories tend to consider craving as a "somewhat biologically primal, homogeneous state" (p.217), which represents the addict's fundamental motive for using alcohol and drugs. Cognitive approaches consider craving as a complex multidimensional process that is a product of higher order mental functions (for a review of these models see Tiffany, 1999). However, rather than understand conditioning and cognitive approaches as contradictory, Drummond (2001) argues that is perhaps more useful to regard them as different levels of analysis. 
One cognitive model that is complementary to the incentive motivational approach reviewed above is Marlatt and Gordon's (1985) outcome expectancy model. In this model, outcome expectancies are composed of an individual's beliefs about the consequences of a given behaviour (e.g., that they will have a drink of alcohol and feel great, or gamble, win a lot of money, and feel a rush of excitement) and the desirability of those consequences. Beliefs (also referred to as the informational component of the outcome expectancy) are considered to arise via the associative learning described earlier. Positive incentive motivational states characterised by positive affect and/or relief from negative affective states resulting from behaviours, such as gambling, become associated with environmental cues consistently paired with these states. For example, the sounds, lights, or bustle of a casino, have been paired repeatedly with gambling and the reinforcing consequences of gambling. Eventually these cues come to elicit outcome expectancies that gambling will result in, for example, winning and the mood states accompanying winning. The desirability of the consequences (also referred to as the motivational component of outcome expectancies) are a function of the degree to which the anticipated consequences of gambling are rewarding - how much the gambler wants to win, escape, or experience the 'buzz' described above. When applied to substance abusers the desirability of the consequences depends on the magnitude of dependence and whether the organism is drug deprived or sated.

Marlatt and Gordon (1985) therefore define craving as "the degree of desire (incentive value) for the immediate positive outcome one expects as a function of engaging in the addictive behavior" (p. 236). According to this definition, as outcome 
expectancies related to the immediate expected effects of, for example, alcohol increase over time, then so too should craving for alcohol. Similarly, as beliefs about winning and the accompanying the mood altering consequences of winning develop, so too should craving to gamble. Though this model of craving has yet to be examined in gamblers, it has received support from the substance abuse literature (e.g., Cooney, Gillespie, Baker, \& Kaplan, 1987; Goldman \& Rather, 1993)

Both the incentive motivational approach and the outcome expectancy model, however, were developed to account for craving among substance abusers and not those with gambling problems. Though there is some similarity between those with substance abuse problems and those with gambling problems (see APA, 1994), one of the major differences is the reliability with which the substance abuser or gambler can predict the consequences of their behaviour. For those with a substance abuse problem, consuming the psychoactive substance of choice will lead to the expected consciousness altering consequences, i.e., there is a consistent pairing of the positive affective states and or relief from negative affective states resulting from drug use and environmental cues. For example, the alcoholic and the cocaine addict know with great certainty that they will experience a predictable, positively hedonic, altered state of consciousness after consuming their preferred substances. For the problem gambler, however, the situation is more complicated. They may gamble, win the jackpot and feel ecstatic, or they may lose everything and feel devastated. Evidence suggests, however, that problem gamblers demonstrate a selective memory for past wins and more difficulty recalling losses (Toneatto, 1999). Other research has revealed that problem gamblers have elevated 
expectations of winning (e.g., Wohl, Young, Anisman, \& Matheson, 2006; Wohl, Young, \& Hart, 2007), experience a pleasurable state of arousal (e.g., Anderson \& Brown, 1984; Ladouceur et al., 2003), and enter into a dissociative-like state of consciousness while gambling (e.g., Diskin \& Hodgins, 2001; Grant \& Kim, 2003; Jacobs, 1988; Kofoed et al., 1997). While, among problem gamblers, it is possible that expectancies of arousal and dissociation may be reliably predicted (and therefore perhaps akin to the consciousness altering expectations of substance abusers), winning and the affective consequences of winning are not guaranteed.

Even though winning is not guaranteed gamblers report winning as a primary motivation to gamble (Neighbors, Lostutter, Cronce, \& Larimer, 2002; Smith \& Wynne, 2004). They also report that it is the possibility of winning money that makes gambling exciting (Ladouceur et al., 2003). Therefore, it is possible that desire to continue gambling may be contingent on the pattern of wins and losses experienced by the gambler.

\section{Craving and Gambling}

Research examining craving to gamble suggests that pathological gamblers experience more intense cravings than those with substance abuse problems (Castellani \& Rugle, 1995; de Castro, Fong, Rosenthal, \& Tavares, 2007; Tavares et al., 2005). For example, Tavares, Zilberman, Hodgins, and el-Guebaly (2005) measured craving in alcoholics and compared their scores with those of pathological gamblers. They found that pathological gamblers scored significantly higher on craving measures than alcoholics. Similar results were reported by de Castro et al., (2007). Further, Castellani 
and Rugle (1995) measured, what they referred to as the 'inability to resist craving' in alcoholics, cocaine addicts, and pathological gamblers, and found that pathological gamblers scored higher than alcoholics and cocaine addicts on their inability to resist craving. These studies provide strong evidence that, even though gambling is distinct from chemical addictions in many ways, pathological gamblers nonetheless experience craving.

Other gambling researchers have investigated craving to gamble by employing brain-imaging techniques to investigate brain regions associated with craving in pathological gamblers (Crockford et al., 2005; Potenza et al., 2003). In these studies, pathological gamblers as well as controls, watched gambling videos and completed urge measures while undergoing functional magnetic resonance imaging. For example, Crockford, Goodyear, Edwards, Quickfall, and el-Guebaly (2005) found that while watching the videos, pathological gamblers reported significantly greater urges than controls. These urges were accompanied by increased activity in an area of the brain involved in procedural sequence learning, the dorsolateral prefrontal cortex. In a similar study, Potenza and colleagues (2003) had male participants watch videotaped gambling scenarios, then measured gambling-related urges. They also found that problem gamblers reported greater gambling urges after viewing the gambling scenario than controls. In addition, they found concomitant decreased activity in the frontal and orbitofrontal cortex, caudate/basal ganglia, and thalamus - areas of the brain implicated in impulse regulation. 
While most of the extant studies on craving among gamblers have examined the relative magnitude and the brain regions associated with craving to gamble, a few studies have also assessed craving as a success indicator for effective pharmaceutical treatment of pathological gambling (Hollander, DeCaria, Finkell, Begaz, Wong, \& Cartright, 2000; Kim, Grant, Adson, \& Shin, 2001). For example, Hollander et al. (2000) tested the effectiveness of the selective serotonin reuptake inhibitor (SSRI) fluvoxamine in the treatment of pathological gambling. Fluvoxamine has been used in the treatment of obsessive-compulsive disorders (as well as other disorders) and was therefore considered a potential treatment for pathological gamblers. Hollander et al. (2000) found that fluvoxamine had a weak effect of reducing gambling-related urges. In another attempt to find a pharmaceutical treatment for pathological gambling, Kim and colleagues (2001) found that naltrexone, a dopamine antagonist that targets areas of the brain that have been implicated in pleasure and urges (e.g., Berridge, 1996), was highly effective at reducing gambling-related urges.

Taken together, studies investigating craving among gamblers suggest that pathological gamblers report stronger craving to gamble than non-problem gamblers, pathological gamblers appear to self-report stronger craving to gamble than alcoholics or cocaine addicts, when presented with gambling related stimuli pathological gamblers experience increased neuronal activity in well defined brain regions, and finally that craving measures can be useful in measuring the efficacy of pharmaceuticals in treating pathological gambling. These studies, however, also reveal important gaps in the literature on craving to gamble. First, none of the studies reviewed above examined 
gamblers as they actually gambled. Therefore, the research was incapable of examining the influence of gambling outcomes (i.e., wins and losses) on desire to continue gambling. Second, none of the studies reviewed above employed the same measure to assess craving to gamble, indicating the lack of an accepted measurement tool. The current series of studies were designed to fill these gaps.

\section{Overview of the current research}

The first two studies examined the influence of gambling outcomes on the efficacy of a gambling episode to prime desire to continue gambling. In both Studies, desire to gamble was assessed among participants with varying levels of gambling pathology while they played a slot machine located in a virtual reality casino. In Study 1 , it was of interest whether wins and losses would differentially influence the priming effects of a short gambling episode. This was accomplished by manipulating outcomes, such that half of the participants won money and half lost. In Study 2, it was of interest whether the way in which the gambler wins differentially influences desire to continue gambling. Specifically, the efficacy of a single large win versus a series of small wins on priming desire to continue gambling was assessed. To this end, gamblers experienced either a single large win or a series of small wins (equivalent monetary gain). Following, participants were permitted to continue playing as long as they wanted (all subsequent spins being losses) thus permitting evaluation of persistence (resistance to extinction). Studies 3 and 4 examined the multidimensional nature of craving to gamble. As reviewed earlier, both an incentive motivation approach and the outcome expectancy model of craving suggests that craving may have different dimensions; including (but not 
limited to) the anticipation of reward and the expectation of relief from negative mood states. However there currently exists no psychometrically tested multidimensional measure of craving to gamble. Therefore, Studies 3 and 4 were conducted to develop and psychometrically test a multidimensional gambling craving scale. In Study 3 a pool of items were tested on a sample of gamblers to assess the multidimensional nature of craving to gamble. Similar to other multidimensional scales of craving (Love et al., 1998; Tiffany \& Drobes, 1991; Tiffany et al., 1993), it was anticipated that craving to gamble would consist of a desire to gamble, an anticipation of enjoyment from wagering, an expectation of relief from negative affect while engaged in play, and an intention to gamble.

In Study 4, gambling behaviour was assessed in relation to the newly created scale. Specifically, Study 4 was designed to test whether craving to gamble was associated with persistence in the face of continued loss. To this end, gamblers played a slot machine located in a VR casino. After initially winning, participants were told that they could cease playing whenever they wished and could keep all the money they ended with. It was hypothesized that gamblers would persist to the extent that they craved to gamble (as indicated by scores on the Gambling Craving Scale). 
Study 1: The influence of wins and losses on desire to continue gambling Exposure to a small amount of a desired substance can stimulate increased desire for that substance (see DeWit, 1996 for review). For example, when an alcoholic is given a small drink of alcohol, an increased desire for alcohol generally follows (e.g., Ludwig \& Wikler, 1974). This 'priming effect' has also been shown among gamblers (Ladouceur et al., 1987; Loba et al., 2001; Zack \& Poulos, 2007). For example, gamblers reported an increased desire to continue playing following a short gambling session (Loba et al., 2001; Zack \& Poulos, 2007), and risk-taking behaviour among experienced and nonexperienced gamblers escalated over the course of a laboratory gambling task. Paralleling behavioral changes, physiological evidence for priming effects among gamblers has also been observed. Specifically, drugs that activate the dopaminergic system (the neurochemical system thought to be active when gamblers engage in play) have been shown capable of priming the desire to gamble among problematic gamblers (see Zack \& Poulos, 2004).

Previous research on craving and gambling has revealed that when exposed to gambling-related cues, pathological gamblers report significantly greater craving than controls, and increased neuronal activity in well defined brain regions (Crockford, Goodyear, Edwards, Quickfall, \& el-Guebaly, 2005; Potenza, Steinberg, Skudlarski, Fulbright, Lacadie, Wilber, Rounsaville, Gore, \& Wexler, 2003). Thus, when presented with gambling related cues problematic gamblers experience a desire to gamble. It is uncertain, however, whether this desire to gamble changes once the gambler engages in, for example, the first few hands of poker or spins of a slot machine, and whether the 
desire to continue gambling is contingent on the pattern of wins and losses experienced by the gambler.

The small number of studies that have examined priming among gamblers have not considered the effects of outcome on desire to continue play. Is simply engaging in wagering behaviour sufficient to prime motivation to gamble, or is desire to continue gambling influenced by the pattern of wins and losses experienced by the gambler? To address this question, the current investigation assessed the influence of gambling outcomes on the craving or desire to gamble among both healthy and problematic gamblers as they played a slot machine in a virtual gambling environment.

The influence of gambling outcomes on desire to gamble

Gamblers report winning as a primary motivation to gamble (Neighbors et al., 2002; Smith \& Wynne, 2004) resulting in excitement (Ladouceur et al., 2003), positive affect (Brown, Rodda, \& Phillips, 2004), and increased arousal (Coventry \& Constable, 1999; Coventry \& Hudson, 2001). Conversely, gamblers report subjective feelings of unhappiness upon losing money (Hills, Hill, Mamone, \& Dickerson, 2001). These studies suggest the motivation or desire to continue gambling is, at least in part, related to winning or losing. Thus, the priming effects of a gambling session might likewise be greater among gamblers who win during a short gambling session than among those who lose.

Eliciting craving and desire in the laboratory

One of the most popular means of eliciting craving in the substance abuse research has been the use of in vivo cue exposure (e.g., Baumann \& Sayette, 2006). In 
such studies, craving to use a substance is provoked by cues present in the environment in which the drug is most frequently consumed (for review see Litt \& Cooney, 1999). A marijuana user may be asked to view, hold, or smell the drug in a dimly lit room. In gambling-related craving research, videotaped scenes of casinos have been used to provide such in vivo gambling cues (e.g. Crockford et al., 2005; Potenza et al., 2003). Crockford et al. (1998a), for example, demonstrated increased craving among pathological gamblers (relative to controls) following the presentation of a gamblingrelated video. Such cue presentations, however, do not permit the gambler to engage in gambling nor do they provide the experimenter the capability of manipulating elements of the game (such as wins or losses). In contrast to cue presentation through video (or other related forms of electronic messaging), a virtual reality casino environment allows the gambler to be immersed in a natural-looking environment that contains many of the sensory stimuli found in a real casino and also permits the gambler to engage in gambling behaviour.

Indeed, VR environments are being used with increasing frequency in the study of psychological disorders such as phobias (Wiederhold \& Wiederhold, 2000), eating disorders (Alcañiz, Perpiña, Baños, Lozano, Montesa, Botella, Palacios, Villa, \& Alozano, 2000), tobacco addiction (Baumann \& Sayette, 2006), and cocaine addiction (Baumann, Fetzick, Stangl, Brauch, Kenney, Yothers, \& Thompson, 2006), and has been shown to promote stress-related cortisol variations much like those associated with naturalistic stressors (Kelly, Matheson, Ravindran, Merali, \& Anisman, 2006). More recently, Baumann and Sayette (2006) demonstrated that VR environments are capable of 
eliciting craving in smokers, but to date, VR has not been used within the context of craving or desire to gamble (or gambling research more generally). In the current studies, the realism and control over outcomes a VR environment provides were used to assess the influence of wins and losses on craving and desire to continue gambling.

In Study 1, it was of interest whether wins and losses would differentially influence the priming effects of a short gambling episode. This was accomplished by manipulating outcomes, such that half of the participants won money and half lost. Gambling is a function of previous reinforcement history (Skinner, 1953). Indeed, success with gambling (i.e., winning) leads to an increased likelihood that gambling behaviour will continue (Griffiths, 1999). In this line, it was hypothesized that among those with elevated gambling pathology, wins would increase desire to continue gambling, whereas losses would not. Conversely, among non-problem gamblers, it was hypothesized that there would be no change in desire to continue gambling regardless of outcome.

Method

\section{Participants}

First year university students $(N=2062)$ were screened for gambling problems during a mass testing session at the beginning of the 2005 academic year. Seventy-four participants $($ Males $=43 ;$ Females $=31$ ) were selected from this larger sample based on their scores on the Problem Gambling Severity Index (PGSI; Ferris \& Wynne, 2001) (see Appendix A). According to the PGSI, gamblers can be categorized as non-problem, lowrisk, moderate-risk, or problem gamblers. This four category scheme, however, was 
developed for use in population research, whereas a 3 category scheme in which the moderate risk and problem gambler categories are collapsed is advised for research purposes (H. Wynne, personal communication, August 14, 2006). As such, these two categories were collapsed into a single high-risk gamblers category (>2 PGSI symptoms; 30 males and 8 females). The number of PGSI symptoms among the high-risk gamblers ranged from 3 to $15(M=5.76, S D=3.26)$. Because it was of interest whether individuals that were at high-risk for gambling pathology differed from those that gamble, but displayed no symptoms of pathology, a sample of 36 non-problem gamblers (0 PGSI symptoms; 13 males and 23 females) were included in Study1 as a comparison group.

Participants ranged in age from 17 to $47(M=20.93, S D=5.02)$. The majority of participants were Caucasian (62.2\%), whereas other participants were East-Asian (10.8\%), African-Canadian (6.8\%), South Asian (5.4\%) or Middle Eastern (5.4\%). The remainder (9.4\%) self-identified as Native Canadian, Hispanic or multi-ethnic. In return for their participation, participants received $\$ 20$ or if enrolled in an introductory psychology course, participants could opt to receive course-related credit and $\$ 10$.

\section{Procedure and Apparatus}

Upon arrival at the laboratory, participants were directed to a desk located in a part of the room separated by a 7-foot high room divider. On the desk was a computer game joystick and in front of the desk was a 40" plasma screen television with stereo speakers. A computer was connected to the television that ran VR Worlds software (described in detail in Baumann, Neff, Fetzick, Stangl, Basler, Vereneck, \& Schneider, 2003). After signing an informed consent document (Appendix B), participants were 
shown how to navigate around the virtual environment and interact with objects. The lights in the laboratory were then turned off to better immerse the participant in the VR world.

They were then asked to navigate their way through the VR environment and enter the casino. Once in the casino, participants were asked to sit down at a slot machine. Five dollars in betting chips were provided to the participant ( 20 credits) and they were instructed that they could bet 1 token per spin. They were informed that, ostensibly, their chances of winning at the slots in the VR casino were the same as the slot machines at the local casino. In actuality, the game was pre-programmed. During 10 spins, participants in the win condition $(n=38)$ experienced 1 win of 4 credits, 1 win of 2 credits, 3 wins of 1 credit, and 5 losses. Therefore, participants in the win condition finished the $10^{\text {th }}$ spin with 25 credits or an extra $\$ 1.25$ (for a total of $\$ 6.25$ ). Participants in the loss condition $(n=36)$ experienced 1 win of 2 credits, 1 win of 1 credit, and 8 losses. Therefore, those in the loss condition finished the 10 th spin with 15 credits, down by $\$ 1.25$ (for a total of $\$ 3.75$ ). Importantly, it was stressed that any amount of money won during the session would be theirs to keep.

Gamblers' desire to wager was assessed immediately before gambling and again following the $10^{\text {th }}$ spin. Upon completion, all participants were fully debriefed (Appendix C). During this debriefing, the rationale of the experiment was explained to participants. It was also emphasized to the participants that all wins and losses were programmed. This was to insure that participants (particularly those who won) did not leave with an elevated desire to gamble. They were also provided with a debriefing form that explained in 
greater detail the intent of the research. This form included the numbers of the local gambling help-line and the university's health and counselling services.

\section{Measures}

Gambling Pathology. The Problem Gambling Severity Index (PGSI; Ferris \& Wynne, 2001) is a 9-item instrument that is a sub-set of the Canadian Problem Gambling Index (CPGI; Ferris \& Wynne, 2001) and was designed to measure problem gambling severity. The PGSI is typically more conservative and yields lower prevalence rates than other more widely used measures such as the South Oaks Gambling Screen (SOGS; Lesieur \& Blume, 1987) (for discussion see Neal, Delafabbro, \& O'Neil, 2005). The PGSI also assesses gambling problems specifically during the previous 12 months and is thus more conservative than lifetime prevalence measures. Participants respond to questions such as "Thinking about the last 12 months, how often have you bet more than you could really afford to lose?" or "Thinking about the last 12 months when you gambled, how often have you gone back another day to try to win back the money you lost?". Responses are given on a 4-point Likert scale anchored at 1 (Never) and 4 (Almost always).

Desire to gamble. Desire to continue gambling was measured before gambling and then after the $10^{\text {th }}$ spin using a Likert scale ranging from 0 (no desire to gamble at all) to 100 (overwhelming desire to gamble) which asked "How would you rate your desire to gamble?" (adapted from Baumann \& Sayette, 2006; Juliano \& Brandon, 1998). 


\section{Preliminary analysis}

\section{Results}

Analysis of variance (ANOVA) indicated that level of gambling pathology was unrelated to age, $F<1$, or the outcome manipulation variable (win vs. loss), $F<1$. Predictably, the gender composition in the non-problem and high-risk groups was not equivalent, $\chi^{2}(1)=13.94, p<.001$ (see Rush, Moxam, \& Urbanoski, 2002). However, the gender composition in the win (25 males and 13 females) and loss groups (18 males and 18 females) was comparable, $\chi^{2}(1)=1.89$. To assess whether there were gender differences in desire, a 2 (gender) x 2 (outcome: win vs. loss condition) x 2 (gambling pathology: non-problem vs. high-risk) $\times 2$ (desire: before gambling, following $10^{\text {th }}$ spin) mixed measure ANOVA was conducted with desire as the repeated measure. Results indicated no gender main effects or interactions $(p$ 's<.05). Therefore gender was not included in subsequent analyses.

The distribution of desire assessments was found to violate the assumption of normality at the two time points (Shipiro-Wilks $>.92, p<.005$ ). Therefore to reduce skewness and kurtosis, the data were logarithmically transformed. The transformed desire ratings ranged from 0 (not very strong) to 2.00 (very strong) with a midpoint of 1.70 . Bonferroni correction was used in all follow-up tests.

\section{Experimental effects on desire to gamble}

In order to examine the effects of outcome (win vs. loss) and level of gambling pathology on desire to gamble, a 2 (outcome: win vs. loss condition) x 2 (gambling pathology: non-problem vs. high-risk) x 2 (time: desire before gambling, desire following $10^{\text {th }}$ spin) mixed measure ANOVA was conducted with time of assessment as the 
repeated measure. This analysis revealed that, overall, high-risk gamblers reported greater desire to gamble $(M=1.82, S E=0.04)$ than their non-problem counterparts $(M=$ $1.71, S E=0.04), F(1,70)=4.36, p<.05, \eta_{\mathrm{p}}{ }^{2}=0.06$. The most pronounced difference was reported before engaging in gambling. In response to gambling related cues, high risk gamblers reported $(M=1.81, S E=0.04)$ craving to gamble significantly more than non-problem gamblers $(M=1.68, S E=0.04)$.

The main effect of gambling pathology, however, was qualified by a significant three-way interaction between time, outcome, and level of gambling pathology, $F(1,70)$ $=5.02, p<.03, \eta_{\mathrm{p}}{ }^{2}=.07$. To determine which simple interaction was accounting for this effect, a 2 (outcome: win vs. loss condition) x 2 (time: desire before gambling, desire following $10^{\text {th }}$ spin) mixed-measure ANOVA was conducted separately for non-problem and high-risk gamblers. These analyses indicated a significant interaction between condition and time of assessment among the high-risk gambler group only, $F(1,36)=$ $8.62, p<.01, \eta_{\mathrm{p}}{ }^{2}=.19$. Follow-up tests revealed that among high-risk gamblers in the win condition, desire to gamble increased significantly from before gambling $(M=1.78$, $S E=0.04)$ to after the $10^{\text {th }} \operatorname{spin}(M=1.86, S E=0.04), F(1,19)=7.93, p=.01, \eta_{\mathrm{p}}{ }^{2}=.30$. Among those in the loss condition, however, desire to gamble did not change significantly from before gambling $(M=1.85, S E=0.05)$ to after the $10^{\text {th }}$ spin $(M=1.78$, $S E=0.05), p>.10$.

\section{Discussion}

The results of Study 1 supported the general hypothesis that wins and losses differentially influence the priming effects of a short gambling episode among problem 
gamblers. Thus, the present experiment lends further support to the finding that a short gambling episode is associated with increased desire to continue gambling among problematic gamblers (Zack \& Poulos, 2007). However, the present research indicated that priming effects occur only among problem gamblers who win. Specifically, problem gamblers who increased their initial stake reported increased desire to continue gambling, whereas desire remained stable among those problem gamblers who were in the midst of losing their initial stake. Thus simply engaging in wagering appeared to be insufficient to effectively prime motivation to gamble.

Although Study 1 provided evidence that the priming effects of a short gambling episode are contingent on the gambler winning money, not all winning sessions share the same characteristics. Although a winning session can result from a couple of moderate wins or a series of small wins, on occasion, the player will experience a big win. Study 2 tests whether the type of win differentially influences the efficacy of a priming episode to prime motivation to continue gambling. 
Study 2: The influence of win type on desire to continue gambling

For some people, a winning session results from a series of small wins, whereas for others the winning session may stem from one large win. The aim of Study 2 was to examine in more detail the influence of win-type on the efficacy of an episode of gambling to prime desire to continue gambling. Specifically, the efficacy of a single large win versus a series of small wins of equal monetary gain in priming desire to continue gambling in gamblers was assessed. It was also of interest whether the effect of win type varied as a function of gambling-related pathology.

Although the results of Study 1 suggest that wins are important in priming desire to continue gambling, there is a paucity of research on the influence of different types of wins on motivation to gamble. A notable exception, however, is research that has examined influence of a 'big win' on gambling persistence (i.e., the number of slot machine spins the participant continues to play in the face of repeated loss). This research was conducted in an attempt to test the "big win" hypothesis. In has been hypothesized (Custer \& Milt, 1985) that experiencing a big win early in the gamblers career is a predisposing factor in the development of pathological gambling. In two separate tests of the big win hypothesis, Kassinove and Schare (2001) and Weatherly, Sauter, and King (2004) had undergraduates play slot machines that were programmed to deliver a big win (to some of the participants) at a specific trial in the session. These studies produced inconsistent results. Kassinove and Schare (2001) had participants play a slot machine in which they experienced a 'big win' $(\$ 10.00)$ on the $8^{\text {th }}$ trial, intermittent small wins until the $50^{\text {th }}$, and then a sequence of repeated losses in which the participant was permitted to 
stop playing whenever they wished. They found, after controlling for gambling pathology, no significant differences in gambling persistence between those who experienced a large win and those who experienced a series of losses. In another study, Weatherly et al. (2004) reported that those experiencing a big win $(\$ 1.60)$ on the $1^{\text {st }}$ spin stopped playing significantly sooner than those experiencing a big win on the $5^{\text {th }}$ spin. Despite differences in what constitutes a 'big win', both studies tested their paradigm using participants with little or no prior gambling experience (in order to test the "big win" hypothesis). Thus what can be concluded from these studies is that among gamblers with little or no experience, a large win occurring on the $5^{\text {th }}$ to $10^{\text {th }}$ spin may influence gambling persistence. They did not, however, examine desire to gamble. The present experiment examined whether a large win affected the desire to continue gambling among gamblers with varying levels of gambling experience and pathology.

The present study also assessed a possible mechanism by which the outcome of engaging in games of chance may influence the desire to continue gambling. It has been suggested (Darke \& Freedman, 1997; Wohl \& Enzle, 2002, 2003) that some people attempt to maximize outcomes in games of pure chance through the use of their personal luck, a quality some people believe they can deploy to influence random events. As a result of such perceptions, negative outcome expectancies (for continued loss) are offset by positive outcome expectancies consisting of strong beliefs regarding the likelihood of an imminent win (Wohl, 2008). In Study 2, it was hypothesized that the experience of a large win would be especially apt to facilitate self-perceptions of personal luck, as a large win is more infrequent than small wins and thus only the most "abled" person should 
experience such a win (see Custer \& Milt, 1985). As perceptions of personal luck elevate expectations of future gambling success, there should be an associated desire to continue gambling.

In addition to investigating the influence of win type on desire to continue gambling, a second aim of Study 2 was to examine whether the strength of a priming episode would influence participants' gambling persistence. Persistence is operationally defined as the number of trials (i.e., slot machine spins) that the participant continues to engage in the face of repeated loss. Persistence may also correctly be thought of as resistance to extinction. Persistence has frequently been used to assess the influence structural characteristics of electronic gaming, such as the presence or absence of a stop button (Ladouceur \& Sevigny, 2005), temporal presentation of winning symbols (Ladouceur \& Sevigny, 2002; Strickland \& Grote, 1967), and the number of near wins (Cote, Caron, Aubert, Desrochers, \& Ladouceur, 2003).

Do strong desires to gamble lead to greater persistence? The current gambling literature has been silent on this front. It was also of interest in the present investigation to determine whether participants would report a decrease in desire to continue gambling after voluntarily stopping and whether this change in desire would be influenced by either their level of gambling pathology or the type of win experienced before the sequence of losing spins.

To answer these questions, the influence of win type on desire to continue gambling was examined among participants with varying levels of gambling pathology while they played a slot machine located in the same VR casino used in Study 1 . While 
playing, gamblers experienced either a single large win or a series of small wins of equivalent monetary gain. Following, participants were permitted to continue playing as long as they wanted (all subsequent spins being losses) thus permitting evaluation of persistence.

\section{Method}

\section{Participants}

First year university students $(N=1559)$ were screened for gambling problems during mass testing at the beginning of the 2006 academic year. Participants were recruited based on their PGSI scores (Ferris \& Wynne, 2001). As in Study 1, moderaterisk and problem gambler categories were collapsed into a single high-risk gamblers group. From the initial sample, 103 participants were recruited to participate in Study 2 $($ Males $=49 ;$ Females= 54); 31 non-problem, 33 low-risk, and 39 high-risk gamblers. Participants ranged in age from 18 to $44(M=20.07, S D=3.85)$. The majority of participants were Caucasians (74\%). The remainders were Asian (15\%), Middle Eastern (4\%), South Asian (3\%), Latin American (2\%), or African-Canadian (3\%).

\section{Procedure}

Upon arrival at the laboratory, participants were seated in front of a computer running $V R$ Worlds software (see Study 1). The experimenter explained to the participant that the purpose of the experiment was to investigate gambling behaviour. After signing a written informed consent document (Appendix D), participants completed a background questionnaire and measures assessing desire to continue gambling (see Study 1) and perceptions of personal luck (Steenbergh, Meyers, May, \& Whelan, 2002) (Appendix E). 
Following completion of the questionnaire booklet, participants were told they would be gambling in a virtual casino environment. They were then instructed to put on a head-mounted display (HMD; Z800 3D Visor, eMagin Corporation, Fishkill, New York) that would enable them to see and navigate around the virtual environment with the aid of a joystick and mouse. Following these instructions, the lights were turned off and participants entered the casino.

In the VR casino there was an array of 13 slot machines. Participants were told they could select the slot machine they wished to play. All participants were given 20 credits worth 25 cents each $(\$ 5)$ to play the slots. They were told that the chances of winning at the virtual slot machines were the same as those at the local casino and they could keep whatever money they won. They were also shown the payout legend located on the slot machine in front of them. The experimenter then read the payout amounts to the participant: "three cherry's pays 1 credit, three single bars pays 5 credits, three double bars pays 10 credits, and three 7's, the jackpot, pays 50 credits". Finally they were told that they were permitted to bet only one token per spin. Just prior to gambling, participants completed the first of four single item measures asking them to rate the strength of their desire to gamble.

After completing the measure, participants were told to play slots for at least 10 minutes or until they lost all their money. They were also informed that they would be interrupted after 5-minutes to complete additional measures. The experimenter then turned off the light and sat down at a desk on the other side of a room divider to provide the gambler privacy while gambling. 
Although participants were told that they would be interrupted after 5 and 10 minutes, in actuality each participant was interrupted after the $25^{\text {th }}$ and then again after the $50^{\text {th }}$ spin regardless of the time. A monitor that displayed the same screen as seen by the participant was placed on a desk on the experimenter's side of the privacy divider. This screen permitted the experimenter to count the participant's slot machine spins. As soon as they completed 25 spins, the experimenter manually sounded a timer bell, asked the participant to stop gambling, turned on the light, and asked that they complete the second single item measure assessing desire to continue gambling. After completing the measure, the experimenter once again turned off the light, and told participants to continue playing for another 5 minutes or until they lost all their money.

Using a paradigm similar to that described by Cote, Caron, Aubert, Desrochers, and Ladouceur (2003), the pattern of wins and losses in the first 25 spins were identical for all participants: 2 wins of 10 credits, 2 wins of 5 credits, 3 wins of 1 credit, and 18 losses. Therefore, all players ended the first 25 spins with 35 credits $(\$ 8.75)$ or 15 credits more than they started with. The experimental manipulation took place during the second set of 25 spins. Participants were randomly assigned to a large win condition $(n=52)$ in which they won 50 credits $(\$ 12.50)$ on the $50^{\text {th }}$ spin, or a 'series of small wins' condition $(n=51)$ in which they experienced small wins throughout spins 25-50 (which included a win on the $50^{\text {th }}$ spin). Participants in both conditions ended the second set of 25 spins with 60 credits or $\$ 15.00$.

As soon as the participant completed the $50^{\text {th }}$ spin, the experimenter again sounded the timer bell. The experimenter informed the participant that the experiment 
was over and asked them to complete another single item measure assessing their desire to continue gambling. They were then told that the experimenter had collected all the data required and therefore they could either cash out immediately, or continue gambling for as long as they would like. Importantly, unbeknown to the participant, the slot machine was programmed to produce losses on all subsequent spins. This procedure was employed by Cote et al. (2003) and was used to determine the gambler's persistence in the face of loss. Upon voluntary cessation, participants completed measures assessing desire to gamble and perceptions of personal luck (Steenbergh et al., 2002). Regardless of how much money they ended with, participants were given either $\$ 15$ or $\$ 10$ and experimental credit if they were enrolled in an introductory psychology class. As in Study 1 , the rationale of the experiment was explained to participants emphasizing that all wins and losses were programmed. This was to insure that participants did not leave the lab with elevated desire to gamble. They were also provided with a debriefing form (Appendix F) that explained in greater detail the intent of the research. This form included the numbers of the local gambling help-line as well as the university's health and counselling services.

\section{Measures}

Gambling Pathology. Problem gambling severity was assessed using the Problem Gambling Severity Index (PGSI; Ferris \& Wynne, 2001). See Study 1 for a more complete description of this measure.

Desire to gamble. Desire to gamble (single item) was assessed immediately before gambling, after the $25^{\text {th }}$ and $50^{\text {th }}$ spin, then upon voluntary cessation. Participants 
were asked "How strong is your craving to gamble?" They responded on a scale anchored at 0 (not very strong) to 15 (very strong) (see Study 1 for details).

Perceived personal luck. This 10 -item scale measured the extent to which respondents perceived luck to be a personal skill (Steenbergh et al., 2002). These items were chosen because they represent a skill orientation toward gambling (e.g. "My knowledge and skill in gambling contribute to the likelihood that I will make money", "I have a 'lucky' technique that I use when I gamble"). Participants rated each item on a scale ranging from 1 (Strongly Disagree) to 5 (Strongly Agree), and responses were averaged, with higher scores reflecting higher perceived control. Previous research on personal luck (Wohl, Anisman, Matheson, \& Young, 2006; Wohl, Young, \& Hart, 2005; Wohl et al., 2007) has indicated that the scale has very good internal consistency The scale was completed before and after gambling ( $\alpha=.88$ and .91$)$.

Persistence. Persistence was assessed by counting the number of spins the gambler played in the face of repeated loss (see procedure described earlier).

Results

\section{Preliminary Analyses}

An ANOVA indicated no significant age differences by condition (large win vs. small wins), or level of gambling pathology, $F_{\mathrm{S}}<1$. Further, gender composition in the non-problem (10 male and 21 females), low-risk (16 male and 17 females), and high-risk (23 males and 16 females) gambling groups was not significantly different, $\chi^{2}(2)=4.96$, $p=.08$. To assess whether there were gender differences in the dependant variables a series ANOVAs were conducted. A mixed-model ANOVA (with gender, experimental 
condition, and level of gambling pathology as between subject factors) was conducted for the single item desire assessments. In addition, a similar ANOVA was conducted to assess persistence. Because there was no significant main effect of gender, nor were there any significant interactions, $p s>.05$, the data were collapsed across participant gender for all subsequent analyses.

Because the assessments of desire violated the assumption of normality at all time points (Shipiro-Wilks $>.91, p<.001$ ), the data were logarithmically transformed. For the single item measures, the transformed desire ratings ranged from 0 (not very strong) to 1.18 (very strong) with a midpoint of 0.88 . Bonferroni correction was used in all followup tests.

\section{Desire to gamble}

In order to examine the influence of condition (i.e., large win vs. a series of small wins) and level of gambling pathology on desire to continue gambling, a 2 (condition: large win vs. small wins) x 3 (level of pathology: non-problem, low-risk, and high-risk gamblers) $\times 4$ (time: desire before gambling, following $25^{\text {th }}$ spin, following $50^{\text {th }}$ spin, upon voluntary cessation) mixed-measure ANOVA was conducted with time of assessment as the repeated measure. This analysis revealed a main effect of gambling pathology, $F(2,97)=4.22, p<.05, \eta_{\mathrm{p}}{ }^{2}=.08$. As expected high-risk gamblers reported the highest overall desire ratings $(M=0.86, S E=0.04)$ followed by low-risk gamblers $(M$ $=0.82, S E=0.04)$. Non-problem gamblers reported the lowest overall desire levels $(M=$ $0.71, S E=0.04), p s<.05$. Desire also fluctuated significantly over time, $F(3,291)=$ $30.29, p<.001, \eta_{\mathrm{p}}{ }^{2}=.24$. Follow-up tests revealed that desire increased significantly 
from baseline $(M=0.81, S E=0.02)$ to after the $25^{\text {th }} \operatorname{spin}(M=0.84, S E=0.03)$ but then stabilized after the $50^{\text {th }} \operatorname{spin}(M=0.83, S E=0.03)$.

Table 1

Means $( \pm \mathrm{SE})$ of desire ratings at the 4 assessment times by condition.

\begin{tabular}{lccccccccc}
\hline \multicolumn{1}{c}{ Before } & After $25^{\text {th }}$ spin & After $50^{\text {th }}$ spin & \multicolumn{2}{c}{ Voluntary } \\
& \multicolumn{2}{c}{ Gambling } & & & & & \multicolumn{2}{c}{ cessation } \\
\hline & Large & Small & Large & Small & Large & Small & Large & Small \\
& Win & Wins & Win & Wins & Win & Wins & Win & Wins \\
& & & & & & & & \\
\hline Non-Problem & $.77(.06)$ & $.67(.06)$ & $.82(.06)$ & $.64(.06)$ & $.82(.06)$ & $.69(.06)$ & $.72(.06)$ & $.50(.06)$ \\
Low-Risk & $.78(.06)$ & $.83(.06)$ & $.83(.06)$ & $.89(.06)$ & $.77(.06)$ & $.90(.06)$ & $.69(.06)$ & $.84(.06)$ \\
High-Risk & $.94(.05)$ & $.82(.05)$ & $.96(.05)$ & $.86(.06)$ & $.94(.05)$ & $.81(.06)$ & $.87(.05)$ & $.64(.06)$ \\
\hline
\end{tabular}

These effects, however, were qualified by a significant three-way interaction between condition, level of pathology, and time of assessment, $F(6,291)=2.61, p<.05$, $\eta_{\mathrm{p}}{ }^{2}=.05$. See Table 1 for mean desire rating for each group by time of assessment. In order to determine which simple interaction accounted for this effect, separate 2 (condition: large win vs. series of small wins) x 4 (time: desire before gambling, following $25^{\text {th }}$ spin, following $50^{\text {th }}$ spin, upon voluntary cessation) mixed-measure ANOVAs were conducted at each level of gambling pathology (i.e., non-problem, lowrisk, and high-risk gamblers). These analyses revealed a significant interaction between condition and desire among the high-risk gambler group only, $F(3,111)=3.35, p<.05$, $\eta_{\mathrm{p}}^{2}=.08$ 
Follow-up analyses revealed that among high-risk gamblers there were no significant differences in desire between those experiencing a single large win or series of small wins before gambling, after 25 spins, and after 50 spins $(F \mathrm{~s}<1)$. However, upon voluntary cessation, high-risk gamblers who experienced a large win reported significantly greater desire to gamble than those who experienced a series of small wins, $F(1,37)=7.62, p<.001, \eta_{\mathrm{p}}^{2}=.17($ Figure 1$)$

\section{Persistence}

In order to examine the influence of win type and level of gambling pathology on persistence a 2 (condition: large win vs. series of small wins) x 3 (level of pathology: non-problem, low-risk, and high-risk gamblers) ANOVA was conducted. As predicted, those with higher levels of gambling pathology continued to gamble significantly longer in the face of repeated loss than those with lower levels of gambling related pathology $F(2,96)=3.68, p=.03, \eta_{\mathrm{p}}{ }^{2}=.07$. Follow-up analyses revealed that this difference was due to gamblers in the high-risk group persisting significantly longer $(M=19.92, S E=$ $2.23)$ than low-risk $(M=11.66, S E=2.39)$ or non-problem gamblers $(M=13.13, S E=$ $2.47), p s<.05$. In addition, participants experiencing a series of small wins continued to gamble significantly longer $(M=18.01, S E=1.93)$ than those experiencing a single large win $(M=11.79, S E=1.94), F(1,96)=5.16, p=.02, \eta_{\mathrm{p}}{ }^{2}=.05$. There was no significant interaction, $F<1$. 
Figure 1. Desire ratings ( $M+/$-SEM) among high-risk gamblers before gambling, following the $25^{\text {th }}$ and $50^{\text {th }}$ spins, as well as upon voluntary cessation as a function of win type.

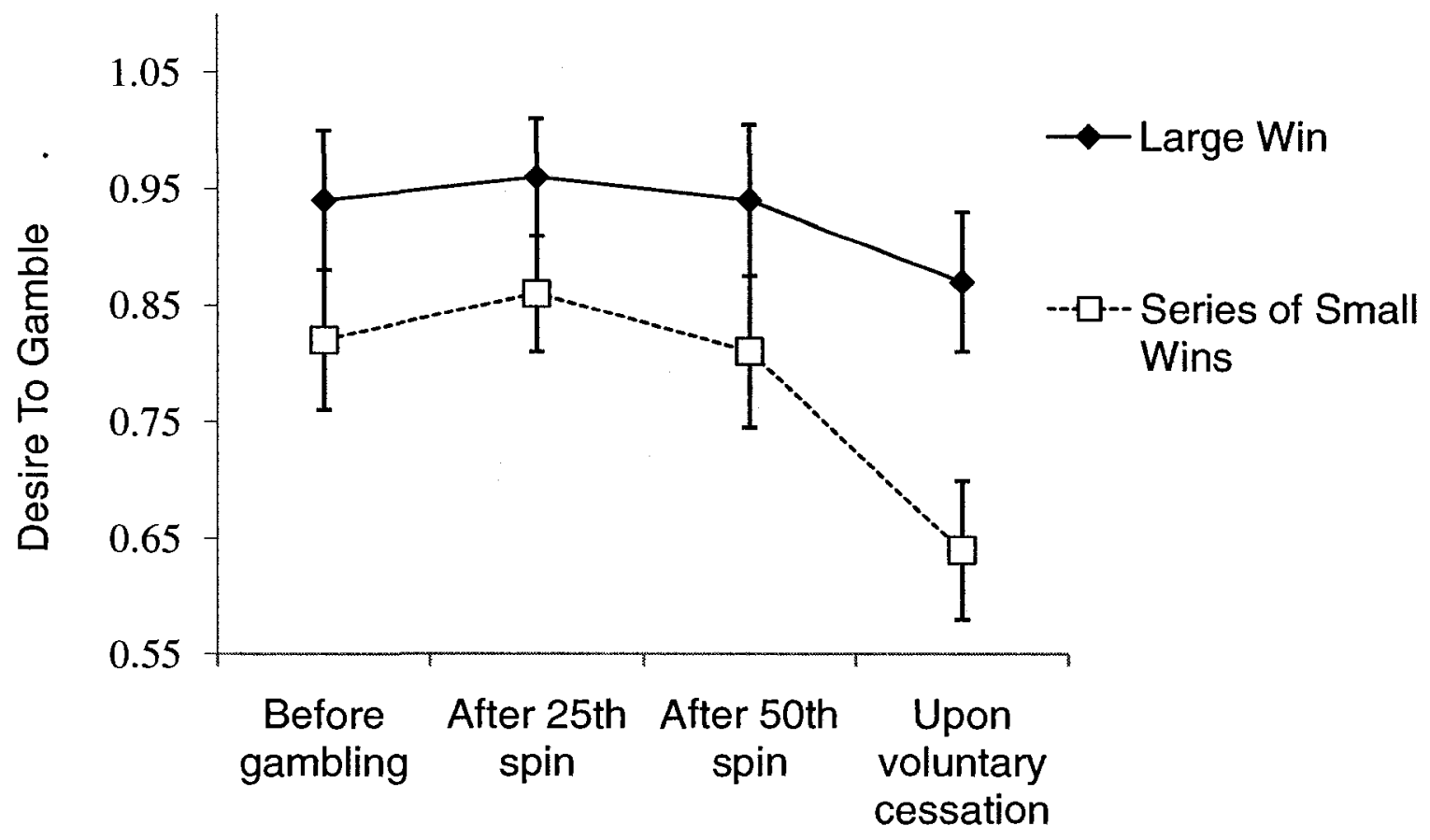

The relationship between desire and persistence was assessed via correlations between self-reported desire following the experimental manipulation (i.e., after the $50^{\text {th }}$ spin) and the number of spins participants made (persistence) in the face of repeated loss. As expected, desire to gamble assessed at all three time points before beginning the sequence of repeated losses was reliably associated with the number of spins in the face of loss $(r s>.20, p<.05)$. 


\section{Personal Luck}

Perceptions of personal luck were assessed before gambling, then again following the persistence phase of the gambling session (i.e., following gambling). Therefore, to examine whether there were differences in perceptions of personal luck caused by the type of win, a 2 (condition: large win vs. series of small wins) x 3 (level of pathology: non-problem, low-risk, and high-risk gamblers) x 2 (perceptions of personal luck: pre vs. post gambling) mixed measures ANOVA was conducted. Overall, perceptions of personal luck decreased over the course of play (pre-gambling, $M=2.14, S E=0.07$; post-gambling, $M=2.03, S E=0.07), F(1,97)=13.29, p<.001, \eta_{\mathrm{p}}{ }^{2}=.12$. As well, there were significant differences in perceptions of personal luck as a function of gambling pathology, $F(2,97)=9.98, p<.001, \eta_{p}{ }^{2}=.17$. High-risk gamblers reported the greatest perceptions of personal luck $(M=2.34, S E=0.12)$ followed by low-risk $(M=$ $2.29, S E=0.13)$ and non-problem gamblers $(M=1.64, S E=0.13) p s<.05$.

Changes in perceptions of personal luck, as with desire to continue gambling, were moderated by both condition and level of gambling pathology, $F(2,97)=7.88, p<$ $.01, \eta_{\mathrm{p}}{ }^{2}=.14$. To understand what accounted for this three-way interaction, 2 (condition: large win vs. series of small wins) $\times 2$ (perceptions of personal luck: pre vs. post) mixedmeasure ANOVAs were conducted at each level of gambling pathology (i.e., nonproblem, low-risk, and high-risk gamblers). These analyses revealed a significant interaction between changes in perceptions of personal luck and condition among the high-risk gambler group only, $F(1,37)=8.22, p<.01, \eta_{\mathrm{p}}{ }^{2}=.18$. Mirroring the craving analysis, follow-up analyses revealed that among high-risk gamblers, in the large win 
condition, perceptions of personal luck remained unchanged (pre-gambling, $M=2.55, S E$ $=0.17$; post-gambling, $M=2.52, S E=0.18), F<1$. However among those experiencing a series of small wins, perceptions of personal luck decreased significantly after gambling (pre-gambling, $M=2.29, S E=0.19$; post-gambling, $M=1.99, S E=0.20), F(1,17)=$ $12.93, p<.01, \eta_{\mathrm{p}}{ }^{2}=.43$

Mediation analysis for craving by personal luck

In order to determine if the effect of the win type manipulation on desire to continue gambling could be explained by perceptions of personal luck, Baron and Kenny's (1986) regression procedure was used to test for mediation. Thus, perception of personal luck was regressed onto the win type manipulation variable (dummy coded as 0 in the series of small wins condition and 1 in the large win condition). As indicated from the ANOVAs reported earlier, the experimental treatment condition had a significant effect on perceptions of personal luck in the first equation, $\beta=.31, t(37)=1.98, p=.05$. The win type manipulation variable also significantly predicted craving, $\beta=.41, t(37)=$ $2.76, p<.01$, in the second equation. Finally, when both the manipulation variable and post-gambling perceptions of personal luck were included as predictors, perceptions of personal luck, $\beta=.45, t(36)=3.19, p<0.01$, but not the manipulated variable, $\beta=.27$, $t(36)=1.95, p>.15$, significantly predicted craving (see Figure 2 ). 


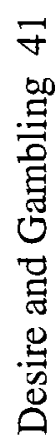
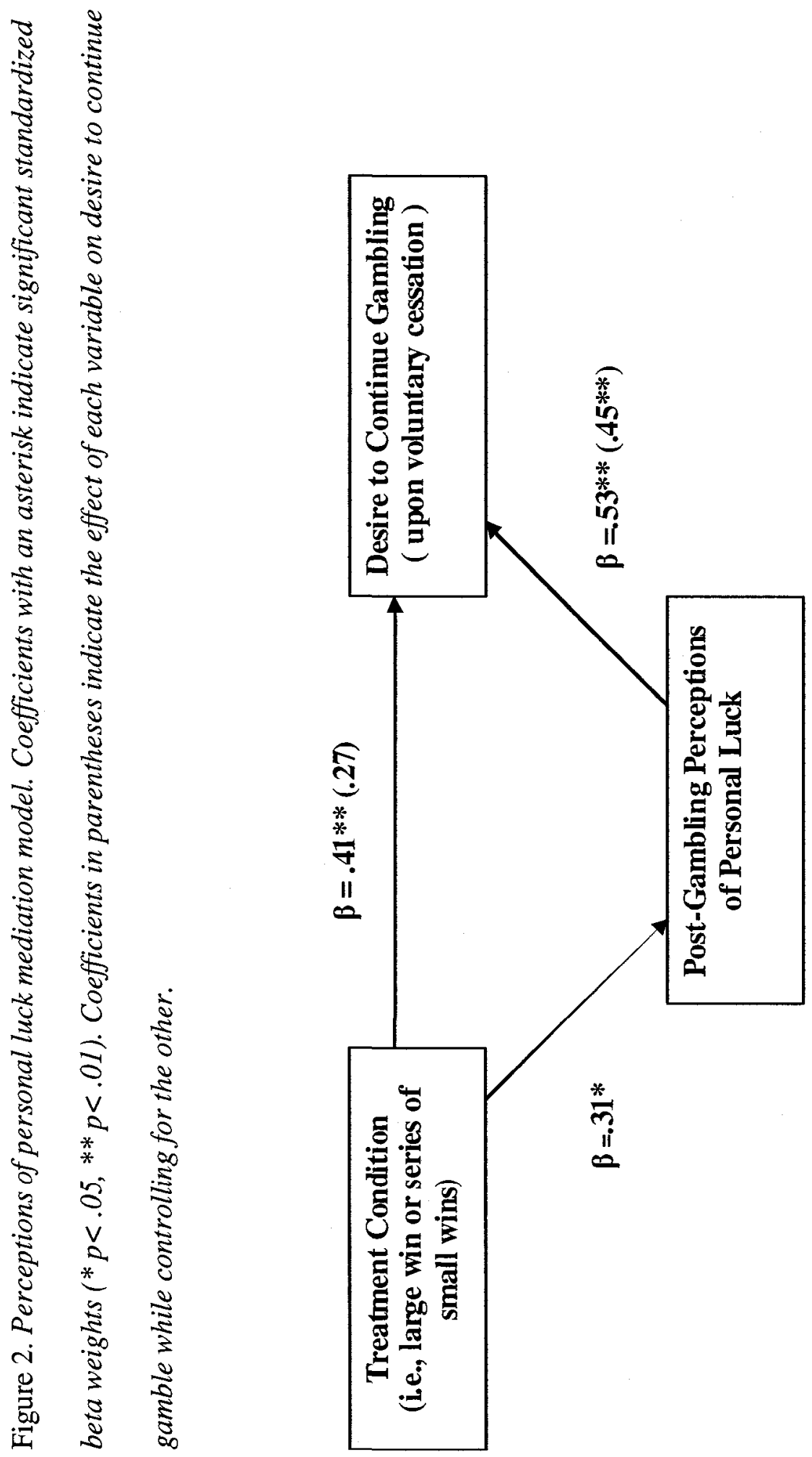
Based on this mediational analysis, it seems that changes in perceptions of personal luck may account for craving differences between high-risk gamblers in the large win and small win conditions. The bootstrapping technique (with 1000 iterations) outlined by Preacher and Hayes (2004) was used to determine whether the mediated effect of condition on craving, via changes in perceptions of personal luck, on craving was significantly different than zero. The indirect effect was estimated to lie between .17 and .001 with $95 \%$ confidence. Because zero is not in the $95 \%$ confidence interval, the indirect effect is considered to be significantly different from zero at $p<.05$.

Discussion

Study 2 replicated the priming effect of wins in Study 1 . However, it appeared that either a single large win or a series of small wins effectively primed desire to continue gambling. That is, regardless of the how a gambler wins during a session, the effect of wins appears to elevate the desire to continue wagering and thus function as an effective priming stimulus. Although type of win did not differentially influence desire to continue gambling immediately following the end of the winning session, between group differences in desire to continue gambling were found in a subsequent session in which gamblers experienced repeated losses and could stop gambling voluntarily. In this session, participants who experienced a series of small wins persisted longer than those experiencing a single large win. This finding is in line with what would be predicted by learning theory. Behaviours learned via a partial reinforcement schedule are subject to the greatest resistance to extinction (Ferster \& Skinner, 1957). 
Interestingly, although a series of small wins resulted in greater persistence than a large win, high-risk gamblers who experienced a large win maintained high levels of desire to continue gambling upon voluntary cessation, whereas participants experiencing a series of small wins reported a significant reduction in desire to gamble. This difference may be due to elevations in outcome expectancies stemming from experiencing the large win. Indeed, high-risk gamblers who experienced a large win voluntarily stopped gambling to the extent that they reported sustained perceptions of personal luck. Importantly, such perceptions fully mediated the effect of win type on desire to continue gambling upon voluntary cessation. Thus, experiencing an infrequent, fortunate, chance event such as a large win, results in maintaining perceptions of personal luck which, in turn leads to sustained desire to continue gambling even in the face of prolonged and consistent loss.

The observed mediation is in line with Wohl and Enzle's (2002; 2003) attributionexpectancy model of gambling as well as Marlatt and Gordon's (1985) assertion that craving is related to the immediate positive outcome expected as a result of engaging in an addictive behaviour. To the point, it is not simply the win that increases gambler's craving to play, but instead, winning alters the gamblers expectancy of continued success, which leads to a desire to continue engaging play. If a gambler thinks they are going to win it is not surprising that craving to continue play would follow.

It is important to note that a single item indicator was employed to assess desire in both experiments. While single item measures of craving are useful in that they provide minimal interruption to the participant while gambling and may be more sensitive to 
moment to moment fluctuations in craving to gamble (e.g., Shiffman, Paty, Gnys, Kassel, \& Hickcox, 1996), they suffer from problems of reliability and are limited by the assumption that craving is a unidimensional motivational state. The absence of a gambling craving measure that is sensitive to dimensions such as anticipation of reward or relief from negative states has limited research on the relation between craving and gambling. In light of this absence, Studies 3 and 4 assessed the factor structure, psychometric properties, and predictive validity of a new multi-item craving scale designed to measure the multidimensional nature of craving to gamble, the Gambling Craving Scale (GACS). 


\section{Study 3: The Gambling Craving Scale}

Though there are several physiological (e.g., heart rate, skin conductance, and blood pressure) and behavioural (e.g., drug seeking or drug use) proxy measures of craving (for a review of these measures, see Sayette et al., 2000), self-report scales are the most common way of assessing craving. The main reason for the popularity of selfreport scales is that craving is generally understood to be a subjective state of desire (APA, 1994; Drummond, 2001; Sayette et al., 2000). If craving is a subjective experience, then self-report is, by definition, the most direct way of measuring it.

Three general types of craving self-report scales appear in the substance abuse literature (Lowman et al., 2000). First, there are questionnaires that measure medical or psychiatric symptomatology posited to be associated with craving. Second, there are single item measures and short unidimensional scales. Lastly, there are questionnaires that tap purported multiple dimensions of craving. The first two of these three classes of assessment have been used to measure craving to gamble.

Researchers examining craving to gamble have used scales assessing impulsivity (Castellani \& Rugle, 1995) and obsessive thoughts about gambling (Hollander et al., 2000) as measures for craving. For example, Hollander et al. (2000) used a modified version of the Yale-Brown Obsessive Compulsive Scale (Goodman, Price, Rasmussen, Mazure, Fleischmann, Hill, Heninger, \& Charney, 1989) to measure gambling urges. By using this scale, obsessive thoughts about gambling were equated with gambling-related craving. However, craving is arguably different from the compulsions experienced by individuals with obsessive compulsive disorder. One component of craving that is absent 
in obsessive-compulsive individuals is the anticipation of a positive mood state following engagement in the behaviour (Davidson \& Neal, 1990). For example, Anton (2000), notes that the Obsessive Compulsive Drinking Scale is not sensitive to the anticipation of pleasure that is an inherent part of craving to drink. Therefore scales that measure obsessive compulsive thoughts provide an incomplete assessment of craving. Similarly, in comparing pathological gamblers to alcoholics and cocaine addicts, Castellani and Rugle (1995) measured impulsivity and defined it as the 'inability to control cravings and urges'. Again, impulsivity is a construct distinct from craving - it is a trait, whereas craving is a state. While impulsivity and obsessive thoughts may be related to craving, they are distinct constructs and therefore should not be confused.

In addition to scales designed to measure related constructs, craving to gamble has been measured in other ways. Single item measures (Crockford \& el-Guebaly, 1998b; Kushner et al., 2007), specific items selected from larger scales (Duvarci \& Varan, 2000; Kim et al., 2001), and short unidimensional scales (de Castro et al., 2007; Potenza et al., 2003; Raylu \& Oei, 2004b; Tavares et al., 2005) have all been used to assess craving to gamble. Specifically, the only scale that has been constructed to measure the desire to gamble is a unidimensional scale. The Gambling Urges Scale (GUS; Raylu \& Oei, 2004b) is a multi-item, single-factor scale. The problem with this type of assessment, however, is that it ignores evidence that craving generally, and craving to gamble specifically, is a multi-faceted construct.

Research suggests that both positively and negatively rewarding consequences of using a drug or engaging in a behaviour are dimensions of craving. For example, Tiffany 
and Drobes (1991) developed the Questionnaire on Smoking Urges in order to measure craving to smoke cigarettes. Analysis of the questionnaire data revealed two distinct dimensions of craving among smokers. The first dimension consisted of a strong desire to smoke that was anticipated as pleasant, enjoyable, and satisfying. The second dimension reflected an anticipation that smoking would provide relief from negative affect (Tiffany \& Drobes, 1991). Further, in reviewing Tiffany and Drobes' (1991) work on craving to smoke, Orford (2001) notes their results do not suggest that desire for relief from negative affect is simply the alleviation of withdrawal symptoms. The questionnaire items representing relief from negative affect were: being less irritable, less depressed, less bored, less tired, being able to control things better, and think more clearly. Research examining the factorial structure of alcohol (Love et al., 1998) and cocaine craving (Tiffany et al., 1993) supports the notion that craving for these substances is multidimensional.

It is hypothesized that craving to gamble is composed of similar dimensions. Research suggests gamblers experience both positive, arousing states (e.g., Anderson \& Brown, 1984; Ladouceur et al., 2003) as well as an escape from negative affective states (e.g., Diskin \& Hodgins, 2001; Grant \& Kim, 2003; Jacobs, 1988; Kofoed et al., 1997; Wood \& Griffiths, 2007) while gambling. Therefore it is hypothesized that craving to gamble is not characterised by simply the desire to gamble, but is also includes expectations of positive affect and relief from negative affect to result from gambling.

The purpose of the present study is to investigate the factor structure of craving to gamble. Research and theory both suggest that craving to gamble is a multidimensional 
construct. Therefore, this Study was conducted to develop the Gambling Craving Scale (GACS). To this end, a pool of items was tested on a sample of gamblers with varying degrees of gambling-related pathology. Like previous multidimensional scales of craving, it was hypothesized that craving to gamble would consist of a desire to gamble, an anticipation of enjoyment from wagering, an expectation of relief from negative affect while engaged in play, and an intention to gamble. It was hypothesized that those with greater levels of gambling pathology should report greater craving. That is, a valid craving scale should be able to differentiate those who engage in problematic play from those that do not. Lastly, greater craving levels were hypothesized to be associated with problematic gambling-related cognitions, negative affective states, and depression.

\section{Methods}

\section{Participants and procedure}

First year university students $(\mathrm{N}=3419)$ were screened for gambling problems during mass testing over a three-year period (2005-2007). A sample of those who indicated they gambled were contacted and asked to complete a series of questionnaires. After being presented with an informed consent document (Appendix G), a total of 220 participants completed a questionnaire booklet. The sample was comprised of 73 nonproblem ( 35 males and 38 females), 60 low-risk ( 41 males and 19 females), and 87 highrisk (63 males and 24 females). Almost half (45.9\%) of participants reported they were unemployed. The majority of participants were Caucasian (66.8\%), whereas other participants were East-Asian (10.5\%), African-Canadian (4.1\%), Middle Eastern (3.2\%), or South Asian (2.3\%). The remainder (13.1\%) self-identified as Native Canadian, 
Hispanic or multi-ethnic. In terms of preferred form of gambling, participants reported playing cards $(47.7 \%)$, lottery tickets $(16.8 \%)$, and slots $(10.9 \%)$ as their favourite form of gambling. A smaller number of those surveyed cited scratch and win tickets (5.5\%), horse racing (4.1\%) and sports betting (4.2\%) as their favourite form of gambling. The remainder $(10.9 \%)$ cited other forms of gambling (bingo, roulette, keno, etc.). In terms of gambling related problems, $10.5 \%$ of participants reported something bad happening to them as a result of their gambling, $15.9 \%$ think life would be better if they gambled less, and $12.4 \%$ reported they were thinking of quitting or cutting down their gambling in the next 6 months.

Following completion of the questionnaire booklet (Appendix $\mathrm{H}$ ), participants were fully debriefed (Appendix I). As compensation, participants were given $\$ 10.00$. If, however, a participant was enrolled in an Introductory Psychology course, they were given the option of a $\$ 10.00$ payment or one bonus percent that could be used toward their final grade in the course.

\section{Measures}

Craving to Gamble. The initial pool of 18 items used to create the Gambling Craving Scale (GACS) were selected from the Questionnaire on Smoking Urges (QSU: Tiffany \& Drobes, 1991). In order to adapt the items for gambling, sentences and phrases referring to smoking were modified to refer to gambling. The resulting set of items contained two negatively worded items to control for response distortion through acquiescence bias. The 18 items assessed 4 hypothesized dimensions of craving (see Tiffany \& Drobes, 1991). Five items assessed the desire to gamble (e.g., "I crave 
gambling right now", "All I want right now is to gamble"), five items tapped anticipation of immediate positive subjective experiences from gambling (e.g., "Gambling now would make things seem just perfect", "Gambling would be fun right now"), four items assessed intention to gamble (e.g., "If I had an opportunity to gamble right now I probably would take it.", "If it were possible I would gamble now"), and four items assessed immediate relief from negative subjective experiences believed to result from gambling (e.g., "If I were gambling now, I could think more clearly", “Gambling would make me less depressed"). Participants responded to these questions on a 7-point scale anchored at 0 (Strongly Disagree) and 7 (Strongly Agree).

Gambling Pathology. As in Study 1, pathological gambling symptomatology was assessed using the Problem Gambling Severity Index (PGSI; Ferris \& Wynne, 2001).

Negative Gambling Outcome Expectancies. This 19-item questionnaire measured the extent to which gamblers feel that their gambling will produce negative consequences for themselves or significant others in their lives (Hart, 2005). Participants were presented with statements such as, "If I were to continue gambling, I believe.... My Partner or family would be harmed" or "I would lose my job." They responded on a 5point scale ranging from 0 (highly unlikely) to 4 (highly likely). A composite score was calculated by averaging the 19 items.

The Gambling Related Cognitions Scale (GRCS). The Gambling-related cognitions scale is a 23-item measure developed by Raylu and Oei (2004a) that assesses participants' gambling-related cognitions. It includes five dimensions (gambling expectancies, illusion of control, predictive control, inability to stop gambling, and 
interpretive bias). Respondents answered questions such as "It is difficult to stop gambling as I am so out of control" (from the 'inability to stop' subscale), on a 7-point scale anchored at 1 (Strongly Disagree) to 5 (Strongly Agree). Scores on each subscale were calculated by averaging items designed to measure the particular construct. A total score is also calculated by averaging all 23 items. This score is used as a general measure of gambling related cognitions.

Depressive affect. The Beck Depression Inventory (BDI: Beck, Ward, Mendelson, Mock, \& Erbaugh, 1961) presents respondents with 21 items comprised of 3-4 statements ranging in the extent to which they self report they are symptomatic, from not at all (e.g., 'I do not feel like a failure') to highly symptomatic (e.g., 'I feel I am a complete failure as a person'). Participants indicated which statement they felt most accurately characterised them. Responses were summed to provide an index of depressive symptomatology.

Mood. The Positive Negative Affect Scale (PANAS; Watson, Clark, \& Tellegen, 1988 ) is a 20 -item scale used to measure both negative and positive moods. Participants were given 20 mood related adjectives, half positive (e.g., attentive, inspired) and half negative (e.g., annoyed, sad), and asked how indicate on a 6-point scale ranging from 0 (not at all) to 6 (extremely) how much each adjective describes how they feel at the moment. The result is two subscales, one assessing the presence of positive affect, the other the presence of negative affect. 
Results

\section{Preliminary Analysis}

The distributions of scores for all variables were examined by viewing frequency histograms and by examining the form of their distributions, namely, skewness and kurtosis. Two cases were removed due to response distortion. Missing data [i.e., 1 or 2 item(s) per questionnaire] occurred in less than $2 \%$ of the cases and was replaced with means.

Sayette et al. (2000) have noted that craving scales can induce craving by the simple act of completing the scale (i.e., words and the associated mental imagery relating to the desired substance or behaviour act as anticipatory cues and thus induce craving). In order to see whether this is occurring, the scale item means were plotted in order of their completion. A visual inspection of this plot suggested no slope indicating this was not happening among the present sample of respondents.

Participants ranged in age from 17 to $47(M=20.77, S D=4.49)$. Age did not differ as a function of sex or gambling type (F's $<1$ ). The number of PGSI symptoms among the high-risk gamblers ranged from 3 to $18(M=5.80, S D=2.80)$. Low-risk gamblers reported 1 to $2(M=1.43, S D=0.50)$ and non-problem gamblers reported 0 PGSI symptoms. Predictably, males reported more symptoms of gambling pathology $(M$ $=3.11, S D=3.22)$ than females $(M=1.95, S D=2.86), F(1,218)=7.25, p<.01, \eta_{\mathrm{p}}{ }^{2}=$ .03 (see Rush et al., 2002). 
Means and standard deviations of all measured variables by gambling type are listed in Table 2. In addition reliabilities (Cronbach's $\alpha$ 's) of all scales are listed in Table 3. 


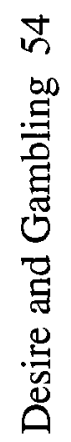

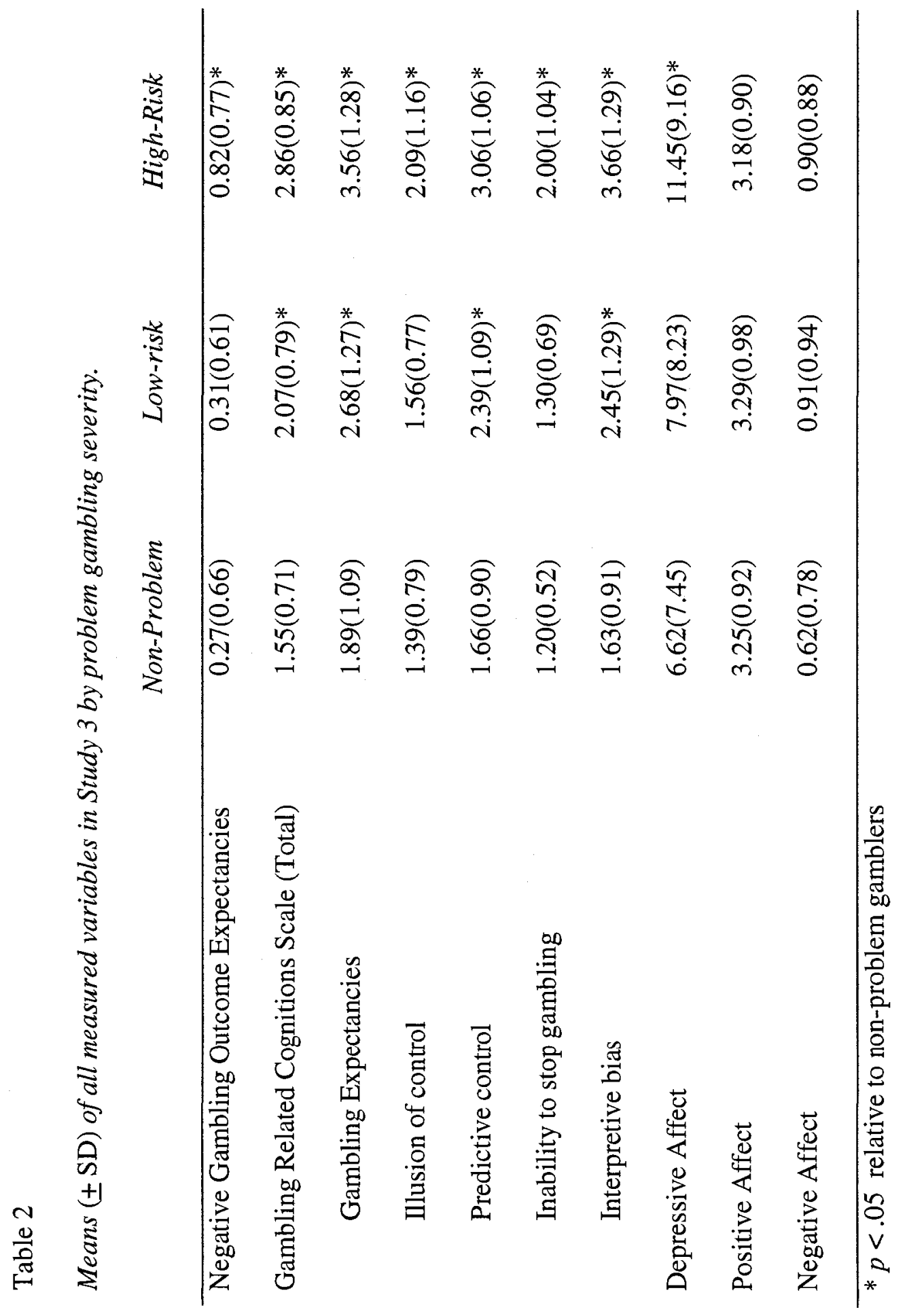




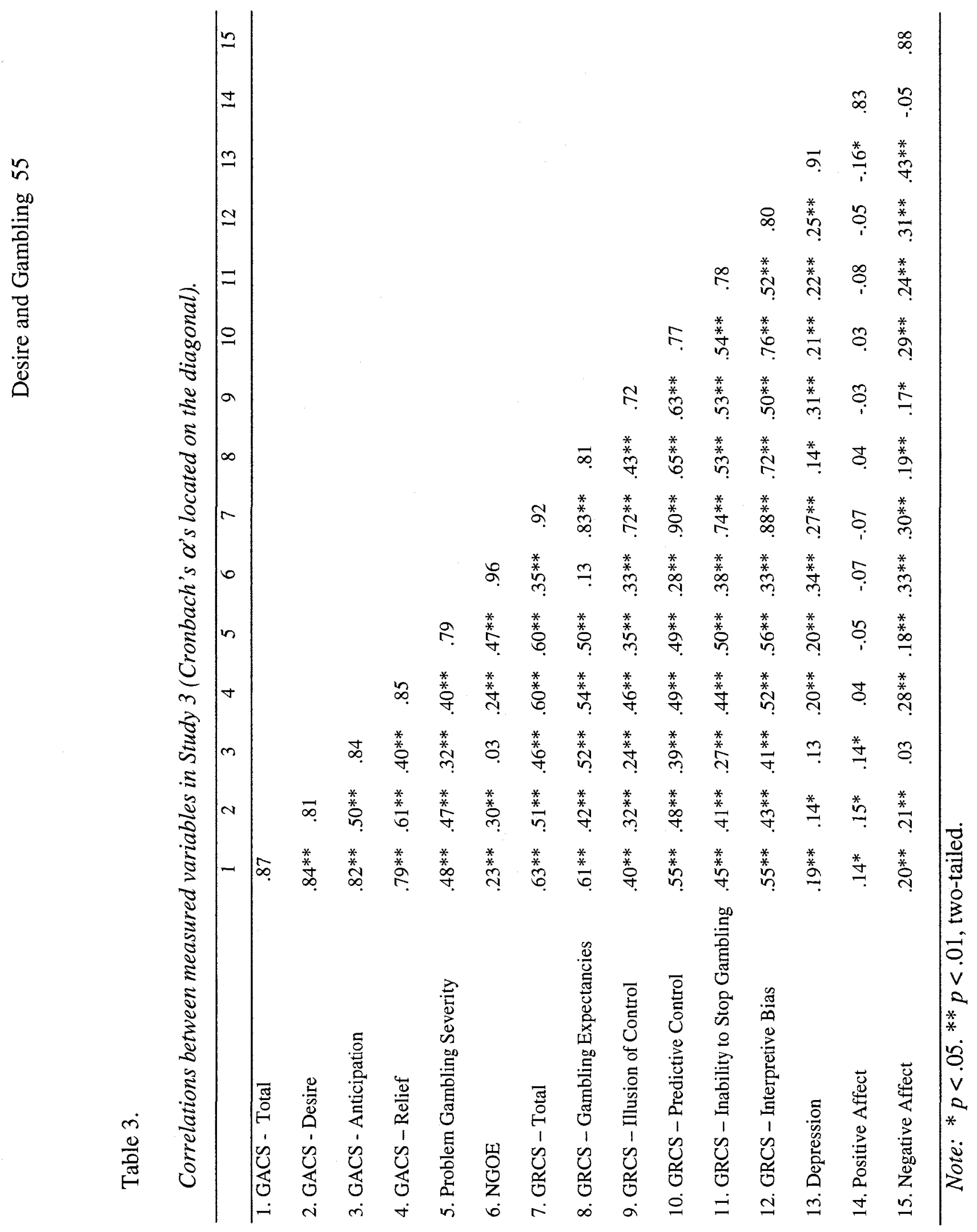


Analysis of Scale Structure

Principal components analysis (PCA) with Promax rotation was performed on the questionnaire responses. Promax rotation was selected because it was considered likely that emerging factors would be related (using an orthogonal rotation, such as Varimax rotation, would not have permitted correlation of factors). Tiffany and Drobes (1991), as well as Davies, Willner, and Morgan (2000) and Cepeda-Benito et al.(2004) used Promax rotation for the creation of their respective craving scales, thus a similar analytic procedure was employed to facilitate cross-study comparisons regarding the factorial structure of craving. PCA produced 3 components with eigenvalues greater than $1(8.70,1.91$, and 1.21$)$ that explained $69.51 \%$ of the variance. To verify that the factor structure remained stable across gender, PCA was conducted on male and female participants separately. Both analyses yielded comparable factorial structures.

Two criteria were used to determine the number of non-trivial components to be retained: eigenvalues greater than one and the Scree test (Cattell, 1966). Both the eigenvalue criterion and the Scree test suggested the presence of 3 non-trivial components. In addition to satisfying these criteria, the pattern of component loadings suggested that there were also theoretically compelling reasons to adopt a three-factor solution.

Items forming the final GACS subscales were selected if they loaded $>.65$ on the component. Further, items were removed if they loaded $>.20$ on the other component or if the difference between loadings on two components was less than .20 (Tiffany \& Drobes, 1991). In addition inter-item correlations were examined. If two items correlated with another item $>.75$ 
the item with lower item total correlation was removed (DeVellis, 2003). Seven items did not meet these inclusion criteria and were culled from the original 18 items. The result was a 9-item scale with three items loading on each of the three components (see Table 4 for items, component loadings, and variance accounted for).

Table 4.

Rotated factor loadings on the three components extracted by principle components analysis of the Gambling Craving Scale (GACS)

\section{Items}

Components

1

Gambling would be fun right now. .88

I would not enjoy gambling right now ${ }^{\mathrm{a}}$. $-.86$

If I had an opportunity to gamble right now I probably would take it.

If I were gambling now I could think more clearly.

I could control things better right now if I could gamble.

.92

Gambling would make me less depressed. 


\section{Labelling the components}

There emerged a substantial degree of conceptual coherence among items loading on the three retained components. Questionnaire items loading on the first component all represented a strong, urgent desire to gamble. Therefore the first extracted component was labelled desire. The three items loading on the second component represented an intention to gamble that was anticipated to be fun and enjoyable. Therefore the second component was labelled anticipation. Finally the third component was comprised of three questions indicating relief from negative experiences expected from gambling (specifically relief from the inability to control things, inability to think clearly, and depression) from gambling. Because these items represented an expectation of relief from negative affect, the third extracted component was labelled relief. It is important to note, the three components were moderately intercorrelated $(.40<r s<.61)$ (see Table 3) suggesting that the GACS scale was composed of three related, but meaningfully different components of an underlying construct, namely craving to gamble.

\section{Validity}

In order to test the convergent validity of the GACS, it was examined whether the total scale or any of the subscales were capable of discriminating between those with differing levels of gambling pathology. ANOVAs revealed significant differences in desire $[F(2,217)=20.40, p$ $\left.<.001, \eta_{\mathrm{p}}{ }^{2}=.16\right]$, anticipation $\left[F(2,217)=20.12, p<.001, \eta_{\mathrm{p}}{ }^{2}=.16\right]$, relief $[F(2,217)=15.44$, $\left.p<.001, \eta_{\mathrm{p}}{ }^{2}=.13\right]$, and GACS total scores $\left[F(2,217)=30.53, p<.001, \eta_{\mathrm{p}}{ }^{2}=.22\right]$ between those with different levels of gambling pathology (see Figure 3). Follow-up tests revealed differences in GACS scores between all gambling subtypes on the GACS total as well as all 
subscales except desire (in which case there were no differences between non-problem and low risk gamblers).

Figure 3. Mean Gambling Craving subscale scores $(M+/-$ SEM) of non-problem, low-risk, moderate risk, and problem gamblers.

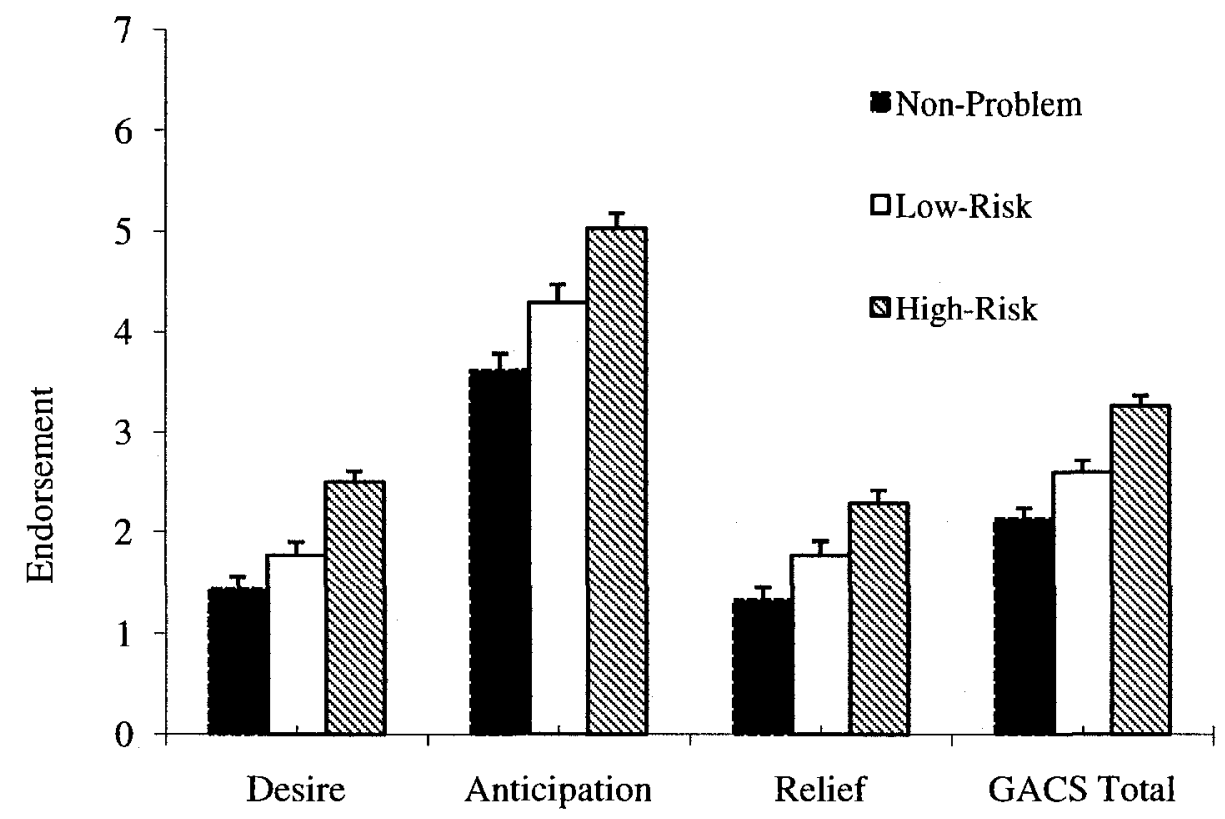

Next, multiple regression analysis was conducted to examine the extent to which GACS scores could predict problem gambling severity while controlling for any overlapping variance between the subscales. The three subscales simultaneously significantly predicted PGSI scores $\left(\mathrm{R}^{2}=.25, p<.001\right)$. In addition results revealed that only the desire subscale, $\beta=.32, t(216)=$ $4.05, p<.001$, and the relief subscale, $\beta=.16, t(216)=2.18, p<.05$, accounted for a significant unique proportion of variance in PGSI scores over and above that accounted for by the other scales. 


\section{Relationship of GACS and GACS subscales with other measures}

To further examine the relationship between the GACS (and its subscales) with the other variables measured in the study (negative gambling outcome expectancies, gambling related cognitions, depression, and positive and negative affect) regression analyses were conducted. The correlations between the GACS total score as well as each subscale with the other variables measured in the study were examined. The results of these analyses are presented in Table 3 . However, the three subscales of the GACS were correlated indicating that they accounted for overlapping variance. Therefore in order to determine the unique proportion of variance each subscale could account for, multiple regression analyses were conducted on each of the measured variables. Similar to the analysis conducted on problem gambling severity above, desire, anticipation, and relief scores were regressed simultaneously onto each of the measured variables. Table 5 lists the total proportion of variance accounted for by the three scales $\left(R^{2}\right.$, s) and the standardized regression coefficients $(\beta$ 's) for each analysis. 


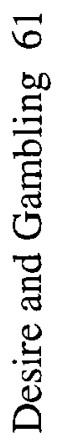

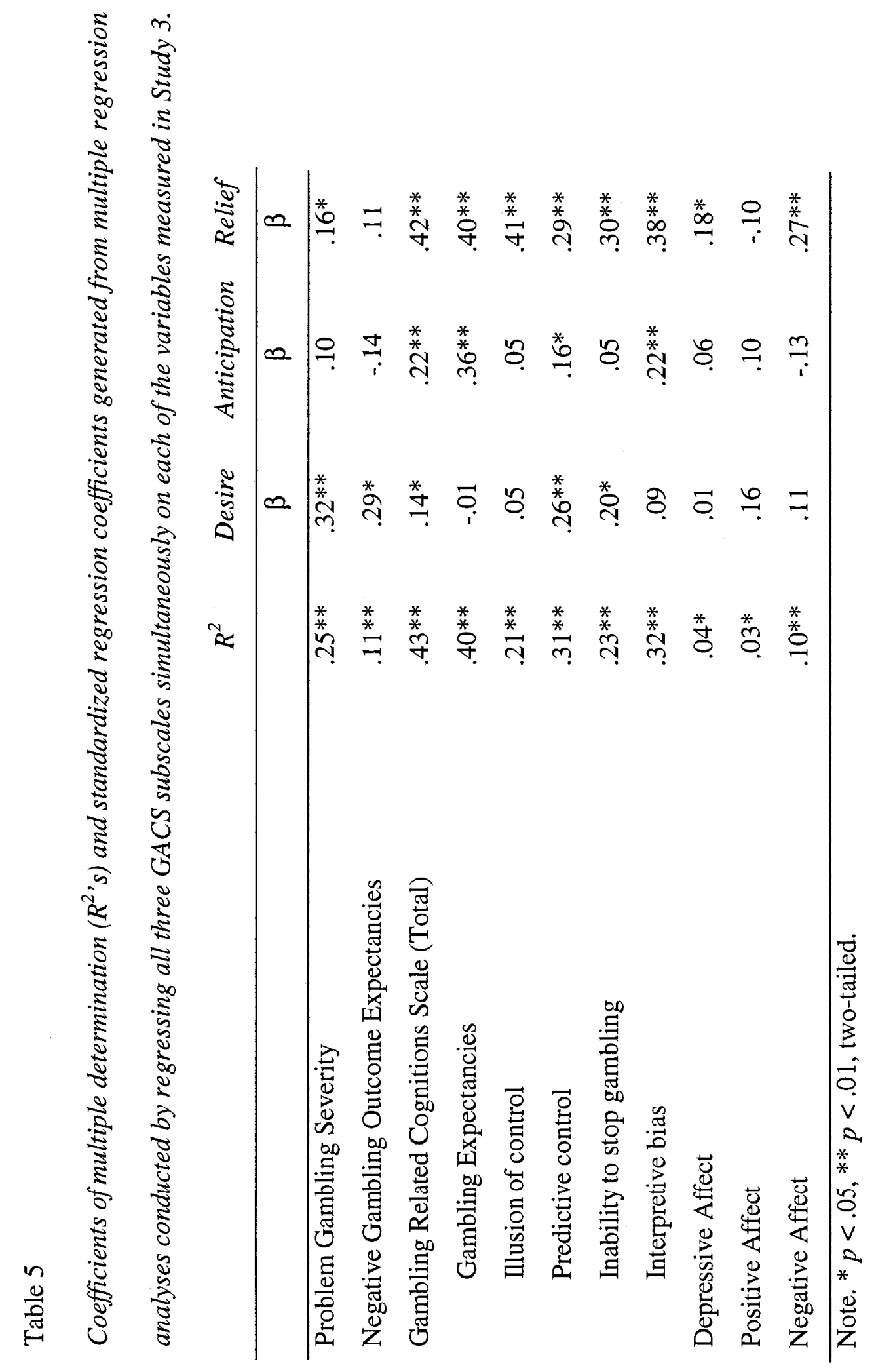


Negative Gambling Outcome Expectancies (NGOE). Significant positive correlations between NGOE and both desire and relief subscales of the GACS indicate that those who report more desire and more relief are more likely to expect negative consequences to result from his or her gambling $(r s>.24)$. There was a non significant correlation between anticipation and negative gambling outcome expectancies. In addition, Table 5 reveals that of the three subscales of the GACS only desire accounted for a significant unique proportion of variance.

Gambling Related Cognitions (GRCS). All three subscales of the GACS were significantly related to the total GRCS score as well its five subscales $(r s>.24$, see Table 4). Of note were the high correlations between both anticipation and relief, and the gambling expectancies subscale of the GRCS ( $r$ 's $>.52$ ). The gambling expectancies subscale contains one item clearly indicating an expectation of positive affect ('Gambling makes me happier'), as well as one item clearly indicating a relief from negative affect ('Having a gamble helps reduce tension and stress'), and two other questions that could be understood as either ('Gambling makes things seem better' and 'Gambling makes the future brighter'). Therefore, the high correlations found between this measure and both GACS subscales were expected. In addition there were also high correlations between the inability to stop gambling subscale of the GRCS and both the desire and relief subscales of the GACS ( $r$ 's > .41) but the relationship between anticipation and the inability to stop gambling was not as strong $(r<28)$. Desire and relief each accounted for a significant unique proportion of variance in inability to stop gambling subscale scores $(\beta$ 's $>.20)$. 
Depression. Similar to the relationship between NGOE and craving, significant positive correlations were also noted between depression and both desire and relief ( $r \mathrm{~s}>$ .14). Also similarly, the relationship between anticipation and depression was not significant. Multiple regression revealed that the only subscale to uniquely predict depression was relief (see Table 5).

Positive and negative affect. There was a significant relationship between positive affect and the GACS total. In addition, as expected, those reporting that they were experiencing negative affect at the time of completing the scale were more likely to report greater relief craving. Further, negative affect and relief craving were still reliably related even when controlling for desire and anticipation.

\section{Discussion}

Study 3 examined the factor structure and psychometric properties of the GACS as a multidimensional scale of craving to gamble. This study produced a new, reliable, 9item, multidimensional measure of craving to gamble. The GACS also demonstrated a high degree of concurrent validity. The full scale was found to reliably predict problem gambling severity, negative gambling outcome expectancies, problematic gambling related cognitions, and depression.

As found with craving for drugs such as alcohol, cigarettes, and cocaine (Love et al., 1998; Tiffany \& Drobes, 1991; Tiffany et al., 1993), craving to gamble was also found to be a multidimensional construct. Specifically, craving to gamble was found to be composed of three related, but distinct components, a strong, urgent desire to gamble, an intention to gamble that was anticipated to be fun and enjoyable, and an expectation 
that gambling would provide relief from negative affect. These dimensions of gambling craving formed the subscales of the new measure.

Though the results of Study 3 demonstrated the GACS had a substantial degree of concurrent validity and provided evidence for the multidimensional nature of craving to gamble, the ability of the GACS to predict actual gambling behaviour was not examined. Therefore in Study 4 the GACS was administered to a group of gamblers and its ability to predict gambling behaviour was determined. 
Study 4: The GACS and gambling behaviour

Animal studies frequently infer craving by examining behaviours such as drugseeking behaviour or drug use (e.g., Hughes, 1987; Koob, 2000). Though some take issue with this operational definition of craving (e.g., Monti, Rohsenow, \& Hutchison, 2000), most craving researchers concede that drug craving is related to drug taking. Therefore, in order to determine the predictive validity of the GACS and its subscales, Study 4 examined whether craving to gamble would predict gambling behaviour.

As defined in Study 2, persistence is the number of trials (i.e., slot machine spins) that the participant continues to gamble in the face of repeated loss. In Study 2, gamblers with elevated levels of pathology persisted longer and desire assessed before and after the priming session reliably predicted persistence. The current experiment therefore examined whether the GACS would predict whether gamblers would persist longer in the face of continued loss. To do so gamblers came to the lab and played a slot machine located in a Virtual Reality (VR) casino. After an initial priming episode (of 50 spins) in which participants won money, they completed another craving assessment. Participants were then told that they could cease playing whenever they wished and could keep all the money they ended with. The number of spins participants persisted despite repeated loss formed the dependant measure. It was hypothesized that if the GACS was a valid index of craving to gamble, it would reliably predict persistence. 
Methods

\section{Participants}

To test whether the GACS could predict gambling behaviour, a sample of participants $(\mathrm{N}=45 ;$ Males $=19 ;$ Females $=27)$ who were screened for gambling problems (see Study 1) were selected to participate. The sample was composed of 14 non-problem, 15 low-risk, and 16 high-risk gamblers selected on the basis of their scores on the PGSI (Ferris \& Wynne, 2001). Participants ranged in age from 18 to $35(M=19.89, S D=$ 3.07). Half the participants sampled, reported they were unemployed. The majority of participants were Caucasian (67.4\%). Other participants were East-Asian (17.4\%), Middle Eastern (6.5\%), African-Canadian (4.3\%), or South Asian (2.2\%). The remainder (2.2\%) self-identified as Hispanic or multi-ethnic. Participants reported that playing cards (32.6\%), lottery tickets (19.6\%), slots $(19.6 \%)$, scratch and win tickets $(10.9 \%)$, and sports betting $(6.5 \%)$ were their preferred forms of gambling. The remainder $(10.8 \%)$ reported preferring other forms of gambling such as bingo, roulette, keno, etc.

In terms of gambling behaviour, $18.6 \%$ of participants reported gambling within the last week, over half (58.1\%) reported gambling within the past month. Almost twothirds $(65.7 \%)$ reported gambling more than once every three months and over one-fifth $(21.7 \%)$ of participants thought life would be better if they gambled less. Thirty percent of participants reported they were thinking of quitting or cutting down their gambling in the next 6 months, and $8.7 \%$ indicated that they had experienced something bad as a result of their gambling. 


\section{Measures}

Craving. Craving to gamble was assessed using the Gambling Craving Scale (GACS). The GACS is a 9 item scale measure developed to assess craving to gamble. It includes 3 dimensions of craving to gamble (desire, anticipation, and relief) (see Study 3). Participants answered questions such as "I crave gambling right now" (from the 'desire' subscale), on a 7-point scale anchored at 1 (Strongly Disagree) to 5 (Strongly Agree). Scores on each subscale are calculated by averaging items designed to measure the craving dimension. A total score is also calculated by averaging all 9 items. This score is used as a general measure of craving to gamble.

Gambling Pathology. As in previous studies, pathological gambling symptomatology was assessed using the Problem Gambling Severity Index (PGSI; Ferris \& Wynne, 2001). See Study 1 for a more complete description.

Persistence. Persistence was assessed by counting the number of spins the gambler played in the face of repeated loss (see Study 2 for a more complete description).

\section{Procedure}

Upon arrival at the laboratory, participants sat at a desk in a part of the room separated by a 7-foot high room divider. After signing an informed consent document (Appendix J), participants completed a background questionnaire including questions about their gambling behaviour and the GACS (Appendix K). The experimenter then explained to the participant that the purpose of the study was to examine gambling behaviour in a VR environment. They were then instructed to put on a head-mounted display (HMD; Z800 3D Visor, eMagin Corporation, Fishkill, New York). The 
experimenter then instructed them how to navigate the environment with the aid of a joystick and mouse. Once they felt comfortable using the equipment, the lights were turned off and participants entered the casino.

Once in the casino, participants were asked to sit down at one of the 13 slot machines dispersed throughout the virtual casino. Five dollars in betting chips were provided to the participant ( 20 credits) and they were instructed that they could bet 1 token per spin. They were informed that, ostensibly, their chances of winning at the slots in the VR casino were the same as the slot machines at the local casino and that they could keep any money they won. In actuality, the game was pre-programmed such that all players experienced the same series of wins and losses. They were asked to play for a minimum of 10 minutes or until they lost all their tokens. In reality they were stopped after 50 spins at which point they had won 40 credits (or $\$ 10.00$ ) or a total of 60 credits $(\$ 15.00)$.

When participants completed the $50^{\text {th }}$ spin, the experimenter sounded the timer bell and told the participant that the experiment was over. Participants were then asked to complete the GACS a second time. Once they had completed the measure they were told that it was their choice whether they would like to cash out immediately or continue gambling for as long as they wished. Importantly, unbeknown to the participant, the slot machine was programmed to produce losses on all subsequent spins. This procedure was used to determine the gambler's persistence in the face of loss.

Upon voluntarily stopping, regardless of how much they ended with, all participants were given $\$ 15$ for participating. If, however, the participant was enrolled in 
an introductory psychology course, they were given the option of $\$ 15$ or $\$ 10$ and experimental credit. The experimenter then explained to the participant the rationale of the study. During this explanation the experimenter emphasized that all wins and losses were programmed. This was done to insure that participants did not leave the lab with elevated craving levels. Participants were also provided with a debriefing form (Appendix L) that explained in greater detail the intent of the research. This form included the numbers of the local gambling help-line as well as the university's health and counselling services.

\section{Results}

\section{Preliminary Analysis}

Significant univariate outliers were identified by examining participants' standardized scores on each variable. Participants with a standard score equal to or greater than $+/-3$ standard deviations on a given variable were considered outliers. These scores were adjusted by returning the individual's score to 3 standard deviations from the mean. Missing data occurred in less than $2 \%$ of the cases and was replaced with means.

ANOVAs indicated that males and females did not report differences on any of the GACS subscale or GACS total score at either time point (i.e., before gambling and before extinction session), $p \mathrm{~s}>.05$. Males reported more symptoms of gambling pathology $(M=2.42, S D=1.54)$ than females $(M=1.30, S D=1.59), F(1,43)=6.34, p<$ $.05, \eta_{p}{ }^{2}=.13$. There was no gender differences in persistence, $p s>.05$. To assess whether there were gender differences in Craving, a 2 (gender) x 3 (gambling pathology: non-problem, low-risk, and high-risk) $\times 2$ (craving: before gambling, following $50^{\text {th }}$ spin) 
mixed measure ANOVA was conducted with craving as the repeated measure. Results indicated no gender main effects or interactions for the GACS Total score or any of the subscales $(p s<.05)$. Therefore gender was not included in subsequent analyses.

Confirmatory Factor Analysis (CFA) using Lisrel was conducted on the GACS questionnaire both before gambling and after the $50^{\text {th }}$ spin (i.e., immediately before beginning the extinction session). CFA revealed that the proposed factorial structure of the GACS completed before gambling was an excellent fit to the data, Chi Square (24)= $19.93, p=.70$ and the goodness of fit index $(\mathrm{GFI})=0.91$. In addition, root mean square error of approximation (RMSEA) was found to be $<.01$ and the non-normed fit index (NNFI) was 1.04. These values also indicated a well-fitting model as values less than .06 and greater than 0.9 (respectively) are indicative of a good fit (Hu \& Bentler, 1999) . CFA analysis on the GACS items assessed immediately before the extinction trials also suggested an acceptable model fit [Chi Square $(24)=19.93, p>.05 ; \mathrm{GFI}=.85$; RMSEA $=.10 ;$ and NNFI $=.92]$.

Table 6 lists the means and standard deviation of all measured variables. Reliability estimates for the GACS total and the subscales are presented in Table 7. 


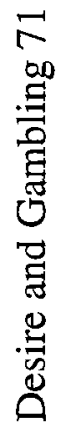

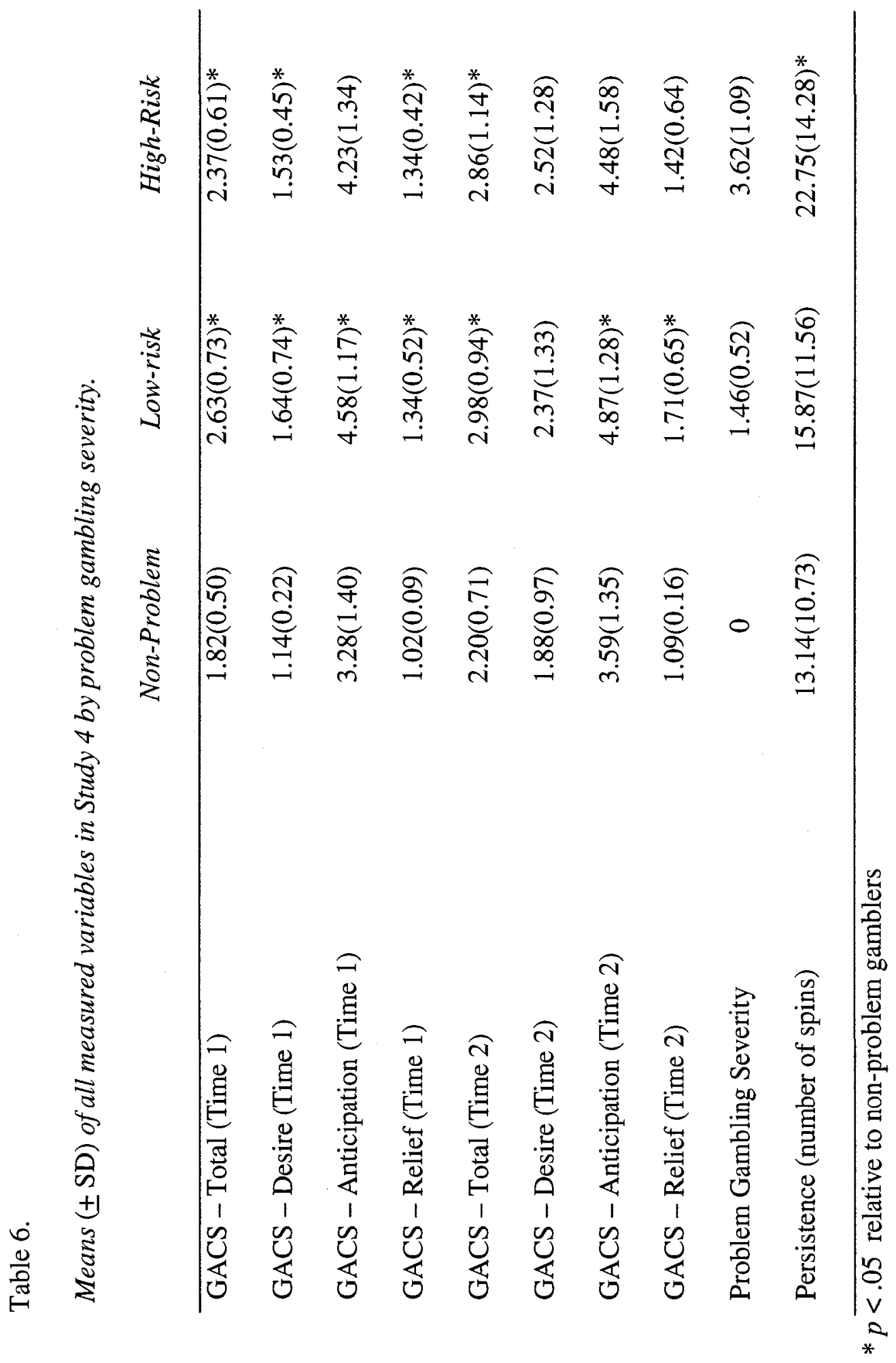




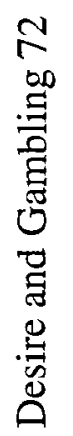

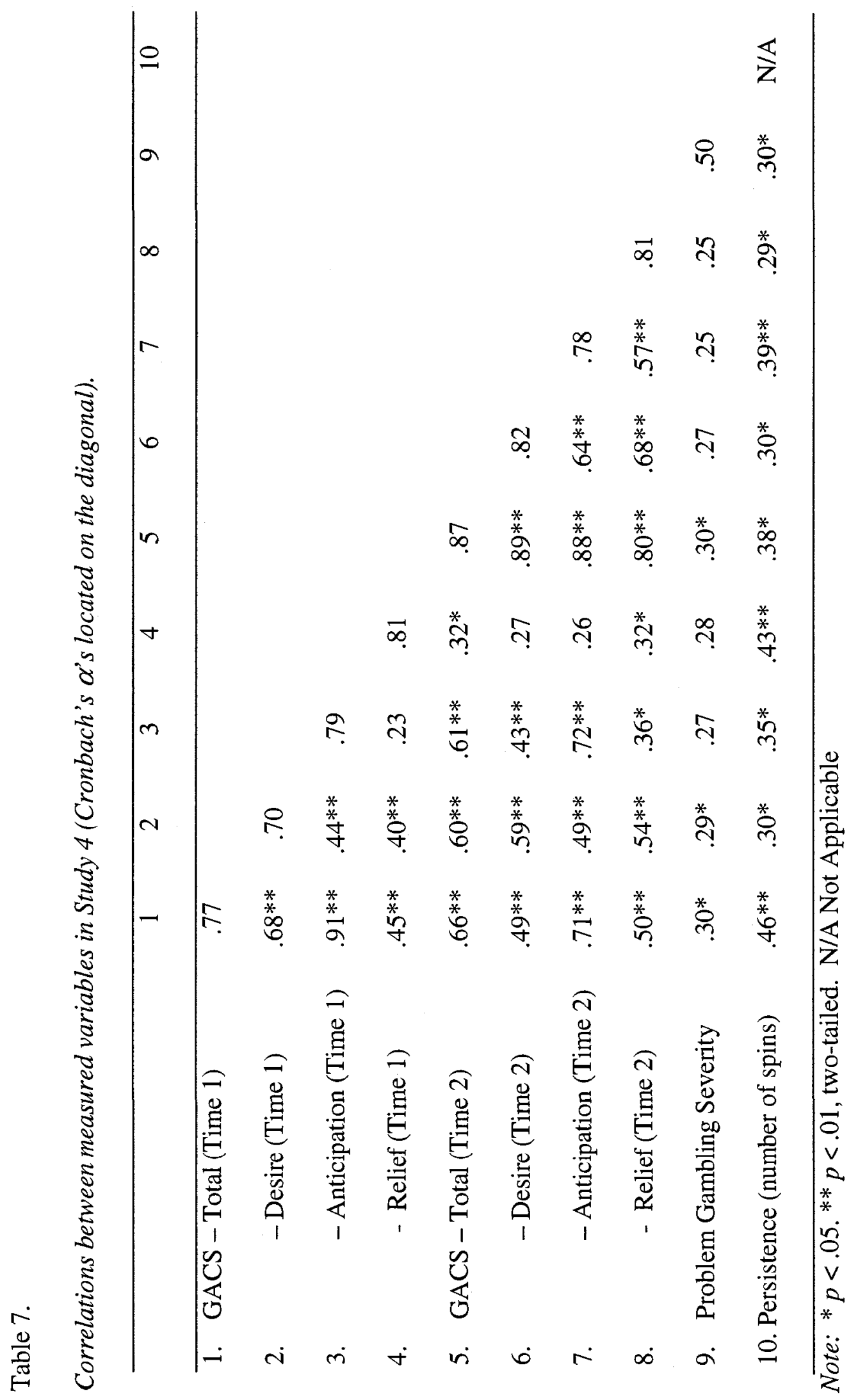


Persistence

Participants varied in the degree to which they persisted in the face of repeated loss. Four $(8.7 \%)$ did not gamble at all and therefore completed playing with all the credits they had won. Nineteen participants (41.3\%) continued gambling for 20 or more consecutive spins in the face of repeated loss. One participant gambled until he(she) had no more credits left (63 spins). As expected problem gambling severity ( $r=.30, p<.05)$ was reliably associated with persistence.

GACS total scores, both before and after the priming episode, predicted persistence ( $r$ 's $>.38$ ). In addition, so did each subscale ( $r$ 's $>.30$ ) (see Table 7). To determine the unique proportion of variance in persistence accounted for by each subscale, all three subscales were entered into the regression equation simultaneously. The three GACS subscales assessed immediately before gambling simultaneously significantly predicted the number of spins in the face of loss $\left(\mathrm{R}^{2}=.25, p<.001\right)$. However, when controlling for shared variance with the other scales, only the relief subscale, $\beta=.35, t(42)=2.44, p<.05$, accounted for a significant unique proportion of variance in persistence over and above that accounted for by the other scales. The same analysis conducted on craving assessed immediately before the extinction session revealed that the ability of the three subscales to predict persistence was marginally significant $\left(\mathrm{R}^{2}=.16, p=.07\right)$ and none of the three subscales uniquely predicted persistence. 


\section{Priming and the GACS}

In order to determine whether craving to gamble increased following the short gambling session (i.e., the first 50 spins) a 3 (gambling pathology: non-problem, lowrisk, and high-risk gamblers) x 2 [craving (GACS total): before gambling, following the $50^{\text {th }}$ spin] mixed-measure ANOVA was conducted with craving as the repeated measure. This analysis revealed that, overall, craving increased from before gambling $(M=2.28$, $S D=0.64)$ to following $50^{\text {th }} \operatorname{spin}(M=2.69, S D=0.97), F(2,43)=12.74, p<.01, \eta_{\mathrm{p}}{ }^{2}=$ .23. In addition, confirming the significant correlation between problem gambling severity and both craving assessments (see Table 7), the analysis also indicated a main effect of gambling pathology, $F(2,43)=4.44, p<.05, \eta_{\mathrm{p}}{ }^{2}=.17$. Follow-up comparisons indicated that non problem gamblers reported significantly less craving ( $M$ $=2.28, S D=0.64)$, than either low-risk $(M=2.60, S D=1.26)$ or high risk $(M=2.81, S D=$ 1.26), $p<.05$. No significant differences between low-risk and high risk gamblers, $p>.05$ were present. Finally, there was no interaction between craving and level of gambling pathology.

In order to examine which dimension of craving to gamble might be accounting for the increase in craving following the initial 50 spins (i.e., the priming effect), three within-subjects ANOVAs were conducted. As there was no interaction found in the omnibus test above, level of gambling pathology was removed as a factor in these analyses. Results indicated that desire increased significantly from before $(M=1.4, S D=$ $0.56)$ to after the priming episode $(M=2.27, S D=01.23), F(1,43)=30.76, p<.001, \eta_{\mathrm{p}}$ 
${ }^{2}=.41$, whereas the anticipation and relief subscales of the GACS remained unchanged, $p ' s>.05$.

\section{Discussion}

Study 4 was conducted to determine whether craving (as measured by the GACS) could predict gambling behaviour. Indeed, craving assessed both before gambling and immediately before the extinction trial reliably predicted gambling persistence in the face of repeated loss. Thus gamblers who craved more continued to gamble despite continuously losing. As persistent gambling in the face of repeated loss is a defining characteristic of pathological gambling (APA, 1994), the association between craving as measured by the GACS and persistence lends support to the predictive validity of this new scale.

As noted previously, craving has received relatively little attention among gambling researchers. One possible reason is the lack of a valid, reliable, psychometrically tested questionnaires designed to measure craving. Though there is one existing measure of gambling urges (Raylu \& Oei, 2004b), its utility is limited by the assumption that craving is a unidimensional motivational state. Taken together, Studies 3 and 4 provide gambling researchers with a new multidimensional measure of gambling craving. 


\section{General Discussion}

Eating, drinking, and drug taking are examples of human activities which normally follow a pattern of behaviour characterized by periods of drive and satiety (Wise, 2004). They represent appetitive behaviours in which internal regulatory mechanisms governing the behaviour can become dysfunctional, resulting in excessive consumption (Orford, 2001). Gambling is also considered an appetitive behaviour that may result in excessive consumption (APA, 1994 ). Considering the popularity of gambling as well as the high rates of problematic play in the general population (e.g., Marshall \& Wynne, 2003; Wiebe et al., 2006; Wiebe et al., 2001), understanding how desire to gamble fluctuates prior to, during, and following a gambling session is important in understanding why people gamble and why they find it hard to stop once engaged. To address these issues, the four studies conducted herein examined desire to gamble before, during, and after a short gambling episode.

In Study 1, wins and losses differentially influenced the priming effects of a short gambling episode. Specifically, problem gamblers who won during a brief gambling session reported greater desire to continue gambling than those who lost. These results revealed an association between a short gambling episode and desire to continue gambling among problematic gamblers. However, Study 1 showed that that priming effects of a short gambling session manifest only among problem gamblers who win. Problem gamblers who won reported an increased desire to continue gambling, whereas desire remained stable (between the start of the session and the end) among problem 
gamblers who lost. Desire to gamble, however, was not altered by the outcome of the gambling session among non-problem gamblers.

Study 2 further clarified the influence of wins on the desire to continue gambling by assessing whether gamblers respond similarly to a large win and a series of small wins. It was found that among problematic gamblers, the experience of a large win influenced desire to continue playing following voluntary cessation. Specifically, problematic gamblers who experienced a series of small wins as well as all recreational gamblers (regardless of win type) showed a reduction in desire to play upon voluntary cessation relative to when the session began. In contrast, problematic gamblers who experienced a big win showed no such reduction. It was hypothesized that problematic gamblers would attribute the big win to the self, and in doing so, their sense of selfefficacy would be enhanced as would their expectations of future gambling success (see Bandura, 1997). Evidence suggests (Wohl et al., 2007) that by attributing wins internally and losses externally, problem gamblers develop elevated perceptions of personal luck. These perceptions of personal luck are, in turn, responsible for elevated expectancies of winning. Indeed, the mediation analysis suggests that such a process was at play. Participants who were at high-risk for gambling pathology and experienced a big win reported greater desire to continue gambling to the extent that they perceived themselves personally lucky; that is to have the skill or ability to win at games of pure chance. The results thus highlight the role of expected outcomes in the development and maintenance of craving to gamble. 
Taken together, Studies 1 and 2 supported previous findings that a short episode of gambling is effective in priming motivation to continue gambling (Ladouceur et al., 1987; Loba et al., 2001; Zack \& Poulos, 2007). The results of Studies 1 and 2, however, suggest that simply playing was not particularly effective as a priming stimulus. Instead, it appeared that the efficacy of a priming episode was contingent on the gambler winning. Zack and Poulos (2004) found that the dopamine stimulant d-amphetamine was effective at priming desire to gamble among problem gamblers, whereas alcohol was not. In effect, stimulating dopamine activity, which is believed to affect reward processes (Wise, 2004), was an effective prime in promoting desire to gamble. In a like fashion, the present results suggest that the efficacy of a brief priming episode was contingent on positive outcomes for sufficient activation of reward pathways necessary to prime motivation to continue gambling. Thus, it is possible that winning in the current experiments primed desire to continue gambling by stimulating similar neurochemical systems, whereas losing did not result in similar patterns of activation.

As the results of Study 1 and 2 provided evidence for craving as a factor in the facilitation and maintenance of gambling, two additional studies were conducted to further examine craving and gambling. Previous research has found that some gamblers engage in gambling to experience positive affective states (e.g., Anderson \& Brown, 1984; Ladouceur et al., 2003). Importantly, gamblers may also wager to escape from negative affective states (e.g., Diskin \& Hodgins, 2001; Grant \& Kim, 2003; Jacobs, 1988; Kofoed et al., 1997; Wood \& Griffiths, 2007). It was hypothesized that craving to gamble may be best characterised as a multidimensional construct that is composed of, 
not only the desire to gamble, but also expectations of positive affect (positive reinforcement) and relief from negative affect (negative reinforcement). Thus, Studies 3 and 4 were conducted to develop a multidimensional scale that taps these aspects of craving to gamble.

In Study 3 a pool of items were pilot tested on a sample of gamblers with varying degrees of gambling pathology. Results indicated that gambling craving is composed of three related, but meaningfully different components. These components were: 1) a strong, urgent desire to gamble, 2) an intention to gamble that was anticipated to be fun and enjoyable, and 3) an expectation that gambling would provide relief from negative affect. Even though these components were related, suggesting that they were dimensions of a single underlying construct (namely craving to gamble), each dimension demonstrated a high level of concurrent validity. There were significant differences in desire, anticipation, and relief between gamblers of differing levels of gambling-related pathology. Further, those with elevated levels of pathology reported greater desire and relief craving even after removing any variance shared between the three subscales. In addition to being related to level of gambling pathology, the three dimensions of gambling craving were also related to problematic gambling related cognitions.

Results of Study 3 also indicated that gamblers were more likely to report relief craving to the extent that they were depressed. The link between gambling and depression is well established (Blasczczynski \& McConaghy, 1989; McCormick, Russo, \& Ramirez, 1984). The relief subscale (that includes the item "Gambling would make me less depressed") indicates that, perhaps depression might perpetuate gambling insomuch as 
gambling is used an 'escape' from this negative state. Indeed, the more negative affect participants in Study 3 reported, the greater they reported relief craving. However, the fact that gamblers who craved to gamble also expected negative consequences from continued gambling suggests that gambling may also facilitate depression in the future. It is perhaps this reciprocal interplay between negative gambling consequences and the desire for relief from the negative financial, social and emotional consequences of gambling, that is responsible for the gambler's "spiral of options and involvement" or "the chase" (Lesieur, 1979). A quotation from Custer and Milt (1985) illustrates this reciprocal interplay:

Before all this happened - before the losing streak began - he was gambling to win. Now he is gambling to recoup ... The motivating force [to gamble] has changed. Before it was propelled by the euphoria of winning and the devouring desire to perpetuate it. Now it is propelled by the depression and anguish of losing and the overwhelming need to quell these feelings" (Custer \& Milt, 1985, p. 106).

Though the GACS demonstrated a high level of concurrent validity in Study 3, it was important to determine if the scale would reliably predict gambling behaviour. Thus, Study 4 tested whether craving to gamble was associated with persistence in the face of continued loss. To this end, gamblers played a slot machine located in a VR casino. After initially winning, participants were told that they could cease playing whenever they wished and could keep all the money they ended with. Results indicated that gamblers persisted to the extent that they reported craving to gamble. Indeed, the GACS total as 
well as each of the subscales were related to gamblers' persistence in the face of repeated loss. Taken together, Studies 3 and 4 demonstrated that not only did the GACS demonstrate concurrent validity, but also demonstrated predictive validity by being capable of predicting actual gambling behaviour.

In addition, Study 4 confirmed the priming effects observed in Studies 1 and 2, using a multidimensional measure of craving to gamble. Recall, only problem gamblers showed increased desire in the first two studies. In Study 4, however, both problem and non-problem gamblers reported an increased desire to gamble following a series of winning spins using the multidimensional measure. Results comparable to that observed in Study 4 have been found in investigations of the priming effects of alcohol (Chutuape et al., 1994; Hodgson, Rankin, \& Stockwell, 1979). Indeed, a small drink of an alcoholic beverage increased desire for alcohol among both problem drinkers (Hodgson et al., 1979) and social drinkers (Chutuape et al., 1994; DeWit \& Chutuape, 1993). However, these results do stand in contrast to those observed in Study 1. In Study 1 recreational gamblers did not report increases in desire to gamble following a short winning gambling session. This could be due to the length of the priming session or the amount won. In Study 1 the priming session was only 10 spins, after which participants had won $\$ 1.25$ more than they started with. In the Study 4 the priming session was 50 spins and participants won $\$ 10.00$ more than they began with. As Study 1 and Study 4 are the only experiments that have examined the influence if wins on the priming effects of a gambling episode, priming session length and amount won may be variables that warrant further investigation. 
The results of Studies 3 and 4 indicated that desire was a dimension related to, but distinct from, the expected consequences of gambling (fun, enjoyment, alleviation of depression, etc.). This finding nicely dovetails with those of Love, James, and Willner (1998) who found that craving for alcohol was composed of a desire to drink that was related to, but separate from, the expected (positively and negatively reinforcing) consequences of drinking. The notion that craving to gamble is characterized by a desire to gamble, which is distinct from the expected consequences of gambling (i.e., anticipation and relief), is also in line with Marlatt and Gordon's (1985) outcome expectancy model of craving. They define craving as the degree of desire for the immediate positive outcomes expected as a result of engaging in an addictive behaviour. Therefore, according to this definition craving is composed the beliefs about the consequences of the behaviour and the desirability of those consequences. Results from the current research suggests that craving to gamble is composed of expectations of fun and enjoyment as well as relief from negative subjective experiences (beliefs), as well as a desire for these expected consequences.

\section{Implications}

Studies 1 and 2 have implications for chasing losses. Chasing losses is the attempt to recover one's gambling losses by further gambling (O'Connor \& Dickerson, 2003) and is one of the defining characteristics of pathological gambling (APA, 1994). Study 1 revealed that high-risk gamblers, who already experienced high levels of desire to gamble in response to gambling related cues, not only experienced a further increase in desire early in a gambling session in which wins prevailed, but levels of desire remained stable 
even following a sequence of losing spins. These heightened (or sustained) levels of desire may hinder the gamblers ability to stop wagering in a given session or might contribute to increased betting levels throughout a session (e.g., Schellinck \& Schrans, 1998). Furthermore, a large win was particularly effective in maintaining the desire to gamble even after gambling cessation that occurred following repeated losses. It is conceivable that this sustained desire to gamble might contribute to between session chasing losses. In effect, early small wins might contribute to within-session chasing, whereas early large wins might contribute to chasing losses between sessions. If this were indeed the case, it would behoove health care professionals to speak with their clients about how particular patterns of wins and losses, as well as the types of wins and losses, influence desire to continue play. Doing so might aid in relapse management (that is, if abstinence from wagering was not the treatment goal).

Results from current series of studies also have other important clinical implications. Study 2 indicated that it is not simply winning that increased gambler's craving to play, but instead, winning altered participants' expectancies of continued success, which lead to sustained desire to continue gambling. Further Studies 3 and 4 , indicated that craving to gamble is composed of, not only the desire to gamble, but also expectations of positive affect and relief from negative affect to result from gambling. Taken together, it is possible that elevated expectations of winning are what is accounting the changes in affect problem gamblers expect as a consequence of gambling. Given this is the case, these results have important clinical applications for managing relapse among recovering problem gamblers. According to Marlatt and Gordon (1985), elevated craving 
is associated with increased risk of relapse among recovering addicts. If desire to play among problem gamblers is, at least in part, a function of exaggerated expectations of winning (and the affect altering consequences of winning), then the effectiveness of clinical interventions may be enhanced through a focus on reducing these elevated winning expectancies. By doing so, the desire (or craving) to gamble may begin to wane, making relapse less likely to occur.

\section{Limitations}

Some limitations of the present investigation should be noted. First, in Studies 1 and 2, participants did not use their own money when playing slots. Consequently, the participants were not as financially invested in the final outcome of the betting session as they might have been had there been a possibility of personal monetary loss. As such, high-risk gamblers in this experiment may not have experienced the same degree of arousal or excitement from the 'large' win they experienced as they might have in a 'real' gambling situation. To the point, such gamblers may have persisted longer in the face of loss had they been betting with their own money. Further, though the VR casino offered the participant a simulation of a casino environment in which to play slots, laboratory research on gambling has been criticized as having insufficient ecological validity (Anderson \& Brown, 1984). Of course ecological validity could be enhanced by studying patrons in real casinos as they wagered real money. However, historically casino operators have not been overly receptive to this idea. In addition, such studies, were they plausible, would also lack the experimental control required to ensure acceptable levels of internal validity. Given such difficulties, using a VR casino to study gambling 
behaviour in the laboratory meets the practical and controllability demands of an experimental study, while providing the gambler a somewhat realistic environment within which to gamble.

In order to assess persistence, participants in Study 2 voluntarily ceased gambling following a series of repeated losses. In most appetitive behaviours such as eating or drug taking, following the initial mouthful of food or dose of drug, further consumption of the food or drug offers diminishing returns (e.g., the $25^{\text {th }}$ chip from a bag of potato chips is not as rewarding as the $1^{\text {st }}$ chip). According to the incentive motivational approach, the strength of the unconditioned stimulus in priming desire to continue consumption depends on the internal state of the organism (i.e., whether the organism is deprived or sated).Though participants were permitted to gamble as long as they liked, they experienced persistent and continued loss. It would be of interest to determine whether prolonged exposure to gambling in which problem gamblers experiences a 'realistic' number of wins and losses has a satiating effect or whether it results in sustained or even increased desire to gamble.

In addition to the limitations of Studies 1 and 2, one possible limitation of Study 3 that deserves mention arises from the decision not to include questions regarding expectations of winning (e.g., "If I gambled right now I would win money" or "I want to win money gambling") in the initial pool of GACS test items. Given the importance of wins and losses in the desire to continue gambling highlighted in Studies 1 and 2, it may seem as though such items should have been included. The rationale for not including such items was derived from studies examining the factor structure of craving for drugs 
such as nicotine, cocaine or alcohol (Love et al., 1998; Tiffany \& Drobes, 1991; Tiffany et al., 1993). The wording of the items in these scales suggested that craving is associated with the affective consequences of drug use not with the direct drug effects. In other words people anticipate the enjoyment and relief expected to result from 'getting high' not 'getting high', per se. These scales included items such as "Drinking would make me feel good" instead of "Drinking would make me drunk." In the same way it was thought that gamblers would likely crave the affective consequences of winning rather than winning directly. Future iterations of the scale, however, may wish to include questions about winning to determine if winning expectations are distinct from the affect altering consequences of winning.

Finally, in Studies 3 and 4 participants that completed the GACS ranged from healthy to highly problematic gamblers and reported a variety of ethnic backgrounds. However, this initial development of the GACS was conducted using a sample composed of mainly young adults who were attending university. Therefore the scale should be tested on samples from other populations to determine its generalizability (Netemeyer, Bearden, \& Sharma, 2003).

\section{Concluding remarks}

The present research is the first to empirically examine the influence of gambling outcomes on the efficacy of a priming episode of gambling. It is also the first to examine the factor structure of craving to gamble. The results suggest that gamblers do not only crave to initiate play, but also desire to continue once engaged. This research indicates that not only the pattern of wins and losses, but also the types of wins and losses 
differentially impact gamblers' desire to continue play. As such, the patterns of wins and losses experienced early in the gambling session may well be important to understanding why gamblers are - or are not - able to stop gambling. Results also suggest that craving to gamble is a multidimensional construct composed of both the expected consequences of gambling and the desire for those consequences. Therefore, it is possible that craving to gamble may be managed by therapeutic interventions aimed at reducing the expected consequences of gambling among problematic gamblers. It is hoped that these studies provide a solid foundation from which to further examine the antecedents and consequences of craving to gamble. 


\section{References}

Alcañiz, M., Perpiña, C., Baños, R., Lozano, J. A., Montesa, J., Botella, C., et al. (2000). A New Realistic 3D Body Representation in Virtual Environments for the Treatment of Disturbed Body Image in Eating Disorders. CyberPsychology \& Behavior, 3, 433-439.

Anderson, G., \& Brown, R. I. F. (1984). Real and laboratory gambling, sensation-seeking and arousal. British Journal of Psychology, 75, 401-410.

Anton, R. F. (2000). Obsessive-compulsive aspects of craving: development of the Obsessive Compulsive Drinking Scale. Addiction, 95, S211-S217.

APA. (1994). Diagnostic and Statistical Manual of Mental disorders (4th ed.).

Washington, DC: American Psychiatric Association.

Bandura, A. (1997). Self-efficacy: The exercise of control. New York: W. H. Freeman \& Co.

Baron, R. M., \& Kenny, D. A. (1986). The moderator-mediator variable distinction in social psychological research: Conceptual, strategic, and statistical consideration. Journal of Personality and Social Psychology, 51, 1173-1182.

Baumann, S., B., Fetzick, S., Stangl, G., Brauch, K., Kenney, J., Yothers, T., et al. (2006). A flexible virtual reality cue-exposure platform for drug abuse studies. Paper presented at the 11 th Annual Cyber Therapy Conference, Gatineau, Québec. 
Baumann, S., B., Neff, C., Fetzick, S., Stangl, G., Basler, L., Vereneck, R., et al. (2003). A Virtual Reality System for Neurobehavioral and Functional MRI Studies. CyberPsychology \& Behavior, 6, 259-266.

Baumann, S., B., \& Sayette, M. A. (2006). Smoking Cues in a Virtual World Provoke Craving in Cigarette Smokers. Psychology of Addictive Behaviors, 20, 484-489.

Beck, A. T., Ward, C. H., Mendelson, M., Mock, J., \& Erbaugh, J. (1961). An inventory for measuring depression. Archive of General Psychiatry, 4, 561-569.

Berridge, K. C. (1996). Food reward: Brain substrates of wanting and liking. Neuroscience Biobehavioral Review, 20, 1-25.

Berridge, K. C., \& Robinson, T. E. (1995). The mind of an addicted brain: Neural sensitization of wanting versus liking. Current Directions in Psychological Science, 4, 71-76.

Bindra, D. (1974). A motivational view of learning, performance, and behavior modification. Psychological Review, 81, 199-213.

Blasczczynski, A., \& McConaghy, N. (1989). The medical model of pathological gambling: Current shortcomings. Journal of Gambling Behavior, 5, 42-52.

Brown, S. L., Rodda, S., \& Phillips, J. G. (2004). Differences between problem and nonproblem gamblers in subjective arousal and affective valence amongst electronic gaming machine players. Addictive Behaviors, 29, 1863-1867.

Castellani, B., \& Rugle, L. (1995). A comparison of pathological gamblers to alcoholics and cocaine misusers on impulsivity, sensation seeking, and craving. International Journal of the Addictions, 30, 275-289. 
Cattell, R. B. (1966). The scree test for the number of factors. Multivariate Behavioral Research, 1, 245-276.

Cepeda-Benito, A., Henry, K., \& Gleaves, D. H. (2004). Cross-cultural investigation of the questionnaire of smoking urges in american and spanish smokers. Assessment, $11,152-159$.

Chutuape, M. A., Mitchell, S., \& DeWit, H. (1994). Ethanol preloads increase ethonal preference in social drinkers. Experimental and Clinical Psychopharmacology, 2, 29-36.

Cooney, N. L., Gillespie, R. A., Baker, L. H., \& Kaplan, R. F. (1987). Cognitive changes after alcohol cue exposure. Journal of Consulting and Clinical Psychology, 55, $150-155$.

Cote, D., Caron, A., Aubert, J., Desrochers, V., \& Ladouceur, R. (2003). Near wins prolong gambling on a video lottery terminal. Journal of Gambling Studies, 19, 433-438.

Coventry, K. R., \& Constable, B. (1999). Physiological arousal and sensation-seeking in female fruit machine gamblers. Addiction, 94, 425 - 430.

Coventry, K. R., \& Hudson, J. (2001). Gender differences, physiological arousal and the role of winning in fruit machine gamblers. Addiction, 96, 871 - 879.

Crockford, D. N., \& el-Guebaly, N. (1998a). Naltrexone in the treatment of pathological gambling and alcohol dependence. Canadian Journal of Psychiatry, 43, 86.

Crockford, D. N., \& el-Guebaly, N. (1998b). Psychiatric comorbidity in pathological gambling: a critical review. Canadian Journal of Psychiatry, 43, 43-50. 
Crockford, D. N., Goodyear, J. E., Edwards, J., Quickfall, J., \& el-Guebaly, N. (2005). Cue-induced brain activity in pathological gamblers. Biological Psychiatry, 58, 787-795.

Custer, R., \& Milt, H. (1985). When Luck Runs Out: Help for Compulsive Gamblers and Their Families. New York: Facts on File Publications.

Darke, P. R., \& Freedman, J. L. (1997). The belief in good luck scale. Journal of Research in Personality, 31, 486-511.

Davidson, G. C., \& Neal, J. M. (1990). Abnormal Psychology. New York: John Wiley \& Sons.

Davies, G. M., Willner, P., \& Morgan, M. J. (2000). Smoking-related cues elicit craving in tobacco "chippers": a replication and validation of the two-factor structure of the Questionnaire of Smoking Urges. Psychopharmacology, 152, 334-342.

de Castro, V., Fong, T., Rosenthal, R., \& Tavares, H. (2007). A comparison of craving and emotional states between pathological gamblers and alcoholics. Addictive Behaviors, 32, 1555-1564.

DeVellis, R., F. (2003). Scale Development: Theory and Applications (2nd ed. Vol. 26). Thousand Oaks: Sage.

DeWit, H. (1996). Priming effects with drugs and other reinforcers. Experimental and Clinical Psychopharmacology, 4, 5-10.

DeWit, H., \& Chutuape, M. A. (1993). Increased ethanol choice in social drinkers following ethanol preload. Behavioral Pharmacology, 4, 29-36. 
Diskin, K. M., \& Hodgins, D. C. (2001). Narrowed focus and dissociative experiences in a community sample of experienced video lottery gamblers. Canadian Journal of Behavioural Science, 33, 58-64.

Drummond, D. C. (2001). Theories of drug craving, ancient and modern. Addiction, 96, 33-46.

Drummond, D. C., Litten, R. Z., Lowman, C., \& Hunt, W. A. (2000). Craving research: future directions. Addiction, 95, S247-S255.

Duvarci, I., \& Varan, A. (2000). Descriptive features of Turkish pathological gamblers. Scandinavian Journal of Psychology, 41, 253-260.

Ferris, J., \& Wynne, H. (2001). The Canadian Problem Gambling Index: Final report. Ottawa: Canadian Centre on Substance Abuse.

Ferster, C. B., \& Skinner, B. F. (1957). Schedules of reinforcement. New York: Appleton Century Crofts.

Goldman, M. S., \& Rather, B. C. (1993). Substance use disorders: Cognitive models and architecture. In K. S. Dobson \& P. C. Kendall (Eds.), Psychopathology and cognition (pp. 245-292). San Diego: Academic Press Inc.

Goodman, W. K., Price, L. H., Rasmussen, S. A., Mazure, C., Fleischmann, R. L., Hill, C. L., et al. (1989). The Yale Brown Obsessive Compulsive Scale. Archives of General Psychiatry, 46, 1006-1011.

Grant, J. E., \& Kim, S. W. (2003). Dissociative symptoms in pathological gambling. Psychopathology, 36, 14341439. 
Griffiths, M. D. (1999). The psychology of the near miss (revisited): A comment on Delfabbro and Winefield. British Journal of Psychology, 90, 441-445.

Hart, K. E. (2005). The negative gambling outcome expectancies scale. Unpublished Scale.

Hills, A. M., Hill, S., Mamone, N., \& Dickerson, M. (2001). Induced mood and persistence at gaming. Addiction, 96, 1629-1638.

Hodgson, R., Rankin, H., \& Stockwell, T. (1979). Alcohol dependence and the priming effect. Behavior Research and Therapy, 17, 379-387.

Hollander, E., DeCaria, C. M., Finkell, J. N., Begaz, T., Wong, C. M., \& Cartright, C. (2000). A randomized double-blind fluvoxamine/placebo crossover trial in pathological gambling. Biological Psychiatry, 47, 813-817.

Hu, L., \& Bentler, P. M. (1999). Cutoff criteria for fit indexes in covariance structure analysis: Conventional criteria versus new alternatives. Structural Equation Modelling, 6, 1-55.

Hughes, J. R. (1987). Craving as a psychological construct. British Journal of Addiction, $82,38-39$.

Hutchison, K. E., Swift, R., Rohsenow, D. J., Monti, P. M., Davidson, D., \& Almeida, A. (2001). Olanzapine reduces urge to drink after drinking cues and a priming dose of alcohol. Psychopharmacology, 155, 27-34.

Jacobs, D. F. (1988). Evidence for a common dissociative-like reaction among addicts. Journal of Gambling Behavior, 4, 27-37. 
Juliano, L. M., \& Brandon, T. H. (1998). Reactivity to instructed smoking availability and environmental cues: Evidence with urge and reaction time. Experimental and Clinical Psychopharmacology, 6, 45-53.

Kassinove, J. I., \& Schare, M. L. (2001). Effects of the "Near Miss" and the "Big Win" on Persistence at Slot Machine Gambling. Psychology of Addictive Behaviors, 15, $155-158$.

Kelly, O., Matheson, K., Ravindran, A., Merali, Z., \& Anisman, H. (2006). Ruminative coping among patients with dysthymia before and after pharmacotherapy. Depression and Anxiety, 24(4), 233-243.

Kim, S. W., Grant, J. E., Adson, D. E., \& Shin, Y. C. (2001). Double-blind naltrexone and placebo comparison study in the treatment of pathological gambling. Biological Psychiatry, 49, 914-921.

Kofoed, L., Morgan, T., Buchkowski, J., \& Carr, R. (1997). Dissociative experiences scale and MMPI-2 scores in video poker gamblers, other gamblers, and alcoholic controls. Journal of Nervous \& Mental Disease, 185, 58-60.

Koob, G. F. (2000). Animal models of craving for ethanol. Addiction, 95, S73-S81.

Kushner, M. G., Abrams, K., Donahue, C., Thuras, P., Frost, R., \& Kim, S. W. (2007). Urge to gamble in problem gamblers exposed to a casino environment. Journal of Gambling Studies, 23, 121-132.

Ladouceur, R., Mayrand, M., \& Tourigny, Y. (1987). Risk-taking behavior in gamblers and nongamblers during prolongud exposure. Journal of Gambling Behavior, 3, 115-122. 
Ladouceur, R., \& Sevigny, S. (2002). Symbols presentation modality as determinant of gambling behavior. The Journal of Psychology, 136, 443-448.

Ladouceur, R., \& Sevigny, S. (2005). Structural characteristics of video lottery terminals: Effects of of a stopping device on illusion of control and gambling persistence. Journal of Gambling Studies, 21, 117-131.

Ladouceur, R., Sevigny, S., Blaszczynski, A., O'Connor, K., \& Lavoie, M. E. (2003). Video lottery: winning expectancies and arousal. Addiction, 98, 733-738.

Lesieur, H. (1979). The compulsive gambler's spiral of options and involvement. Psychiatry: Journal for the Study of Interpersonal Processes, 42, 79-87.

Lesieur, H., \& Blume, S. B. (1987). The South Oaks Gambling Screen (SOGS): A New Instrument for the Identification of Pathological Gamblers. American Journal of Psychiatry, 144, 1184-1188.

Litt, M. D., \& Cooney, N. L. (1999). Inducing craving for alcohol in the laboratory. Alcohol Research \& Health, 33, 174-178.

Loba, P., Stewart, S. H., Klein, R. M., \& Blackburn, J. R. (2001). Manipulations of the features of standard video lottery terminal (VLT) games: effects in pathological and non-pathological gamblers. Journal of Gambling Studies, 17, 297-320.

Love, A., James, D., \& Willner, P. (1998). A comparison of two alcohol craving questionnaires. Addiction, 93, 1091 - 1102.

Lowman, C., Hunt, W. A., Litten, R. Z., \& Drummond, D. C. (2000). Research perspectives on alcohol craving: an overview. Addiction, 95, S45-S54. 
Ludwig, A. M., \& Wikler, A. (1974). "Craving" and relapse to drink. Quarterly Journal of Studies on Alcohol, 35, 108-130.

Ludwig, A. M., Wikler, A., \& Stark, L. H. (1974). The first drink: psychobiologicalaspects of craving. Archives of General Psychiatry, 30(539-547).

Marlatt, G. A. (1985). Cognitive factors in the relapse process. In G. A. Marlatt \& J. R. Gordon (Eds.), Relapse prevention. New York: Guilford Press.

Marlatt, G. A., \& Gordon, J. R. (1985). Relapse prevention. New York: Guilford Press. Marshall, K., \& Wynne, H. (2003). Fighting the odds. Perspectives on Labour and Income, 4, 5-13.

McCormick, R. A., Russo, A. M., \& Ramirez, L. F. (1984). Affective disorders among pathological gamblers seeking treatment. American Journal of Psychiatry, 141, 215-218.

Monti, P. M., Rohsenow, D. J., \& Hutchison, K. E. (2000). Toward bridging the gap between biological, psychobiological and psychosocial models of alcohol craving. Addiction, 95, S229-S236.

Myers, M. G., Stice, E., \& Wagner, E. F. (1999). Cross-validation of the temptation coping questionnaire: adolescent coping with temptations to use alcohol and illicit drugs. Journal of Studies on Alcohol, 60, 712-718.

Neal, P., Delafabbro, P., \& O'Neil, M. (2005). Problem Gambling and Harm: Towards a National Definition (No. ABN:0 9751194 1). Melbourne, Australia: The SA Centre for Economic Studies with the Department of Psychology, University of Adelaide. 
Neighbors, C., Lostutter, T., Cronce, J., \& Larimer, M. (2002). Exploring college student gambling motivation. Journal of Gambling Studies, 18, 361-370.

Netemeyer, R., G., Bearden, W., O., \& Sharma, S. (2003). Scaling Procedures: Issues and Applications. Thousand Oaks, CA: Sage.

O'Connor, J., \& Dickerson, M. (2003). Definition and measurement of chasing in off course betting and gaming machine play. Journal of Gambling Studies, 19, 359385.

Orford, J. (2001), Excessive Appetites: A Psychological View of Addictions (2nd ed.). Chichester: John Wiley \& Sons Ltd.

Pavlov, I. P. (1927). Conditioned Reflexes. London: Routledge and Kegan Paul.

Potenza, M. N., Steinberg, M. A., Skudlarski, P., Fulbright, R. K., Lacadie, C. M., Wilber, M. K., et al. (2003). Gambling urges in pathological gambling: a functional magnetic resonance imaging study. Archives of General Psychiatry, 60 , 828-836.

Preacher, K. J., \& Hayes, A. F. (2004). SPSS and SAS procedures for estimating indirect effects in simple mediation models. Behavior Research Methods, Instruments, and Computers, 36, 717-731.

Raylu, N., \& Oei, T. P. S. (2004a). The Gambling Related Cognitions Scale (GRCS): Development, confirmatory factor validation and psychometric properties. Addiction, 99, 757-769. 
Raylu, N., \& Oei, T. P. S. (2004b). The Gambling Urge Scale: Development, Confirmatory Factor Validation, and Psychometric Properties. Psychology of Addictive Behaviors, 18, 100-105.

Rush, R., Moxam, R. S., \& Urbanoski, K. A. (2002). Characteristics of people seeking help from specialized programs for the treatment of problem gambling in Ontario. eGambling, 6.

Sayette, M. A., Shiffman, S., Tiffany, S. T., Niaura, R. S., Martin, C. S., \& Schadel, W. G. (2000). The measurement of drug craving. Addiction, 95, S189-S210.

Schellinck, T., \& Schrans, T. (1998). Nova Scotia Video Lottery players' survey: Report for the Nova Scotia Department of Health, Halifax, Nova Scotia.

Shiffman, S., Paty, J. A., Gnys, M., Kassel, J. A., \& Hickcox, M. (1996). First Lapses to smoking: Within-subjects analysis of real-time reports. Journal of Consulting and Clinical Psychology, 64, 366-379.

Skinner, B. F. (1953). Science and Human Behaviour. New York: Free Press.

Smith, G. J., \& Wynne, H. (2004). VLT gambling in Alberta: a preliminary analysis: Alberta Gambling Research Institute.

Steenbergh, T. A., Meyers, A. W., May, R. K., \& Whelan, J. P. (2002). Development and validation of the gamblers' beliefs questionnaire. Psychology of Addictive Behaviors, 16, 143-149.

Stewart, J., DeWit, H., \& Eikelboom, R. (1984). Role of unconditioned and conditioned drug effects in self-administration of opiates and stimulants. Psychological Review, 91, 251-268. 
Strickland, L. H., \& Grote, F. W. (1967). Temporal presentation of winning symbols and slot machine playing. Journal of Experimental Psychology, 74, 10-13.

Tavares, H., Zilberman, M. L., Hodgins, D. C., \& el-Guebaly, N. (2005). Comparison of craving between pathological gamblers and alcoholics. Alcoholism: Clinical \& Experimental Research, 29, 1427-1431.

Tiffany, S. T. (1990). A cognitive model of drug urges and drug-use behavior: Role of automatic and non-automatic processes. Psychological Review, 97, 147-168.

Tiffany, S. T. (1999). Cognitive concepts of craving. Alcohol Research and Health, 23, $215-224$.

Tiffany, S. T., Carter, B. L., \& Singleton, E. G. (2000). Challenges in the manipulation, assessment and interpretation of craving relevant variables. Addiction, 95, S177S187.

Tiffany, S. T., \& Drobes, D. J. (1991). The development and initial validation of a questionnaire on smoking urges. British Journal of Addiction, 86, 1467-1476.

Tiffany, S. T., Singleton, E., Haertzen, C. A., \& Henningfield, J. E. (1993). The development of a cocaine craving questionnaire. Drug and Alcohol Dependence, $34,19-28$.

Toneatto, T. (1999). Cognitive psychopathology of problem gambling. Substance Use and Misuse, 34, 1593-1604.

Verheul, R., Van den Brink, W., \& Geerlings, P. (1999). A three-pathway psychobiological model of craving for alcohol. Alcohol and Alcoholism, 34, 197 222. 
Watson, D., Clark, L. A., \& Tellegen, A. (1988). Development and validation of brief measures of positive and negative affect: The PANAS Scales,. Journal of Personality and Social Psychology, 54, 1063-1070.

Weatherly, J. N., Sauter, J. M., \& King, B. M. (2004). The "big win" and resistance to extinction when gambling. Journal of Psychology, 138, 495-504.

Wiebe, J., Mun, P., \& Kauffman, N. (2006). Gambling and problem gambling in Ontario. Toronto, Ontario: Responsible Gambling Council.

Wiebe, J., Single, E., \& Falkowski-Ham, A. (2001). Measuring gambling and problem gambling in Ontario: Canadian Centre on Substance Abuse, Responsible Gambling Council (Ontario).

Wiederhold, B. K., \& Wiederhold, M. D. (2000). Lessons learned from 600 virtual reality sessions. Cyberpsychology \& Behavior, 3, 393-400.

Wikler, A. (1948). Recent progress in research on the neurophysiologic basis of morphine addiction. American Journal of Psychiatry, 105, 329-338.

Wise, R. A. (1988). The neurobiology of craving: Implications for the understanding of treatment of addiction. Journal of Abnormal Psychology, 97, 118-132.

Wise, R. A. (2004). Drive, incentive, and reinforcement: the. antecedents and consequences of motivation. Nebraska Symposium on Motivation, 50, 159-195.

Wohl, M. J. A. (2008). Belief in a lucky self: The role of personal luck in the facilitation and maintenance of gambling behavior. Psychologie Francaise.

Wohl, M. J. A., Anisman, H., Matheson, K., \& Young, M. M. (2006). Personal Luck, Outcome Expectancies, and Subjective Appraisals as Predictors of Health and 
Readiness to Seek Treatment Among Young Adults. Ottawa: Ontario Problem Gambling Research Centre.

Wohl, M. J. A., \& Enzle, M. E. (2002). The deployment of personal luck: Illusory control in games of pure chance. Personality and Social Psychology Bulletin, 28, 13881397.

Wohl, M. J. A., \& Enzle, M. E. (2003). The effects of near wins and losses on self perceived personal luck and subsequent gambling behavior. Journal of Experimental Social Psychology, 39, 184-191.

Wohl, M. J. A., Young, M. M., Anisman, H., \& Matheson, K. (2006). Expectancies of success, appraisals, and a reluctance to seek treatment: the role of perceived personal luck in the maintenance of pathological gambling behavior. Paper presented at the 13th International Conference on Gambling and Risk-taking, Lake Tahoe, Nevada.

Wohl, M. J. A., Young, M. M., \& Hart, K. E. (2005). Untreated young gamblers with game-specific problems: Self-concept involving luck, gambling ecology and delay in seeking professional treatment. Addiction Research \& Theory, 13, 445 459.

Wohl, M. J. A., Young, M. M., \& Hart, K. E. (2007). Self-perceptions of dispositional luck: Relationship to DSM gambling symptoms, subjective enjoyment of gambling and treatment readiness. Substance Use and Misuse, 42, 43-63. 
Wood, R., \& Griffiths, M. D. (2007). A qualitative investigation of problem gambling as an escape based coping strategy. Psychology and Psychotherapy: Theory, Research and Practise, 80, 107-125.

Zack, M., \& Poulos, C. X. (2004). Amphetamine primes motivation to gamble and gambling related semantic networks in problem gamblers. Neuropsychopharmacology, 29, 195-207.

Zack, M., \& Poulos, C. X. (2007). A D2 antagonist enhances the rewarding and priming effects of a gambling episode in pathological gamblers.

Neuropsychopharmacology, 32, 1678-1686. 


\section{Appendix A. Study 1 Screening Questionnaire}

Please fill out the following information about yourself and your background:

1. Age:

2. Gender (circle one): Male / Female

3. Ethnicity (circle \# from a-h below):
a) Caucasian/European origin
b) African-Canadian/American
c) East Asian (Chinese, Japanese, Korean)
d) South Asian (Indian, Pakistani, Sri Lankan, etc.)
e) Middle Eastern
f) Native Canadian/American
g) Hispanic and South American Origin
h) Other or multi-ethnic origin 
Instructions: THINK ABOUT THE LAST 12 MONTHS and tell us - as truthfully as you can about your gambling. Some of the items may not seem to apply to you. In this case, answer 1 (for 'Never').

1. Have you bet more than you could really afford to lose?

$\begin{array}{ccccc}\mathbf{1} & \mathbf{2} & \mathbf{3} & \mathbf{4} & \mathbf{5} \\ \text { Never } & \text { Sometimes } & \text { Most of the time } & \text { Almost always } & \text { Don't Know }\end{array}$

2. Still thinking about the last 12 months, have you needed to gamble with larger amounts of money to get the same feeling of excitement?

$\begin{array}{ccccc}\mathbf{1} & \mathbf{2} & \mathbf{3} & \mathbf{4} & \mathbf{5} \\ \text { Never } & \text { Sometimes } & \text { Most of the time } & \text { Almost always } & \text { Don't Know }\end{array}$

3. When you gambled, did you go back another day to try to win back the money you lost?

$\begin{array}{ccccc}\mathbf{1} & \mathbf{2} & \mathbf{3} & \mathbf{4} & \mathbf{5} \\ \text { Never } & \text { Sometimes } & \text { Most of the time } & \text { Almost always } & \text { Don't Know }\end{array}$

4. Have you borrowed money or sold anything to get money to gamble?

$\begin{array}{ccccc}1 & \mathbf{2} & \mathbf{3} & \mathbf{4} & \mathbf{5} \\ \text { Never } & \text { Sometimes } & \text { Most of the time } & \text { Almost always } & \text { Don't Know }\end{array}$

5. Have you felt that you might have a problem with gambling?

$\begin{array}{ccccc}\mathbf{1} & \mathbf{2} & \mathbf{3} & \mathbf{4} & \mathbf{5} \\ \text { Never } & \text { Sometimes } & \text { Most of the time } & \text { Almost always } & \text { Don't Know }\end{array}$

6. Has gambling caused you any health problems, including stress or anxiety?

$\begin{array}{ccccc}\mathbf{1} & \mathbf{2} & \mathbf{3} & \mathbf{4} & \mathbf{5} \\ \text { Never } & \text { Sometimes } & \text { Most of the time } & \text { Almost always } & \text { Don't Know }\end{array}$

7. Have people criticized your betting or told you that you had a gambling problem, regardless of whether or not you thought it was true?

$\begin{array}{ccccc}1 & \mathbf{2} & \mathbf{3} & \mathbf{4} & \mathbf{5} \\ \text { Never } & \text { Sometimes } & \text { Most of the time } & \text { Almost always } & \text { Don't Know }\end{array}$

8. Has your gambling caused any financial problems for you or your household?

$\begin{array}{ccccc}\mathbf{1} & \mathbf{2} & \mathbf{3} & \mathbf{4} & \mathbf{5} \\ \text { Never } & \text { Sometimes } & \text { Most of the time } & \text { Almost always } & \text { Don't Know }\end{array}$

9. Have you felt guilty about the way you gamble or what happens when you gamble?

$\begin{array}{ccccc}\mathbf{1} & \mathbf{2} & \mathbf{3} & \mathbf{4} & \mathbf{5} \\ \text { Never } & \text { Sometimes } & \text { Most of the time } & \text { Almost always } & \text { Don't Know }\end{array}$




\section{Appendix B. Study 1 Informed Consent}

The purpose of an informed consent is to ensure that you understand the purpose of the study and the nature of your involvement. The informed consent has to provide sufficient information such that you have the opportunity to determine whether you wish to participate in the study.

Study Title: Reactions to virtual gaming

Study Personnel: $\quad$ Dr. Michael Wohl, Department of Psychology, Carleton University Phone: (613) 520-2600 ext 2908

Dr. Hymie Anisman, Department of Psychology, Carleton University

Phone: Phone: (613) 520-2699

Dr. Kim Matheson, Department of Psychology, Carleton University

Phone: (613) 520-2684

If you have any ethical concerns about this study please contact Dr. C. Davis, (Chair of the Carleton University Research Ethics Committee for Psychological Research, 520-2600, ext. 2251), or Dr. M. Gick, (Chair, Department of Psychology, Carleton University at 520-2600, ext. 2648).

Purpose and Task Requirements: The purpose of this study is to assess perceptions, mood, and cortisol levels (a stress related hormone) and urges in response to gambling. As well, we wish to identify the coping responses that are perceived as effective in certain situations by different people. We will be asking you to wear virtual reality headgear which creates a realistic and interactive casino atmosphere (sights and sounds). The virtual casino has the capability to interact with the user in a gaming situation, and you will have the opportunity to do so. You will also be asked to complete a series of questionnaires about your background (e.g., family history), personal characteristics (e.g., how you cope with things in your life), and gambling (e.g., propensity to gamble and attitudes toward gambling). We will also be asking for saliva samples to look for physical indications of stress, specifically your levels of a stress hormone called cortisol. Providing a saliva sample simply involves placing a piece of dental cotton in your mouth for two minutes and then placing it in a test tube. In addition, your heart rate and blood pressure will be monitored throughout the testing procedure.

Potential Risk and Discomfort: There are no physical risks in this study. Some individuals may experience discomfort when asked to respond to personal, sensitive questions that require focusing on a potentially stressful situation.

Anonymity/Confidentiality: The data collected in this study will be kept confidential. Your informed consent form will be separated from your questionnaire and kept in a separate and secured file by one of the research investigators who will keep this information confidential. Your questionnaire responses will be associated with a code that you will generate, and this code will be used to match your questionnaire with your saliva samples.

Right to Withdraw: Your participation in this study is entirely voluntary. At any point during the study you have the right to not complete certain questions or to withdraw with no penalty whatsoever.

I have read the above description of the study concerning my reactions to virtual gaming. The data collected will be used in research publications and/or for teaching purposes. My signature indicates that I agree to participate in the study, and this in no way constitutes a waiver of my rights.

Full Name (please print):

Participant Signature:

Date:

Researcher Signature:

Date: 


\section{Appendix C. Study 1 Debriefing}

This post-test information is designed to help you understand the nature of the research. This experiment is part of a larger research project being conducted to examine young adults gambling behaviour and attitudes. Specifically, the purpose of this study is to assess the effects of gambling anticipation on neuroendocrine and affective responses among individuals with varying degrees of gambling interest. The two groups of participants are 'at risk' (pathological/ problem), and 'not at risk' (recreational) gamblers, as previously identified by the DSM-IV checklist for pathological gambling. Using the virtual reality combined with an actual gaming simulation, we assess the behavioural and neuroendocrine consequences associated with negative or positive gambling outcomes. Results from this project will facilitate the identification of features that render young adults vulnerable to pathology, and will provide the basis for us to develop workshops and materials that may be used as an intervention strategy for problem-gambling among young adults.

The saliva samples, heart rate, and blood pressure collected during the study will provide physiological measures that indicate anticipation of the gambling task as a function of the study manipulations. Several attributes of gambling may be associated with altered hypothalamic-pituitary-adrenal (HPA) and cardiovascular activity that is characterized by elevated circulating cortisol levels and increased heart rate and blood pressure. This may provide important clues concerning who is most likely to develop gambling problems. When most individuals are exposed to gambling-related stimuli, or anticipate the opportunity to gamble, it is unlikely that marked physiological changes would be induced. However, among those with gambling problems, stimuli that trigger anticipatory responses might have more profound behavioural and neurochemical consequences. These stimuli may be associated with physiological activation that, combined with positive expectations, might propel the individual to enact their gambling propensities. Indeed, in male problem gamblers, such cues elicited gambling urges coupled with brain activity changes measured by functional MRI (in frontal, paralimbic, and limbic brain structures). Importantly, decreased neuronal activity was apparent in brain regions implicated in impulse regulation. It is our expectation that among individuals at risk for problem gambling, elevated cortisol, heart rate, and blood pressure will occur in response to gambling stimuli (sight, sound of gambling activities), and these will rise still further in anticipation of being able to gamble. In contrast, as problem gamblers may attribute loss to factors external to themselves and maintain their view of themselves as lucky, loss would not be expected to provoke particularly marked cortisol responses. In effect, it may be that anticipatory factors are more central to gambling behaviours and persistence in the face of loss than are the actual outcomes.

Previous research (Wohl, Young, \& Hart, 2004) has found that some gamblers have extreme beliefs in personal luck or optimism, so that they over-attribute their wins to the self, and have exaggerated expectations of future gambling successes. As such, among 
some gamblers, anticipation of gambling may provoke a 'high' (eustress) similar to that experienced by people engaging in other risk-taking behaviours (e.g., skydivers). This process may contribute to a strong desire to gamble and a persistent reluctance to seek treatment when gambling reaches problematic levels. To assess this possibility, we asked you to complete measures that assess your belief in personal luck, your expectations of success at the gambling game, and your mood while gambling.

It is also being assessed whether some gamblers are less likely to be influenced by the outcomes, as they will maintain a positivity bias irrespective of outcome. Paralleling these appraisals, it is estimated that negative gambling outcomes will have little effect on physiological measures (cortisol, heart rate, blood pressure) among some gamblers. To test this hypothesis, outcomes for the games you played were predetermined such that half of participants (randomly assigned) won $60 \%$ of gambles and half lost $80 \%$ of gambles. Thereafter, appraisals of the completed gambling session and expectations about a subsequent second set of 10 gambles were collected. This is included to determine whether characteristics of pathological gambling are associated with disturbed appraisals of negative experiences and colour gambling expectancies. I was unable to disclose this part of the study to you at the onset because you might have felt pressure to respond in the way you thought I expected you to, rather than reacting the way you normally would. The possibility that some participants might react on what they believed the experimenter expected is called the demand awareness effect. This can be a problem in research because the results could reflect nothing having to do with the psychological or physiological processes being studied, but could simply reflect demand awareness.

As such, after you finish reading this debriefing form, the experimenter will present a new informed consent form. The purpose of an informed consent is to ensure that you now understand the true purpose of the study and that you agree to allow your data to be used for research and teaching purposes. Because you were only told of the procedures and not the purpose of this study at the outset, we will be asking for your consent to allow your data to be used for research and teaching purposes.

If you have any questions about this study when you leave, please feel free to use the contact information on this debriefing form that you are allowed to keep.

Lastly, if you think you may be experiencing depression or PTSD, it is suggested that you either contact your family physician, or one of the organizations listed below. It is not a good idea to allow problems to fester, as ruminating over these problems will typically not make them go away. Your family physician or counselor will usually be able to help you or to refer you to someone who can.

Distress Centre: Ottawa And Region (613) 238-1089

Web Site: www.dcottawa.on.ca

Distress Centres of Toronto: (416) 408 help

Distress Centre of Hamilton: (905) 5258611

KW Distress Line: (519) 7451166 
Health and Counselling Services at Carleton 520-6674.

If you have any questions or comments about this research, then please feel free to contact Matthew Young (520-2600 ext. 6312; mmyoung@connect.carleton.ca ), Carolyn Barnes (520.2600 ext. 2683; cbarnes@ connect.carleton.ca), Dr. Michael Wohl (520.2600 ext. 2908; mwohl@ connect.carleton.ca), Dr. Hymie Anisman (520.2600 ext. 2699; hymie anisman@carleton.ca), or Dr. Kim Matheson (520-2684;

kimmatheson@pigeon.carleton.ca).

If you have any ethical concerns about this study please contact Dr. C. Davis (Chair of the Carleton University Ethics Committee for Psychological Research, 520-2600, ext. 2251) or Dr. M. Gick (Chair of the Department of Psychology at Carleton University, 520-2600, ext. 2648).

We thank you very much for participating in this study. Your assistance will help us better understand gambling behavior among young adults. 


\section{Appendix D: Study 2 Informed Consent}

The purpose of an informed consent is to ensure that you understand the purpose of the study and the nature of your involvement. The informed consent has to provide sufficient information such that you have the opportunity to determine whether you wish to participate in the study.

Study Title: $\quad$ Reactions to virtual gaming

Study Personnel: $\quad$ Matthew Young, MA, Department of Psychology, Carleton University

Phone: (613) 520-2600 ext 6312

Dr. Michael Wohl, Department of Psychology, Carleton University

Phone: (613) 520-2600 ext 2908

$<$ span $><$ span lang=EN-CA style='font-size: 10.0pt; mso-bidifont-size: 12.0pt; mso-ansi-language: $\mathrm{EN}^{-C^{\prime}}>$ 'Dr. Hymie Anisman, Department of Psychology, Carleton University

Phone: Phone: (613) 520-2699

Dr. Kim Matheson, Department of Psychology, Carleton University

Phone: (613) 520-2684 </span $>$

If you have any ethical concerns about this study please contact Dr. J. Mantler, (Chair of the Carleton University Research Ethics Committee for Psychological Research, 520-2600, ext. 4173), or Dr. M. Gick, (Chair, Department of Psychology, Carleton University at 520-2600, ext. 2648).

Purpose and Task Requirements: The purpose of this study is to assess to gamble behaviour among university students. We will be asking you to wear virtual reality headgear which creates a realistic and interactive casino atmosphere (sights and sounds). The user has the capability of interacting with the virtual casino in a gaming situation, and you will have the opportunity to do so. You will also be asked to complete a series of questionnaires about your background (e.g., family history), and gambling (e.g., propensity to gamble and attitudes toward gambling).

Potential Risk and Discomfort: There are no physical risks in this study. Some individuals may experience discomfort when asked to respond to personal, sensitive questions. In addition, some individuals may experience discomfort or nausea when interacting with the virtual reality console (a.k.a. "Cybersickness"). If you do feel nauseous when using the virtual reality console, please take a break (i.e., close your eyes), if the nausea continues, please tell the experimenter and he or she will terminate the study.

Anonymity/Confidentiality: The data collected in this study will be kept confidential. Your informed consent form will be separated from your questionnaire and kept in a separate and secured file by one of the research investigators who will keep this information confidential. Your questionnaire responses will be associated with a code that you will generate, and this code will be used to match your questionnaire with your saliva samples.

Right to Withdraw: Your participation in this study is entirely voluntary. At any point during the study you have the right to not complete certain questions or to withdraw with no penalty whatsoever.

I have read the above description of the study concerning my reactions to virtual gaming. The data collected will be used in research publications and/or for teaching purposes. My signature indicates that I agree to participate in the study, and this in no way constitutes a waiver of my rights.

Full Name (please print):

Participant Signature:

Date: 
Desire and Gambling 110

Researcher Signature:

Date: 


\section{Appendix E. Study 2 Questionnaire}

\section{Background}

\section{Age}

2. Sex

\section{Ethnic/racial background}

4. Do you currently gamble? (circle one from 'a' to ' $d$ ' below)
a) YES, I currently gamble
b) NO, I used to but I haven't gambled in the last the last 6 months
c) NO, I have never gambled (if c skip to the following page) 


\title{
P of PL
}

\begin{abstract}
Instructions:
Please indicate your agreement with these statements by circling the appropriate answer.
\end{abstract}

1

2

3

4

5

Strongly Disagree Disagree Slightly Agree Somewhat Agree Strongly Agree

1. I think of gambling as a "challenge"

2. My knowledge and skill in gambling contribute to the likelihood that I will make money.

3. My choices or actions affect the outcome of the game on which I am betting.

4. I keep track of previous winning bets so that I can

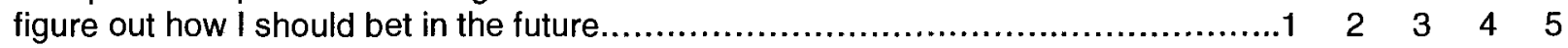

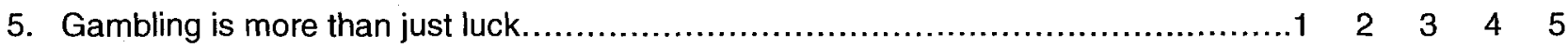

6. My gambling wins are evidence that I have skill and knowledge related to gambling.............................................. $2 \quad 2 \quad 3 \quad 4 \quad 5$

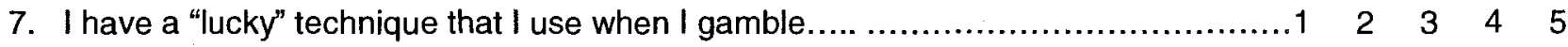

8. Even though I may be losing with my gambling strategy or plan, I maintain that strategy or plan because I know it will eventually come through for me.

9. I am pretty accurate at predicting when a "win" will occur

10. I have more skills and knowledge related to gambling than most people who gamble.

\section{PLEASE PLACE A POST-IT ON THIS PAGE, CLOSE YOUR BOOKLET, AND INFORM THE EXPERIMENTER THAT YOU HAVE COMPLETED THE INITIAL QUESTIONNAIRES!}




\section{P of PL}

\section{Instructions:}

Please indicate your agreement with these statements by circling the appropriate answer.

\begin{tabular}{crrrr}
\hline 1 & 2 & 3 & 4 & 5 \\
Strongly Disagree & Disagree & Slightly Agree & Somewhat Agree & Strongly Agree \\
\hline
\end{tabular}

1. I think of gambling as a "challenge"

2. My knowledge and skill in gambling contribute to

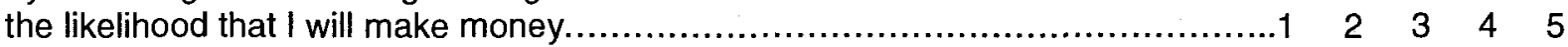

3. My choices or actions affect the outcome of the game on which I am betting.

4. I keep track of previous winning bets so that I can

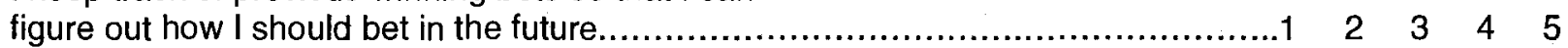

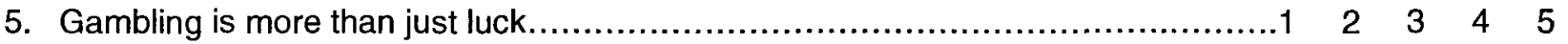

6. My gambling wins are evidence that I have skill

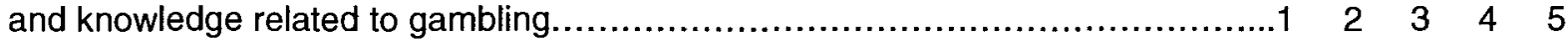

7. I have a "lucky" technique that I use when I gamble.................................. $2 \quad 2 \quad 3 \quad 4 \quad 5$

8. Even though I may be losing with my gambling strategy or plan, I maintain that strategy or plan because I know it will eventually come through for me.................................

9. I am pretty accurate at predicting when a "win" will occur

10. I have more skills and knowledge related to gambling than most people who gamble. 


\section{Appendix F. Study 2 Debriefing}

This post-test information is designed to help you understand the nature of the research. This experiment is part of a larger research project being conducted to examine gambling behaviour and attitudes of young adults. Specifically, the purpose of this study is to assess craving to gamble among individuals with varying degrees of gambling interest. The three groups of participants are non-problem, 'at risk', and problem gamblers, as previously identified by the Problem Gambling Severity Index. Using the virtual reality combined with an actual gaming simulation, we assessed craving. Results from this project will facilitate the identification of features that render young adults vulnerable to pathology, and will provide the basis for us to develop workshops and materials that may be used as an intervention strategy for problem-gambling among young adults.

Though empirical evidence suggests that craving is central to substance addiction, it has yet to received much investigation in the context of gambling. Therefore we conducted this study to learn more about the nature of craving within the context of gambling behaviour.

Previous research conducted in our lab has examined the influence of wins and losses on gambling craving. This research revealed that participants' craving to gamble increased significantly following a sequence winning slot machine spins. In contrast, participants reported no change in craving levels following a sequence of losing spins. In the present study we wish to examine in more detail the influence wins on craving to gamble.

Previous research (Wohl, Young, \& Hart, 2005) has found that some gamblers have extreme beliefs in personal luck or optimism, so that they over-attribute their wins to the self, and have exaggerated expectations of future gambling successes. As such, among some gamblers, anticipation of gambling may provoke a 'high' (eustress) similar to that experienced by people engaging in other risk-taking behaviours (e.g., skydivers). This process may contribute to a strong desire to gamble (craving) and a persistent reluctance to seek treatment when gambling reaches problematic levels. To assess this possibility, we asked you to complete measures that assess your belief in personal luck, your expectations of success at the gambling game, your mood while gambling, and your craving to gamble.

The results of slot machine you just played were predetermined to win in a particular sequence. We were unable to disclose this part of the study to you at the onset because it would have influenced your behaviour and responding to the questions. As such, after you finish reading this debriefing form, the experimenter will present a new informed consent form. The purpose of an informed consent is to ensure that you now understand the true purpose of the study and that you agree to allow your data to be used for research and teaching purposes. Because you were only told of the procedures and not the purpose of this study at the outset, we will be asking for your consent to allow your data to be used for research and teaching purposes.

If you have any questions about this study when you leave, please feel free to use the contact information on this debriefing form that you are allowed to keep. 
Lastly, if you think you may have gambling problems, it is suggested that you either contact one of the organizations listed below. It is not a good idea to allow problems to fester, as ruminating over these problems will typically not make them go away. In addition, your family physician or counselor will may also be able to help you or to refer you to someone who can help.

Ontario Problem Gambling helpline 1-888-230-3505 http://www.opgh.on.ca/ Addictions and Problem Gambling Services of Ottawa (613) 789-8941 http://www.apgsostjpo.ca/find eng.html

Distress Centre: Ottawa And Region (613) 238-1089 http://www.dcottawa.on.ca Health and Counselling Services at Carleton University (613) 520-6674.

If you have any questions or comments about this research, then please feel free to contact Matthew Young (520.2600 ext. 6312; mmyoung@ connect.carleton.ca), Tania Morrison (520.2600 ext. 2683; tmorriso@connect.carleton.ca), Dr. Michael Wohl (520.2600 ext. 2908; mwohl@ connect.carleton.ca), Dr. Hymie Anisman (520.2600 ext. 2699; hymie anisman@ carleton.ca), or Dr. Kim Matheson (5202684; kimmatheson@pigeon.carleton.ca).

If you have any ethical concerns about this study please contact Dr. J. Mantler, (Chair of the Carleton University Research Ethics Committee for Psychological Research, 520-2600, ext. 4173), or Dr. M. Gick, (Chair, Department of Psychology, Carleton University at 520-2600, ext. 2648).

We thank you very much for participating in this study. Your assistance will help us better understand gambling behavior among young adults. 


\section{Appendix G. Study 3 Informed Consent}

The purpose of an informed consent is to ensure that you understand the purpose of the study and the nature of your involvement. The informed consent has to provide sufficient information such that you have the opportunity to determine whether you wish to participate in the study, or not.

Study Title: Personal experiences and gambling

Study Personnel: $\quad$ Dr. Michael Wohl, Department of Psychology, Carleton University

Phone: (613) 520-2600 ext 2908

$<$ span $><$ span lang=EN-CA style='font-size: $10.0 \mathrm{pt}$; mso-bidi-font-size: $12.0 \mathrm{pt}$; msoansi-language: EN-CA'>Dr. Hymie Anisman, Department of Psychology, Carleton University

Phone: Phone: (613) 520-2699

$</$ span $><$ span lang=EN-CA style='font-size: 10.0pt; mso-bidi-font-size: $12.0 \mathrm{pt}$; msoansi-language: EN-CA'>Dr. Kim Matheson, Department of Psychology, Carleton University Phone: (613) 520-2684 </span>

Other Research Personnel: Tania Morrison (tmorriso@connect.carleton.ca), Christopher Motz (cpmotz@connect.carleton.ca), Matthew Young (mmyoung@connect.carleton.ca), Neil McVicar (neilmcvicar@hotmail.com), Meara Zinn (meara_z@hotmail.com), Amanda Lahey (alahey@connect.carleton.ca), Allison Hauck (ahauck@ @onnect.carleton.ca), Samantha Jolicoeur (sam532@ @otmail.com), April McGrath (amcgrath@connect.carleton.ca)

If you have any ethical concerns about how this study please contact Dr. J. Mantler (Chair of the Carleton University Ethics Committee for Psychological Research, 520-2600, ext. 4173) or Dr. M. Gick (Chair of the Department of Psychology at Carleton University, 520-2600, ext. 2648).

Purpose and Task Requirements: We are asking you to fill out a number of questionnaires regarding your background (e.g., family history), personal characteristics (e.g., how you cope with things in your life), and gambling (e.g., propensity to gamble and attitudes toward gambling). The questionnaires will take about 60 minutes to complete.

Potential Risk and Discomfort: There are no physical risks in this study. Some individuals may experience discomfort when asked to respond to personal, sensitive questions that require focusing on a potentially stressful situation.

Anonymity/Confidentiality: In this questionnaire, we will be asking you to indicate whether or not you have been involvement in illegal activity (e.g., theft). We will not ask specifics about this behavior. Know that all the data collected in this study will be kept confidential. Because we will want to keep track of your answers in this questionnaire to match up with possible later measures, we will have to be able identify who you are on your questionnaire. We will do this using a personal code that you will develop momentarily.<span style="msospacerun: yes; mso-bidi-font-size: 12.0pt"> However, we take special precautions to make sure that no-one else will be able to identify you and what your responses were. Any identifying information associated with your code will be confined to a single page that will be separated from your questionnaire, and kept in a separate and secured file by the research investigators who will keep this information confidential.

Right to Withdraw: Your participation in this study is entirely voluntary. At any point during the study you have the right to not complete certain questions or to withdraw with no penalty whatsoever.

I have read the above description of the study concerning personal experience and gambling. The data collected will be used in research publications and/or for teaching purposes. My signature indicates that I agree to participate in the study, and this in no way constitutes a waiver of my rights.

Full Name (please print):

Participant Signature:

Date: 
Desire and Gambling 117

Researcher Signature:

Date:

$+2+2$ 
Appendix H. Study 3 Questionnaire

1. Age

2. Sex

3. Ethnicity (circle \# from a-h below):

a. Caucasian/European origin

b. African-Canadian/American

c. East Asian (Chinese, Japanese, Korean)

d. South Asian (Indian, Pakistani, Sri Lankan, etc.)

e. Middle Eastern

f. Native Canadian/American

g. Hispanic and South American Origin

h. Other or multi-ethnic origin

4. Current employment status (circle \# from 1-4 below):

a. Not employed

b. Part-time

c. Full-time

d. Seasonal/Temporary/Contract

5. Do you currently gamble? (circle one from ' $a$ ' to ' $d$ ' below)

a. YES, I currently gamble

b. YES, I occasionally gamble

c. NO, I used to but I haven't gambled in the last the last 6 months

d. NO, I have never gambled (if $\mathbf{c}$ skip to the following page)

6. What is your favourite form of gambling (e.g., cards, sports betting, horse racing, lottery tickets, etc)?

7. Has anything bad ever happened to you as a result of your gambling? (circle one)

YES / NO

8. Would life be better if you gambled less? (circle one)

YES / NO

9.Are you seriously thinking of quitting or cutting down on your gambling?

a) YES, within the next 30 days

b) YES, within the next 6 months

c) NO, not thinking of quitting or cutting down 
GACS

INSTRUCTIONS: Please indicate your agreement or disagreement to the following statements by circling the appropriate response.

1. If I had an opportunity to gamble right now I probably would take it.

Strongly Disagree / Strongly Agree

2. I would do almost anything to gamble now.

3. Gambling now would make things seem just perfect.

4. If I were offered an opportunity to gamble right now, I would gamble.

5. If I were gambling now I could think more clearly.

6. I could control things better right now if I could gamble.

7. Gambling would be fun right now.

8. I crave gambling right now.

9. All I want right now is to gamble.

\begin{tabular}{lllllll}
1 & 2 & 3 & 4 & 5 & 6 & 7 \\
\hline & 2 & 3 & 4 & 5 & 6 & 7
\end{tabular}

10. I need to gamble now.

$\begin{array}{lllllll}1 & 2 & 3 & 4 & 5 & 6 & 7\end{array}$

$\begin{array}{lllllll}1 & 2 & 3 & 4 & 5 & 6 & 7\end{array}$

$\begin{array}{lllllll}1 & 2 & 3 & 4 & 5 & 6 & 7\end{array}$

$\begin{array}{lllllll}1 & 2 & 3 & 4 & 5 & 6 & 7\end{array}$

$\begin{array}{lllllll}1 & 2 & 3 & 4 & 5 & 6 & 7\end{array}$

$\begin{array}{lllllll}1 & 2 & 3 & 4 & 5 & 6 & 7\end{array}$

$\begin{array}{lllllll}1 & 2 & 3 & 4 & 5 & 6 & 7\end{array}$

11. If it were possible, I probably would gamble now.

12. Gambling would be very satisfying now.

13. Nothing would be better than gambling right now.

14. I would not enjoy gambling right now.

15. I have an urge to gamble.

$2 \quad 3 \quad 4 \quad 5 \quad 67$

$+$

16. My desire to gamble seems overpowering.
17. Gambling would make me less depressed

18. I would be less irritable right now if I could gamble

\begin{tabular}{|lllllll}
1 & 2 & 3 & 4 & 5 & 6 & 7 \\
1 & 2 & 3 & 4 & 5 & 6 & 7
\end{tabular}


Instructions: Below is a list of things that you might or might not expect to happen in the future as a result of your gambling. If you do not gamble please circle ' 9 ' (not applicable). Please indicate the likelihood of the following things happening:

If I was to continue my gambling behavior, I believe ...

$\begin{array}{cccccc}\begin{array}{c}\text { Highly } \\ \text { unlikely }\end{array} & \text { Unlikely Possible } & \text { Likely } & \begin{array}{c}\text { Highly } \\ \text { Likely }\end{array} & \begin{array}{c}\text { Not } \\ \text { Applicable }\end{array} \\ 0 & 1 & 2 & 3 & 4 & 9 \\ 0 & 1 & 2 & 3 & 4 & 9 \\ 0 & 1 & 2 & 3 & 4 & 9 \\ 0 & 1 & 2 & 3 & 4 & 9 \\ 0 & 1 & 2 & 3 & 4 & 9 \\ 0 & 1 & 2 & 3 & 4 & 9 \\ 0 & 1 & 2 & 3 & 4 & 9 \\ 0 & 1 & 2 & 3 & 4 & 9 \\ 0 & 1 & 2 & 3 & 4 & 9 \\ 0 & 1 & 2 & 3 & 4 & 9 \\ 0 & 1 & 2 & 3 & 4 & 9 \\ 0 & 1 & 2 & 3 & 4 & 9 \\ 0 & 1 & 2 & 3 & 4 & 9 \\ 0 & 1 & 2 & 3 & 4 & 9 \\ 0 & 1 & 2 & 3 & 4 & 9 \\ 0 & 1 & 2 & 3 & 4 & 9 \\ 0 & 1 & 2 & 3 & 4 & 9 \\ 0 & 1 & 2 & 3 & 4 & 9 \\ 0 & 1 & 2 & 3 & 4 & 9\end{array}$




\section{GRCS}

Please indicate (by circling) the extent to which you agree with the value expressed in each statement.

\begin{tabular}{cccccccc}
\hline Strongly & Moderately & Mildly & Neither Agree & Mildly & Moderately & Strongly \\
Disagree & Disagree & Disagree & or Disagree & Agree & Agree & Agree \\
& 1 & 2 & 3 & 4 & 5 & 6 & 7 \\
\hline
\end{tabular}

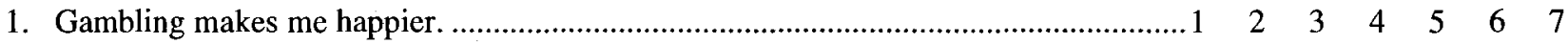

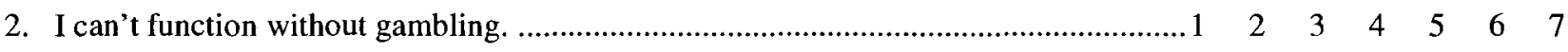

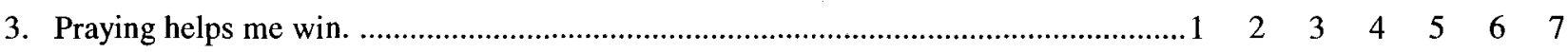

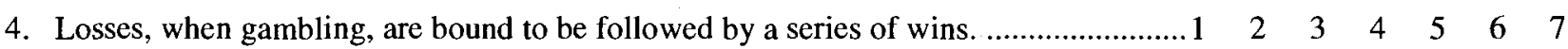

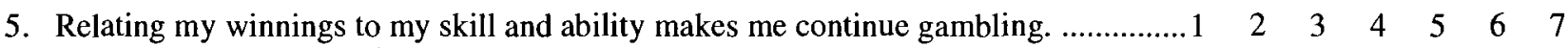

6. Gambling makes things seem better. ....................................................................... $1 \begin{array}{llllllll}2 & 3 & 4 & 5 & 6 & 7\end{array}$

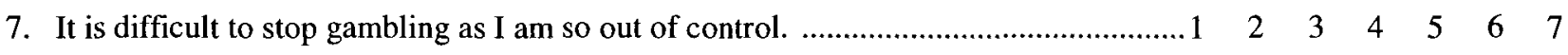

8. Specific numbers and colours can help increase my chances of winning. ................... $1 \quad 2 \quad \begin{array}{lllllll} & 2 & 4 & 5 & 6 & 7\end{array}$

9. A series of losses will provide me with a learning experience that will help

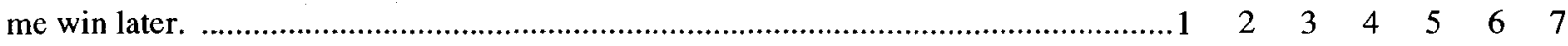

10. Relating my losses to bad luck and bad circumstances makes me

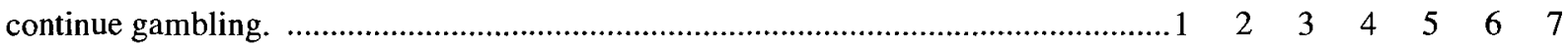

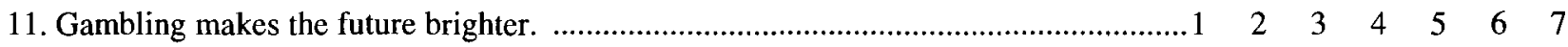

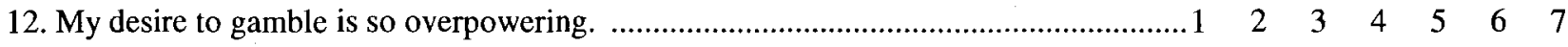

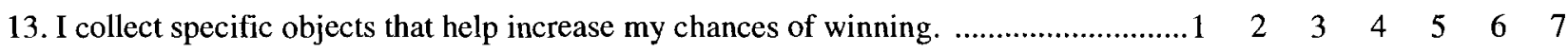

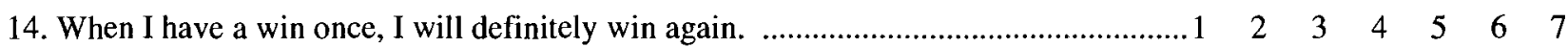

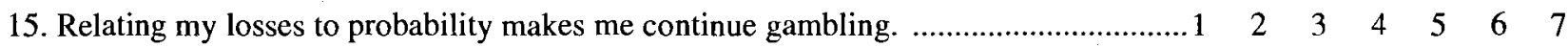

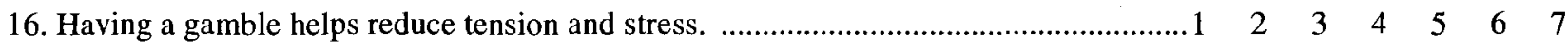

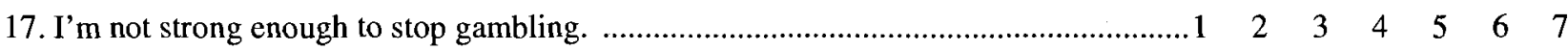

18. I have specific rituals and behaviours that increase my chances of

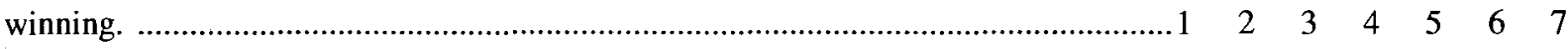

19. There are times that I feel lucky and thus, gamble those times only. ......................... $1 \begin{array}{lllllll} & 2 & 3 & 4 & 5 & 6 & 7\end{array}$

20. Remembering how much money I won last time makes me continue

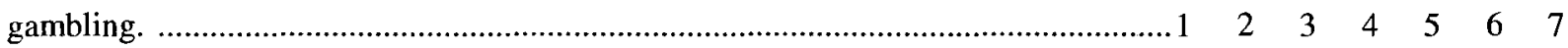

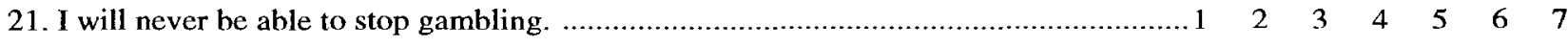

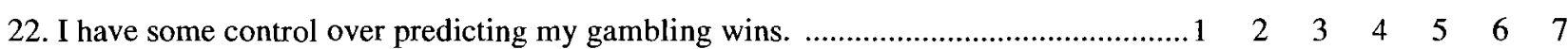

23. If I keep changing my numbers, I have less chances of winning than if I

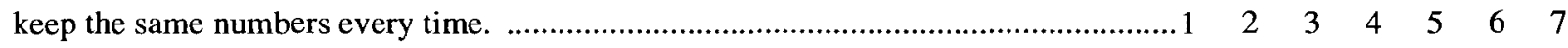




\section{BDI - INVENTORY}

INSTRUCTIONS: On this questionnaire are groups of statements. Please read the entire group of statements of each category. Then pick out ONE statement in that group which best describes the way you feel. Check off the number beside the statement you have chosen.

1.

$0=1$ do not feel sad

$1=1$ feel sad or blue

$2 \mathrm{a}=\mathrm{I}$ am blue or sad all of the time and I can't snap out of it

$2 \mathrm{~b}=\mathrm{I}$ am so sad or unhappy that it is very painful

$3=$ I am so sad or unhappy that $I$ can't stand it

2. $0=\mathrm{I}$ am not particularly pessimistic or discouraged about the future

$1=1$ feel discouraged about the future

$2 \mathrm{a}=1$ feel I have nothing to look forward to

$2 b=$ I feel I won't every get over my troubles

$3=1$ feel that the future is hopeless and things cannot improve

3. $\quad 0=I$ do not feel like a failure

$1=$ I feel I have failed more than the average person

$2 \mathrm{a}=1$ feel I have accomplished very little that is worthwhile or that means anything

$2 b=$ As I look back on my life, all I can see is a lot of failures

$3=$ I feel I am a complete failure as a person

4. $0=$ I am not particularly dissatisfied

- $1 \mathrm{a}=1$ feel bored most of the time

$-1 b=\mid$ d don't enjoy things the way $\mid$ used to

$2=1$ don't get satisfaction out of anything anymore

$3=1$ am dissatisfied with everything

5. _ $0=1$ don't feel particularly guilty

- $1=1$ feel bad or unworthy a good part of the time

$2 \mathrm{a}=1$ feel quite guilty

$2 b=$ I feel bad or unworthy practically of the time now

$3=1$ feel as though I am very bad or worthless

6. $0=1$ don't feel I am being punished

$1=1$ have a feeling that something bad may happen to me

- $2=1$ feel I am being punished or will be punished

$3 a=1$ feel $I$ deserve to be punished

$3 \mathrm{~b}=1$ want to be punished

7. $0=1$ don't feel disappointed in myself

— $1 \mathrm{a}=1$ am disappointed in myself

$1 \mathrm{~b}=1$ don't like myself

-2 $=1$ am disgusted with myself

$3=1$ hate myself

8. $0=1$ do not feel I am any worse than anybody else

$1=1$ am very critical of myself for my weaknesses or mistakes

$2 \mathrm{a}=1$ blame myself for everything that goes wrong

$2 \mathrm{Z}=\mathrm{I}$ I feel I have many bad faults

9. $0=1$ don't have thoughts of harming myself

$1=I$ have thoughts of harming myself but I would not carry them out 
$2 \mathrm{a}=1$ feel I would be better off dead

$2 \mathrm{~b}=1$ have definite plans about committing suicide

$2 \mathrm{c}=$ I feel my family would be better off if I were dead

$3=1$ would kill myself if $I$ could

10. $0=$ I don't cry anymore than usual

1 = I cry more now than I used to

$2=1$ cry all the time now. I can't stop it

$3=1$ used to be able to cry but now I can't cry at all even though I want to

11. $0=$ I am no more irritated now than I ever am

1 = I get annoyed or irritated more easily than I used to

$2=1$ get irritated all the time

$3=1$ don't get irritated at all the things that used to irritate me.

12. $0=1$ have not lost interest in other people

$1=1$ am less interested in other people than I used to be

$2=1$ have lost most of my interest in other people and I have little feeling for them

$3=1$ have lost all my interest in other people and don't care about them at all

13. $0=1$ make decisions about as well as ever

$1=1$ am less sure of myself now and try to put off making decisions

2 = I can't make decisions anymore without help

$3=1$ can't make decisions at all anymore

14. $0=1$ don't feel I look any worse than I used to

$1=I$ am worried that I am looking old or unattractive

2 = I feel that there permanent changes in my appearance and they make me look unattractive

$3=I$ feel that $I$ am ugly or repulsive looking

15. $\quad 0=1$ can work about as well as before

$1 \mathrm{a}=$ It takes extra effort to get started at doing something

$1 b=\mid$ don't work as well as I used to

$2=$ I have to push myself very hard to do anything

$3=$ I can't do any work at all

16. $0=I$ can sleep as well as usual

$1=$ I wake up more tired in the morning than I used to

$2=1$ wake up 1-2 hours earlier than usual and find it hard to get back to sleep

$3=1$ wake up early every day and can't get more than 5 hours sleep

17. $0=1$ don't get anymore tired than usual

$1=$ I get tired more easily than I used to

$2=1$ get tired from doing anything

- $3=1$ get too tired to do anything

18. $0=$ My appetite is no worse than usual

$1=$ My appetite is not as good as it used to be

2 = My appetite is much worse now

$3=1$ have no appetite at all any more 
19. $0=1$ haven't lost much weight, if any, lately

$1=$ I have lost more than 5 pounds

$2=1$ have lost more than 10 pounds

$3=1$ have lost more than 15 pounds

20. $0=1$ am no more concerned about my health than usual

$1=1$ am concerned about aches and pains or upset stomach or constipation or other unpleasant feelings in my body

2 = I am so concerned with how I feel or what I feel that it's hard to think of much else 3 = I am completely absorbed in what I feel

21. _ $0=1$ have not noticed any recent change in my interest in sex

$1=I$ am less interested in sex than I used to be

$2=1$ am much less interested in sex now

$3=1$ have lost interest in sex completely 
MOOD

Please indicate how much each adjective describes how you feel at the moment. There are no right or wrong answers, we just want you to be as honest as possible in indicating how you're feeling right now.

\begin{tabular}{|c|c|c|c|c|c|c|c|c|}
\hline Active.............. Not at all & 0 & 1 & 2 & 3 & 4 & 5 & 6 & Extremely \\
\hline Afraid..............Not at all & 0 & 1 & 2 & 3 & 4 & 5 & 6 & Extremely \\
\hline Alert.............. Not at all & 0 & 1 & 2 & 3 & 4 & 5 & 6 & Extremely \\
\hline Angry................Not at all & 0 & 1 & 2 & 3 & 4 & 5 & 6 & Extremely \\
\hline Annoyed............Not at all & 0 & 1 & 2 & 3 & 4 & 5 & 6 & Extremely \\
\hline Anxious............. Not at all & 0 & 1 & 2 & 3 & 4 & 5 & 6 & Extremely \\
\hline Ashamed...........Not at all & 0 & 1 & 2 & 3 & 4 & 5 & 6 & Extremely \\
\hline Attentive............ Not at all & 0 & 1 & 2 & 3 & 4 & 5 & 6 & Extremely \\
\hline Confused............Not at all & 0 & 1 & 2 & 3 & 4 & 5 & 6 & Extremely \\
\hline Contempt...........Not at all & 0 & 1 & 2 & 3 & 4 & 5 & 6 & Extremely \\
\hline Depressed......... Not at all & 0 & 1 & 2 & 3 & 4 & 5 & 6 & Extremely \\
\hline Determined.........Not at all & 0 & 1 & 2 & 3 & 4 & 5 & 6 & Extremely \\
\hline Disdain............... Not at all & 0 & 1 & 2 & 3 & 4 & 5 & 6 & Extremely \\
\hline Disgust...............Not at all & 0 & 1 & 2 & 3 & 4 & 5 & 6 & Extremely \\
\hline Distressed........ Not at all & 0 & 1 & 2 & 3 & 4 & 5 & 6 & Extremely \\
\hline Embarrassed.......Not at all & 0 & 1 & 2 & 3 & 4 & 5 & 6 & Extremely \\
\hline Enraged........... Not at all & 0 & 1 & 2 & 3 & 4 & 5 & 6 & Extremely \\
\hline Enthusiastic...... .Not at all & 0 & 1 & 2 & 3 & 4 & 5 & 6 & Extremely \\
\hline Excited................ Not at all & 0 & 1 & 2 & 3 & 4 & 5 & 6 & Extremely \\
\hline Frustrated.............Not at all & 0 & 1 & 2 & 3 & 4 & 5 & 6 & Extremely \\
\hline Guilty .................. at all & 0 & 1 & 2 & 3 & 4 & 5 & 6 & Extremely \\
\hline Happy.................Not at all & 0 & 1 & 2 & 3 & 4 & 5 & 6 & Extremely \\
\hline Helpless............ .Not at all & 0 & 1 & 2 & 3 & 4 & 5 & 6 & Extremely \\
\hline Hostile...............Not at all & 0 & 1 & 2 & 3 & 4 & 5 & 6 & Extremely \\
\hline Humiliated...........Not at all & 0 & 1 & 2 & 3 & 4 & 5 & 6 & Extremely \\
\hline Indifferent...........Not at all & 0 & 1 & 2 & 3 & 4 & 5 & 6 & Extremely \\
\hline Infuriated.............Not at all & 0 & 1 & 2 & 3 & 4 & 5 & 6 & Extremely \\
\hline Inspired...............Not at all & 0 & 1 & 2 & 3 & 4 & 5 & 6 & Extremely \\
\hline Interested............Not at all & 0 & 1 & 2 & 3 & 4 & 5 & 6 & Extremely \\
\hline Irritable..............Not at all & 0 & 1 & 2 & 3 & 4 & 5 & 6 & Extremely \\
\hline Jittery................. Not at all & 0 & 1 & 2 & 3 & 4 & 5 & 6 & Extremely \\
\hline Nervous...............Not at all & 0 & 1 & 2 & 3 & 4 & 5 & 6 & Extremely \\
\hline Proud................. Not at all & 0 & 1 & 2 & 3 & 4 & 5 & 6 & Extremely \\
\hline Regretful..............Not at all & 0 & 1 & 2 & 3 & 4 & 5 & 6 & Extremely \\
\hline Responsible..........Not at all & 0 & 1 & 2 & 3 & 4 & 5 & 6 & Extremely \\
\hline Sad...................... at all & 0 & 1 & 2 & 3 & 4 & 5 & 6 & Extremely \\
\hline
\end{tabular}




\section{Appendix I. Study 3 Debriefing}

This post-survey information is designed to help you understand the nature of the research. The questionnaire that you just completed will help us determine how much first year students at Carleton University gamble. Specifically, the purpose of this study is to assess the propensity of gambling among young adults at Carleton and the predictors associated with a willingness to seek treatment. This research will help reveal mechanisms by which gambling behavior is facilitated and promoted, which may have important implications for the rise of gambling pathology. It will also provide us with some insights regarding people who don't gamble, which might reflect something that makes them more resilient to the temptation. Results from this project will also assist in determining the factors that predict treatment seeking behaviour among the young adults in our student population and the general population as well. Specifically, we hypothesize that people's expectancy of success will predict their willingness to seek treatment.

Among university students, rates of pathological and problem gambling are double that reported in the general population. In stark contrast to research showing high rates of problematic gambling among young adults; other research shows rates of treatment seeking among this group are astonishingly low. This is an invisible problem at Carleton and abroad. Although drug and alcohol abuse take center stage with respect to research, treatment, and awareness, problem gambling has not received the same attention. Yet, if we examine the available statistics, there is a strong possibility that in each of your classes there at least one or two pathological gamblers. The symptoms of problem gambling include: Borrowing money to gamble; inability to stop gambling; feeling irritable if you do not gamble for a period of time; going back to the casino to win back lost money; lost relationships due to gambling behavior; spending a lot of time thinking about gambling; and needing to spend more and more money to get the same excitement out of gambling. This is not a comprehensive list, but someone who has problems with gambling may experience a few of the above symptoms (2-3), but not necessarily all of the above symptoms. As researchers, we are not allowed to provide advice or treatment regarding gambling problems. But if you have concerns about your gambling behaviour you may wish to contact Gamblers Anonymous 567-3271 or if you have a family member who gambles you might wish to call Gam-Anon 567-3271

Also, approximately $10-15 \%$ of people will suffer some degree of depression during their lifetime. With advances in modern medicine, most people can readily be treated for this illness, which if unattended can be long lasting and affect many aspects of one's life. The symptoms of depression comprise: Poor or depressed mood, or a reduction in the pleasure gained from otherwise positive experiences; Sleep disturbances; Eating disturbances (loss of appetite, or overeating despite not being hungry), which may be linked to weight changes; Lack of sexual interest; fatigue and lethargy (you don't feel like doing anything); an inability to focus (e.g., have a hard time reading); reduced interactions with family and friends; and thoughts of suicide. Someone who is depressed may experience several (3-4), but not necessarily all of the above symptoms.

If you think you may be experiencing depression, it is suggested that you either contact your family physician, or one of the organizations listed below. It is not a good idea to allow problems to fester, as ruminating over these problems will typically not make them go away. Your family physician or counselor will usually be able to help you or to refer you to someone who can. Distress Centre: Ottawa And Region (613) 238-1089; Web Site: www.dcottawa.on.ca; Distress Centres of Toronto: (416) 408 help; Distress Centre of Hamilton: (905) 5258611 ; KW Distress Line: (519) 7451166

If you have any questions or comments about this research, then please feel free to contact Tania Morrison (520.2600 ext. 2683; tmorriso@ connect.carleton.ca), Chris Motz (520.2600 ext. 2683; cpmotz@connect.carleton.ca), Dr. Michael Wohl (520.2600 ext. 2908; mwohl@connect.carleton.ca), Dr. Hymie Anisman (520.2600 ext. 2699; hymie anisman@carleton.ca), or Dr. Kim Matheson (520-2684; kimmatheson@pigeon.carleton.ca). 
If you have any ethical concerns about how this study please contact Dr. J. Mantler (Chair of the Carleton University Ethics Committee for Psychological Research, 520-2600, ext. 4173) or Dr. M. Gick (Chair of the Department of Psychology at Carleton University, 520-2600, ext. 2648).

We thank you very much for participating in this study. Your assistance will help us better understand gambling behavior among young adults. 


\section{Appendix J: Study 4 Informed Consent}

The purpose of an informed consent is to ensure that you understand the purpose of the study and the nature of your involvement. The informed consent has to provide sufficient information such that you have the opportunity to determine whether you wish to participate in the study.

Study Title: Reactions to virtual gaming

Study Personnel: $\quad$ Matthew Young, MA, Department of Psychology, Carleton University

Phone: (613) 520-2600 ext 6312

Dr. Michael Wohl, Department of Psychology, Carleton University

Phone: (613) 520-2600 ext 2908

$</$ span $><$ span lang=EN-CA style='font-size: 10.0pt; mso-bidifont-size: 12.0pt; mso-ansi-language: EN-CA'>Dr. Hymie Anisman, Department of Psychology, Carleton University

Phone: Phone: (613) 520-2699

Dr. Kim Matheson, Department of Psychology, Carleton University

Phone: (613) 520-2684 </span $>$

If you have any ethical concerns about this study please contact Dr. J. Mantler, (Chair of the Carleton University Research Ethics Committee for Psychological Research, 520-2600, ext. 4173), or Dr. M. Gick, (Chair, Department of Psychology, Carleton University at 520-2600, ext. 2648).

Purpose and Task Requirements: The purpose of this study is to assess to gamble behaviour among university students. We will be asking you to wear virtual reality headgear which creates a realistic and interactive casino atmosphere (sights and sounds). The user has the capability of interacting with the virtual casino in a gaming situation, and you will have the opportunity to do so. You will also be asked to complete a series of questionnaires about your background (e.g., family history), and gambling (e.g., propensity to gamble and attitudes toward gambling).

Potential Risk and Discomfort: There are no physical risks in this study. Some individuals may experience discomfort when asked to respond to personal, sensitive questions. In addition, some individuals may experience discomfort or nausea when interacting with the virtual reality console (a.k.a. "Cybersickness"). If you do feel nauseous when using the virtual reality console, please take a break (i.e., close your eyes), if the nausea continues, please tell the experimenter and he or she will terminate the study.

Anonymity/Confidentiality: The data collected in this study will be kept confidential. Your informed consent form will be separated from your questionnaire and kept in a separate and secured file by one of the research investigators who will keep this information confidential. Your questionnaire responses will be associated with a code that you will generate, and this code will be used to match your questionnaire with your saliva samples.

Right to Withdraw: Your participation in this study is entirely voluntary. At any point during the study you have the right to not complete certain questions or to withdraw with no penalty whatsoever.

I have read the above description of the study concerning my reactions to virtual gaming. The data collected will be used in research publications and/or for teaching purposes. My signature indicates that I agree to participate in the study, and this in no way constitutes a waiver of my rights.

Full Name (please print):

Participant Signature:

Date: 
Desire and Gambling 129

Researcher Signature:

Date: 


\section{GACS}

INSTRUCTIONS: Please indicate your agreement or disagreement to the following statements by circling the appropriate response.

\begin{tabular}{|c|c|c|c|c|c|c|c|}
\hline 1. If I had an opportunity to gamble right now I probably would take it. & 1 & 2 & 3 & 4 & 5 & & 7 \\
\hline 2. If I were gambling now I could think more clearly. & 1 & 2 & 3 & 4 & 5 & 6 & 7 \\
\hline 3. I could control things better right now if I could gamble. & 1 & 2 & 3 & 4 & 5 & 6 & 7 \\
\hline 4. Gambling would be fun right now. & 1 & 2 & 3 & 4 & 5 & 6 & 7 \\
\hline 5. I crave gambling right now. & 1 & 2 & 3 & 4 & 5 & 6 & 7 \\
\hline 6. I need to gamble now. & 1 & 2 & 3 & 4 & 5 & 6 & 7 \\
\hline 7. I would not enjoy gambling right now. & 1 & 2 & 3 & 4 & 5 & 0 & 7 \\
\hline 8. I have an urge to gamble. & 1 & 2 & 3 & 4 & 5 & 6 & 7 \\
\hline 9. Gambling would make me less depressed & 1 & 2 & 3 & 4 & 5 & & 7 \\
\hline
\end{tabular}

\section{PLEASE PLACE A POST-IT ON THIS PAGE, CLOSE YOUR BOOKLET, AND INFORM THE EXPERIMENTER THAT YOU HAVE COMPLETED THE INITIAL QUESTIONNAIRE!}




\section{GACS}

\section{INSTRUCTIONS: Please indicate your agreement or disagreement to the following} statements by circling the appropriate response.

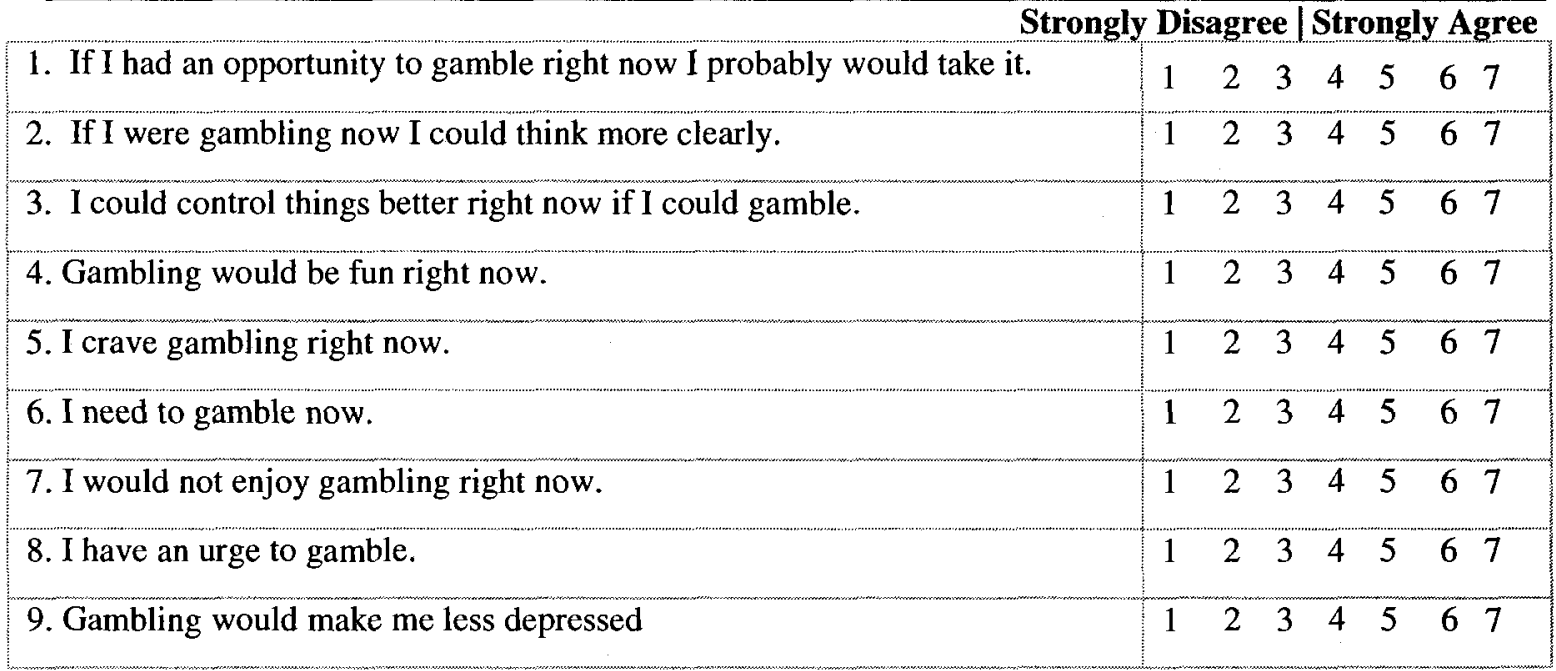




\section{Appendix L. Study 4 Debriefing}

This post-test information is designed to help you understand the nature of the research. This experiment is part of a larger research project being conducted to examine gambling behaviour and attitudes of young adults. Specifically, the purpose of this study is to assess craving to gamble among individuals with varying degrees of gambling interest. The three groups of participants are non-problem, 'at risk', and problem gamblers, as previously identified by the Problem Gambling Severity Index. Using the virtual reality combined with an actual gaming simulation, we assessed craving. Results from this project will facilitate the identification of features that render young adults vulnerable to pathology, and will provide the basis for us to develop workshops and materials that may be used as an intervention strategy for problem-gambling among young adults. Though empirical evidence suggests that craving is central to substance addiction, it has yet to received much investigation in the context of gambling. Therefore we conducted this study to learn more about the nature of craving within the context of gambling behaviour.

Previous research conducted in our lab has examined the influence of wins and losses on gambling craving. This research revealed that participants' craving to gamble increased significantly following a sequence winning slot machine spins. In contrast, participants reported no change in craving levels following a sequence of losing spins. In the present study we wish to examine in more detail the influence wins on craving to gamble.

Previous research (Wohl, Young, \& Hart, 2005) has found that some gamblers have extreme beliefs in personal luck or optimism, so that they over-attribute their wins to the self, and have exaggerated expectations of future gambling successes. As such, among some gamblers, anticipation of gambling may provoke a 'high' (eustress) similar to that experienced by people engaging in other risk-taking behaviours (e.g., skydivers). This process may contribute to a strong desire to gamble (craving) and a persistent reluctance to seek treatment when gambling reaches problematic levels. To assess this possibility, we asked you to complete measures that assess your belief in personal luck, your expectations of success at the gambling game, your mood while gambling, and your craving to gamble.

The results of slot machine you just played were predetermined to win in a particular sequence. We were unable to disclose this part of the study to you at the onset because it would have influenced your behaviour and responding to the questions. As such, after you finish reading this debriefing form, the experimenter will present a new informed consent form. The purpose of an informed consent is to ensure that you now understand the true purpose of the study and that you agree to allow your data to be used for research and teaching purposes. Because you were only told of the procedures and not the purpose of this study at the outset, we will be asking for your consent to allow your data to be used for research and teaching purposes.

If you have any questions about this study when you leave, please feel free to use the contact information on this debriefing form that you are allowed to keep. 
Lastly, if you think you may have gambling problems, it is suggested that you either contact one of the organizations listed below. It is not a good idea to allow problems to fester, as ruminating over these problems will typically not make them go away. In addition, your family physician or counselor will may also be able to help you or to refer you to someone who can help.

Ontario Problem Gambling helpline 1-888-230-3505 http://www.opgh.on.ca/

Addictions and Problem Gambling Services of Ottawa (613) 789-8941 http://www.apgsostjpo.ca/find eng.html

Distress Centre: Ottawa And Region (613) 238-1089 http://www.dcottawa.on.ca

Health and Counselling Services at Carleton University (613) 520-6674.

If you have any questions or comments about this research, then please feel free to contact Matthew Young (520.2600 ext.6312; mmyoung@connect.carleton.ca), Tania Morrison (520.2600 ext. 2683; tmorriso@ @onnect.carleton.ca), Dr. Michael Wohl (520.2600 ext. 2908; mwohl@connect.carleton.ca), Dr. Hymie Anisman (520.2600 ext. 2699;

hymie anisman@carleton.ca), or Dr. Kim Matheson (520-2684;

kimmatheson@pigeon.carleton.ca).

If you have any ethical concerns about this study please contact Dr. J. Mantler, (Chair of the Carleton University Research Ethics Committee for Psychological Research, 520-2600, ext. 4173), or Dr. M. Gick, (Chair, Department of Psychology, Carleton University at 520-2600, ext. 2648).

We thank you very much for participating in this study. Your assistance will help us better understand gambling behavior among young adults. 